Georgia State University

ScholarWorks @ Georgia State University

Communication Sciences and Disorders

Dissertations

Department of Communication Sciences and

Disorders

7-3-2007

\title{
Using Speech Recognition Software to Increase Writing Fluency for Individuals with Physical Disabilities
}

Jennifer Tumlin Garrett

Follow this and additional works at: https://scholarworks.gsu.edu/epse_diss

Part of the Educational Psychology Commons, and the Special Education and Teaching Commons

\section{Recommended Citation}

Garrett, Jennifer Tumlin, "Using Speech Recognition Software to Increase Writing Fluency for Individuals with Physical Disabilities." Dissertation, Georgia State University, 2007.

doi: https://doi.org/10.57709/1061131

This Dissertation is brought to you for free and open access by the Department of Communication Sciences and Disorders at ScholarWorks @ Georgia State University. It has been accepted for inclusion in Communication Sciences and Disorders Dissertations by an authorized administrator of ScholarWorks @ Georgia State University. For more information, please contact scholarworks@gsu.edu. 


\section{ACCEPTANCE PAGE}

This dissertation, USING SPEECH RECOGNITION SOFTWARE TO INCREASE WRITING FLUENCY FOR INDIVIDUALS WITH PHYSICAL DISABILITIES by JENNIFER TUMLIN GARRETT, was prepared under the direction of the candidate's Dissertation Advisory Committee. It is accepted by the committee members in partial fulfillment of the requirements for the degree Doctor of Philosophy in the College of Education, Georgia State University.

The Dissertation Advisory Committee and the student's Department Chair, as representatives of the faculty, certify that this dissertation has met all standards of excellence and scholarship as determined by the faculty. The Dean of the College of Education concurs.

Kathryn Wolff. Heller, Ph.D.

Committee Chair

Linda Fowler, Ph.D

Committee Member

Colleen M. O’Rourke, Ph.D. Committee Member
Paul A. Alberto, Ph.D.

Committee Member

Laura D. Fredrick, Ph.D.

Committee Member

Date

Peggy L. Gallagher, Ph.D.

Chair, Department of Educational Psychology and Special Education

Ronald P. Colarusso, Ed.D.

Dean, College of Education 


\begin{abstract}
AUTHOR'S STATEMENT
By presenting this dissertation as a partial fulfillment of the requirements for the advanced degree from Georgia State University, I agree that the library of Georgia State University shall make it available for inspection and circulation in accordance with its regulations governing materials of this type. I agree that permission to quote, to copy from, or to publish this dissertation may be granted by the professor under whose direction it was written, by the College of Education's director of graduate studies and research, or by me. Such quoting, copying, or publishing must be solely for scholarly purposes and will not involve potential financial gain. It is understood that any copying from or publication of this dissertation which involves potential financial gain will not be allowed without my written permission
\end{abstract}

Jennifer Tumlin Garrett 


\title{
NOTICE TO BORROWERS
}

All dissertations deposited in the Georgia State University library must be used in accordance with the stipulations prescribed by the author in the preceding statement. The author of this dissertation is:

\author{
Jennifer Tumlin Garrett \\ $609 \mathrm{~N} 6^{\text {th }}$ Street \\ Rochelle, IL 61068
}

The director of this dissertation is:

Dr. Kathryn Wolff Heller

Department of Educational Psychology and Special Education

College of Education

Georgia State University

Atlanta, GA 30303 - 3083 


\title{
VITA
}

\author{
Jennifer Tumlin Garrett
}

ADDRESS:

609 N. $6^{\text {th }}$ Street

Rochelle, IL 61068

815-562-2524

Email: jennifertgarrett@yahoo.com

EDUCATION:

$\begin{array}{ccl}\text { Ph.D. } & 2007 & \begin{array}{l}\text { Georgia State University } \\ \text { Education of Students with Exceptionalities } \\ \text { M.Ed. }\end{array} \\ \text { Beorgia State University } \\ \text { Multiple and Severe Disabilities } \\ \text { Bnd. } & 19984 & \begin{array}{l}\text { University of Georgia } \\ \text { Mental Retardation Education }\end{array}\end{array}$

PROFESSIONAL EXPERIENCE:

2006 to present

$2004-2005$

$2001-2006$

$1998-2004$

$1996-1998$

$1994-1998$
Learning and Behavioral Specialist Teacher, Middle School and High School, Math, Social Science, and Technology

Rochelle Township High School, Rochelle, IL Instructional Lead Teacher Cobb County Schools, Wheeler High School Graduate Research Assistant Georgia State University Orthopedic Impairments Teacher, Grades 9-12 Cobb County Schools, Wheeler High School Special Education Department Chair Gwinnett County Schools, Dyer Elementary Intellectual Disabilities Teacher, Grades K-1 Gwinnett County Schools, Dyer Elementary

PROFESSIONAL SOCIETIES AND ORGANIZATIONS:

1993 - present $\quad$ Council for Exceptional Children

1998 - present
ISAAC - The International Society for Augmentative and Alternative Communication 


\section{PRESENTATIONS AND PUBLICATIONS:}

Heller, K.W., Coleman-Martin, M.B., \& Tumlin Garrett, J. (2007). Adapting environments and using technology. In R.P. Colarusso \& C.M. O’Rourke (Eds.), Special education for all teachers $\left(4^{\text {th }}\right.$ ed.). Dubuque, IA: Kendall Hunt.

Heller, K.W. \& Tumlin Garrett, J. (2006). Cerebral palsy. In K.W. Heller, P.A. Alberto, P. Forney, S. Best, \& M. Schwartzman (Eds.), Understanding Physical health and multiple disabilities. ( $2^{\text {nd }}$ ed.). Manuscript submitted for publication.

Tumlin, J., \& Mezei, P. (2005, April). Using word prediction to increase typing fluency and decrease spelling errors. Poster session presented at the Council for Exceptional Children National Conference, Baltimore, MD.

Tumlin, J., Heller, K. W. (2004). Using word prediction software to increase typing fluency with students with physical disabilities. Journal of Special Education Technology, 19 (3), 5-14.

Heller, K. W., \& Tumlin, J. (2004). Using expanded individualized healthcare plans to assist teachers of students with complex healthcare needs. Journal of School Nursing, 20, 150-160.

Heller K. W., Coleman-Martin, M. B., \& Tumlin, J. J. (2003). Adapting environments and using technology. In R. P. Colarusso \& C.M. O’Rourke (Eds.), Special education for all teachers. ( $3^{\text {rd }}$ ed), (402-437). Dubuque, IA: Kendall Hunt.

Tumlin, J. (2003). Making inclusion work essay. In R. M. Gargiulo (Ed.), Special education in a contemporary society: An introduction to exceptionality (pp. 574575). Belmont, CA: Wadsworth/Thomson Learning.

Heller, K.W., Swinehart-Jones, D., Coleman-Martin, M., \& Tumlin, J. (2002). Overview of the Bureau for Students with Physical and Health Impairments. Poster session presented at Georgia Legislators' Event, Atlanta, GA.

Heller, K. W., Fredrick, L. D., Tumlin, J., \& Brineman, D. G. (2002). Teaching decoding for generalization using the nonverbal reading approach. Journal of Physical and Developmental Disabilities, 14, 19-35.

Heller, K.W., \& Tumlin, J. (2002, April). Teaching decoding for generalization using the Nonverbal Reading Approach. Paper presented at the Council for Exceptional Children National Conference. New York, NY.

Tumlin, J. (1997). Low-tech solutions for low-incidence students. Paper presented at the Council for Exceptional Children State Conference, Macon, GA. 


\section{ABSTRACT \\ USING SPEECH RECOGNITION SOFTWARE TO INCREASE WRITING FLUENCY FOR INDIVIDUALS WITH PHYSICAL DISABILITIES \\ by \\ Jennifer Tumlin Garrett}

Writing is an important skill that is necessary throughout school and life. Many students with physical disabilities, however, have difficulty with writing skills due to disability-specific factors, such as motor coordination problems. Due to the difficulties these individuals have with writing, assistive technology is often utilized. One piece of assistive technology, speech recognition software, may help remove the motor demand of writing and help students become more fluent writers. Past research on the use of speech recognition software, however, reveals little information regarding its impact on individuals with physical disabilities. Therefore, this study involved students of high school age with physical disabilities that affected hand use. Using an alternating treatments design to compare the use of word processing with the use of speech recognition software, this study analyzed first-draft writing samples in the areas of fluency, accuracy, type of word errors, recall of intended meaning, and length. Data on fluency, calculated in words correct per minute (wcpm) indicated that all participants wrote much faster with speech recognition compared to word processing. However, accuracy, calculated as percent correct, was much lower when participants used speech recognition compared to word processing. Word errors and recall of intended meaning were coded based on type and varied across participants. In terms of length, all 
participants wrote longer drafts when using speech recognition software, primarily because their fluency was higher, and they were able, therefore, to write more words.

Although the results of this study indicated that participants wrote more fluently with speech recognition, because their accuracy was low, it is difficult to determine whether or not speech recognition is a viable solution for all individuals with physical disabilities. Therefore, additional research is needed that takes into consideration the editing and error correction time when using speech recognition software. 
USING SPEECH RECOGNITION SOFTWARE TO INCREASE WRITING FLUENCY FOR INDIVIDUALS WITH PHYSICAL DISABILITIES

\author{
by \\ Jennifer Tumlin Garrett

\begin{abstract}
A Dissertation
Presented in Partial Fulfillment of Requirements for the

Degree of

Doctor of Philosophy

in

Education of Students with Exceptionalities

in

the Department of Educational Psychology and Special Education

in

the College of Education

Georgia State University
\end{abstract}

Atlanta, GA

2007 
Copyright by

Jennifer Tumlin Garrett

2007 


\section{ACKNOWLEDGEMENTS}

I cannot imagine that I would have been able to achieve my goal of obtaining my Ph.D. without the help and support of a number of people over the last several years. Dr. Kathy Heller was not only an outstanding professor, advisor, and dissertation committee chair, but also an incredible mentor. Her professionalism, work ethic, and knowledge inspire me, and I have grown so much by merely being associated with her. Thank you, Dr. Heller. I also would not have been able to complete my dissertation without the help and support of my other committee members, Drs. Paul Alberto, Laura Fredrick, Colleen O'Rourke, and Linda Fowler. The amount of feedback and input that you all gave me was much-needed and resulted in a project that was both exciting and worthwhile. Thank you all.

In addition to my committee, a number of fellow students were extremely helpful to and supportive of me thorough this process. First, if it was not for Doug McJannet, I never would have entered the Master's program at Georgia State. He stated what now seems to be the obvious, that the orthopedic impairments program would be a good fit for me, and he certainly was correct. Thanks, Doug, for your life-changing idea. I don't know where I would be if not for your suggestion. Peter Mezei was also instrumental in helping me complete the program. He was my go-to person in Atlanta once I moved away and helped with logistics and made sure I reached all of my deadlines. In addition to that, Peter was a great person to collaborate with, because he thinks with such clarity and depth. Thanks for all of your help, Peter. So many other fellow students helped me along the way, including Mari Beth Coleman-Martin, Dawn Swinehart-Jones, David Cihak, and many others. I also need to extend appreciation to Cobb County Schools for allowing me to grow as a teacher in the district and to return to collect data.

Finally, I would like to thank my close friends and family who supported me throughout the program. I am grateful for the encouragement of people like my friend Sharon Hunt; my parents, Beth and Bill; my sister, Tracy; and my husband, Mike. I never would have made it without you all. Thank you, Mike for supporting me during my year off and for being patient as I extended my graduation date more than once. And to my sister Natalie, you were the biggest inspiration in my life. The 30 years I had with you made me who I am today, and there's not a day that goes by that I do not think of the influence that you have had on me. And finally, to Julianne, although I'll never be able to tell you, had it not been for your existence, I probably still would be trying to finish school. Your short presence within me helped me to set my goals, meet my deadlines, and become Dr. Jennifer Tumlin Garrett. Thank you, and I love you. I truly have been blessed with wonderful people in my life. 


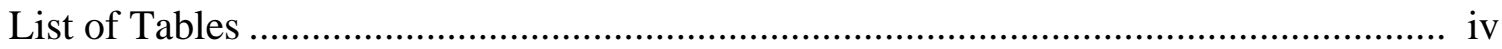

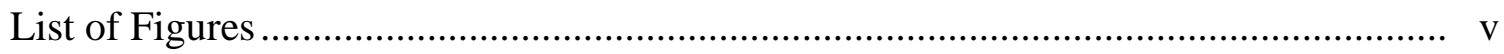

Abbreviations .................................................................................................... vi

Chapter

1 WRITING FLUENCY FOR INDIVIDUALS WITH PHYSICAL DISABILITIES: A REVIEW OF THE LITERATURE ...................................... 1

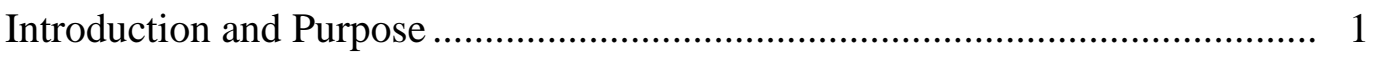

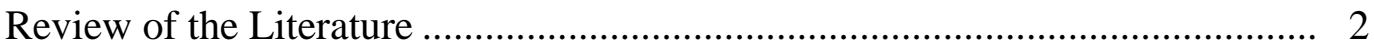

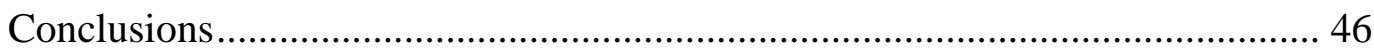

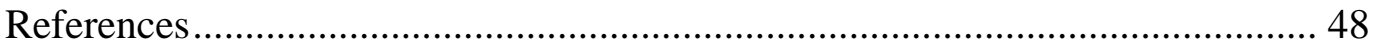

2 USING SPEECH RECOGNITION SOFTWARE TO INCREASE WRITING FLUENCY FOR INDIVIDUALS WITH PHYSICAL DISABILITIES ................................................................. 57

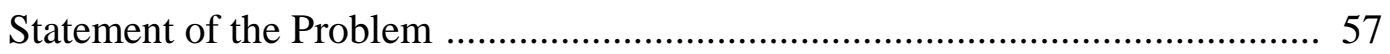

Purpose

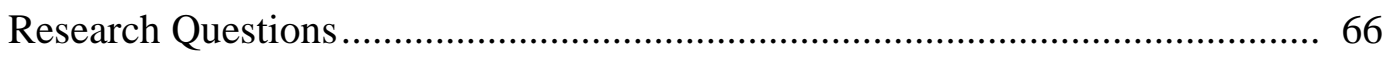

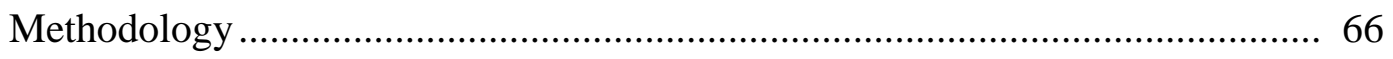

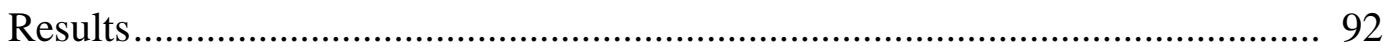

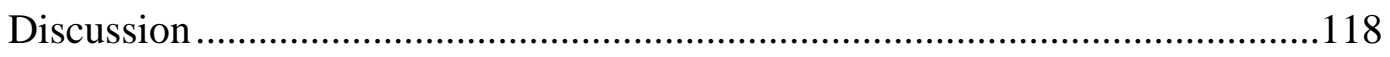

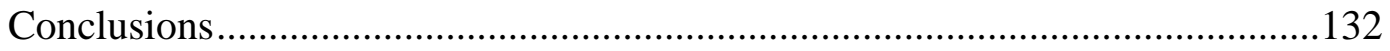

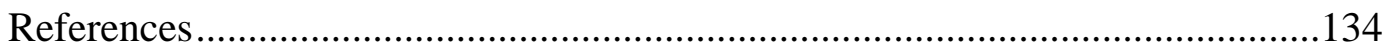

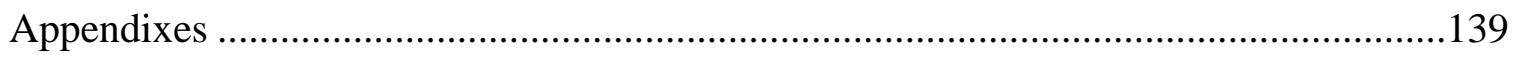




\section{LIST OF TABLES}

Table

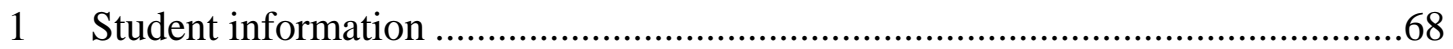

2 Coding for word errors across word processing and speech recognition ............89

3 Percent of word errors across all words ........................................................98

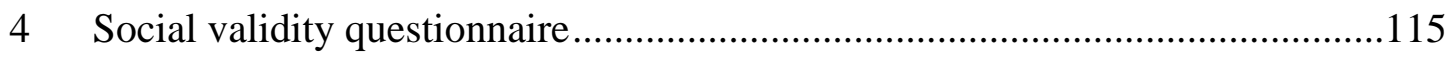




\section{LIST OF FIGURES}

Figure $\quad$ Page

1 Writing fluency across participants ......................................................... 93

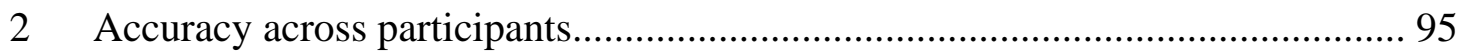

3 Length across participants........................................................................ 100 


\section{ABBREVIATIONS}

$\begin{array}{ll}\text { AT } & \text { Assistive Technology } \\ \text { CP } & \text { Cerebral Palsy } \\ \text { LD } & \text { Learning Disabilities } \\ \text { MD } & \text { Muscular Dystrophy } \\ \text { MID } & \text { Mild Intellectual Disabilities } \\ \text { OI } & \text { Orthopedic Impairments } \\ \text { SMA } & \text { Spinal Muscular Atrophy } \\ \text { wcpm } & \text { Words Correct per Minute } \\ \text { MDVP } & \text { Multi-Dimensional Voice Program (Kay Elemetrics, 1993) }\end{array}$




\title{
CHAPTER 1
}

\section{WRITING FLUENCY FOR INDIVIDUALS WITH PHYSICAL DISABILITIES: A}

\section{REVIEW OF THE LITERATURE}

\author{
Introduction and Purpose
}

Writing is an important skill to acquire not only in school but also in life. It allows individuals to communicate their thoughts in a nonvocal format. For individuals who are nonverbal, it allows them to demonstrate understanding and intelligence. Writing is also an important skill in the school environment, in the community, and in the workplace. However, individuals with physical disabilities often have problems in academic areas, such as writing, due to a number of interactional factors.

Students with physical disabilities have difficulties writing efficiently due to decreased motor control in their hands. Handwriting is often not an option, and typing rate can be extremely slow. Writing accuracy also can be affected due to poor spelling performance (Sandberg, 2001) and extraneous motor movements, which can cause unintended keystrokes (Best, Heller, \& Bigge, 2005). Because individuals with physical disabilities often are unable to write by hand, their only option for written output may be using a word processor. There are many ways that word processors can provide better access for individuals with physical disabilities. However, despite having the word processor set up for modified access, motor problems that affect the typing speed of individuals with physical disabilities may make word processing an inefficient option for producing written output. The use of different types of assistive technology, such as 
speech recognition software, may increase speed because it is activated by voice and is therefore hands-free. Because users do not have to concern themselves with spelling using speech recognition, accuracy also may improve. However, due to the high level of recognition accuracy needed to effectively use speech recognition, more errors may be produced.

The purpose of the review of the literature, therefore, is to examine the impact of physical disabilities on writing and the applicability of using speech recognition software as a possible intervention and strategy to improve writing output for this population. Issues of speed of entry, accuracy rates, and production of errors will be discussed. Because the research base that includes individuals with physical disabilities is limited, research from the learning disabilities field will be discussed due to the fact that individuals with physical disabilities and learning disabilities can experience similar barriers to writing.

\section{Review of the Literature}

\section{Types of Physical Disabilities that Affect Writing}

Several types of physical disabilities exist that may have a negative impact on writing. Therefore, this paper will refer to any orthopedic impairment, as defined below, as a physical disability or physical impairment. In Georgia, the term orthopedic impairment:

Refers to students whose severe orthopedic impairments affect their educational performance to the degree that the student requires special education. This term may include:

(1) Impairment caused by congenital anomalies, e.g., deformity or absence of some member.

(2) Impairment caused by disease, e.g., poliomyelitis or bone tuberculosis.

(3) Impairment from other causes, e.g., cerebral palsy, amputations, and fractures or burns that cause contractures. [refer to 34 CFR 300.7 (8)] 
Secondary disabilities may be present, including, but not limited to, visual impairment, hearing impairment, communication impairment and/or intellectual disability.(http://public.doe.k12.ga.us/DMGetDocument.aspx/exceptional eligibility_oi.pdf?p=4BE1EECF99CD364EA5554055463F1FBBF5D074 D5FB1F2CAEB3B63B3ECB220CDD26C2114F3C57D8D25C69F04B76 $\underline{\text { A08C8D\&Type }=\text { D) }}$

This term includes such common conditions as cerebral palsy, spina bifida, muscular dystrophy, and spinal muscular atrophy.

One of the most common physical disabilities is cerebral palsy. Cerebral palsy refers to "a nonprogressive disorder of voluntary movement caused by damage to the motor centers of the brain before or during birth or within the first few years of life" (Heller, Alberto, Forney, \& Schwartzman, 1996, p. 390). Specific motor issues such as movement patterns, tone, and muscle control are commonly abnormal. In addition to the motor problems that cerebral palsy can cause, there are often associated conditions, such as difficulties in the area of cognition and learning, speech and communication, and vision. All of these factors can have a tremendous impact on the functioning of the individual and must be considered when assessing and providing writing activities for individuals with cerebral palsy.

Problems with fine motor coordination are common with cerebral palsy. Often, these motor patterns can lead to contractures, or shortening of the muscles (ligaments) (Best et al., 2005). Spastic cerebral palsy often results in fingers, wrists, and elbows being in flexion (Heller et al., 1996) and abnormal muscle tightness in the arms, hands, and fingers (Best et al.). This can adversely affect fine motor coordination. Handwriting and keyboarding can be difficult for individuals whose fine motor control is affected due to the inability to control fine motor movements. 
Lack of coordination and range of motion may cause an individual with athetoid cerebral palsy to have difficulty writing due to uncontrolled, nonpurposeful movements with variable tone (Best et al., 2005). Also, these individuals often have a limited range of motion and cannot access the same range of their environment as those with typical motor patterns (Best et al.). Posture is often affected, so proper positioning of materials can be important. Due to these abnormal motor patterns, fine motor work can be more difficult. Reaching the desired target, whether it is for handwriting or keyboarding, can be a challenging and inefficient task for individuals with cerebral palsy and can negatively affect writing.

Cognitive and learning issues also can affect individuals with cerebral palsy (Best et al., 2005; Heller et al., 1996). Individuals with cerebral palsy can have a range of cognitive levels, from gifted to severe or profound mental retardation. However, there is a higher incidence of mental retardation with more severe forms of cerebral palsy. Learning also can be affected, and individuals with cerebral palsy often can have visual or auditory processing difficulties. Cognitive and learning issues related to cerebral palsy can affect an individual's writing. Whether it is collecting and organizing thoughts or the processing time it takes, or just getting words down on paper or on the computer screen, individuals with cognitive or leaning problems in addition to cerebral palsy can experience difficulty writing.

Speech impairments also are common with all types of cerebral palsy (Kotler \& Thomas-Stonell, 1997) and can impact writing. Speech is often affected due to motor coordination issues. If the individual cannot physically write due to cerebral palsy, then dictating and describing what he wants to say is often an accommodation. However, often 
speech and communication issues can get in the way of the individual expressing what he wants to say, thus affecting the individual's ability to produce written work.

There are also a number of additional impairments that must be considered when working with individuals with cerebral palsy. For example, the impact of having visual impairments in addition to cerebral palsy can have an impact on the individual's functioning in his environment. Vision issues secondary to cerebral palsy may affect an individual's ability to write. If the individual has difficulty seeing the output, he might need writing accommodations.

Another common physical disability is spina bifida. Spina bifida is characterized by an outpouching of the spine and subsequent lack of normal nerve functioning, which affects muscles, skin sensation, and body systems, including hand functioning (Shaer, 1997). Learning problems often accompany spina bifida and can include problems in the areas of visual-perceptual skills, organization, attention, and memory (Shaer). Often, language also is impaired and is characterized by cocktail speech, excessive speech, and use of jargon clichés (Heller et al., 1996). Despite the complications from spina bifida, two-thirds of individuals with spina bifida have normal intelligence. The other portion of the population often has varying levels of cognitive ability, often falling in the range of mild mental retardation (Heller et al.). Consequently, unrealistic demands are placed on the individual because of apparent normal language abilities (Heller et al.).

Due to paralysis and decreased hand functioning, adaptations for writing are often necessary. These can include reducing the length of the assignment, choosing alternative assignments, and choosing a different mode of output of the assignment, such as producing work on the computer. Still, due to hand functioning issues, individuals with 
spina bifida may complete work more slowly despite accommodations. Barnes, Dennis, and Hetherington (2004) noted that "even [individuals with spina bifida] with average intellectual skills, are slow writers" and that "the brain anomalies associated with [spina bifida] affect finger function as well as motor planning..., and persistent deficits in these domains could disrupt writing skills in both childhood and adulthood” (p. 656). Additional writing adaptations may be needed when perceptual issues accompany spina bifida.

Another type of physical disability that may impact writing is degenerative diseases. Diseases such as muscular dystrophy (MD) and spinal muscular atrophy (SMA) gradually get worse over time and can result in more complex physical needs in the educational environment as time progresses. Due to limitations in muscle functioning caused by MD, contractures occur, limiting motor movement and range of motion. Along with the weakness in muscles comes issues of coordination as well. As the disease progresses, motor functions such as writing, positioning, and fine motor movement often become difficult. In addition to the motor issues, individuals with muscular dystrophy frequently deal with fatigue. Medical issues also can limit an individual's participation in academic activities. However cognition is not affected (Heller et al., 1996).

Spinal Muscular Atrophy (SMA) is another degenerative disease that, like muscular dystrophy, is characterized by progressive weakness. However the root of SMA begins in the nerves (anterior horn cells in the spinal cord) and ends up affecting muscle strength (Heller et al., 1996). The muscles deteriorate because they are not being used. When the nerves are not transmitting messages to the muscles, they atrophy because they never receive the signal to be used. Therefore, muscles atrophy and individuals with 
SMA have decreased muscle tone (Heller et al.). As with MD, as the disability progresses, so does the loss of muscular function. Again, communication and cognition are not affected, but often individuals have trouble physically accessing the environment. Because of loss of muscular functioning, writing can be difficult and often, assistive technology is necessary.

\section{Specific Characteristics Affecting Writing Process}

Despite the differences of these various physical disabilities, most individuals with physical disabilities share several common characteristics that can impact writing. According to Heller and Swinehart-Jones (2003), if a student has an orthopedic impairment, he may have difficulty with physical access. However, if the disability is health-related, problems related to fatigue and endurance may be present. Individuals with more severe degrees of disability typically will have more complex issues than those with less severe forms of the same disability. Common functional limitations associated with physical disabilities that affect academic performance and writing can include motor limitations, restricted communication, fatigue and endurance limitations, health factors, experiential and conceptual development deficits, neurocognitive impairments, and interactional effects of additional disabilities (Heller \& Swinehart-Jones).

Individuals with physical disabilities obviously have difficulty with movement, which can impact their ability to interact with and manipulate school materials. Motor issues may affect the writing of individuals by decreasing speed due to decreased or uncontrolled movements. Motor movements also can affect accuracy of handwriting or typing. An individual with cerebral palsy, for example, may try to type a desired key and hit another key by mistake. Due to the decreased motor control, it may be difficult for 
individuals with physical disabilities to use standard classroom equipment (Heller \& Swinehart-Jones, 2003), and assistive devices are necessary. Because of these motor limitations, individuals with physical disabilities often need modifications to their materials and school environment in order to ensure their participation in school and their environment. Without modifications, students can become passive or non-participants in their environment and can be deprived of important learning activities and opportunities (Heller, 2003).

Restricted communication can be a negative factor when writing. Dysarthria is common with individuals with cerebral palsy and can create issues with writing. Many individuals with dysarthria have restricted vocabulary due to inability to interact in conversations effectively (Heller \& Swinehart-Jones, 2003). Individuals with spina bifida often have cocktail speech, where they repeat commonly used phrases that do not always fit the context of the conversation. They may therefore lack the ability to write on an expanded topic. Individuals with MD may experience decreased muscle control in the mouth as well as enlarging of the tongue, which can impact speaking.

Other functional effects that a physical disability may have on an individual that impact writing include fatigue, endurance, and pain (Heller, 2003). Because it takes some individuals extra effort to move and plan movements, they often fatigue or tire easily or quickly. They may not be able to sustain long periods of activity without a break and therefore may not be able to produce large quantities of writing due to the amount of effort it takes. Because they often focus so much on the physical act, concentrating on what they are writing can be affected. Also, because they often use alternative ways of typing, such as typing with one hand or using a mouth stick, fatigue must be monitored. 
Individuals with physical disabilities also can experience visual fatigue. Many times, individuals with physical disabilities are not touch typists and must oscillate from looking at the keyboard to looking at the screen. Having to visually track what they are writing can cause visual and physical fatigue. The size of the font for the output must be considered to reduce visual fatigue as much as possible (Heller \& Swinehart-Jones, 2003).

Pain often accompanies physical disabilities, which again, can impact concentration and interaction in the environment. Because of the physical impact of physical disabilities, students may miss portions of classes or the school day or multiple school days due to their disabilities. Absenteeism can be due to many factors, including seizures, fatigue, pain, illness, or having to perform physical procedures. Missing class or portions of a lesson can have a negative impact, and students fall farther behind. It is difficult to catch up because these individuals frequently need extended time to complete the same task as their non-disabled classmates, and this includes make-up work as well (Heller, 2003).

Another factor in academic performance is that of experience. Experience can affect the writing of individuals with physical disabilities in two ways. First, lack of conceptual experiences due to limited motor responses and limited ability to explore the environment can limit one's understanding and conceptualization of the surrounding world. Because in many cases the individuals have not been able to interact with their environment physically, they often lack experiences or concepts that are introduced in school. This can result in misconceptions and misinterpretations and can have an effect on the ideas from which they base their writing. The second way that experience can 
negatively affect individuals with physical disabilities can be in their school experience. Often, students with physical disabilities are not educated in the same way as their nondisabled peers. This can be due to a number of factors, including teacher training, reduced expectations, fatigue, absenteeism, medical factors, lack of creativity and ingenuity of educators, motivation, and behavior. These students may not have had sufficient writing instruction and therefore may struggle when attempting writing assignments. The environment in which the student is educated is therefore important, and effective modifications should be made (Heller, 2003). All of these factors can lead to an ineffective educational experience for individuals with physical disabilities (Heller).

Cognitive demands of writing can also impact individuals with physical disabilities. With individuals with physical disabilities, just the physical planning of writing or typing (motor planning) can cause an unbalanced cognitive load. Transcribing each letter into a physical format can be cognitively taxing. Having to think about spelling, mechanics, and syntax also can be a barrier (Bereiter \& Scardamalia, 1987; MacArthur, 1999a; Sandberg, 2001). The amount of attention and concentration it takes to find or type a key may interfere with the rehearsal needed to keep the content in working memory (Baddeley \& Wilson, 1985). Due to working memory issues, thoughts can be easily lost, and the individual can have difficulty remembering sentences, words, phrases, and spelling of what he wants to write. All of these cognitive factors can have a negative impact on the writing of individuals with physical disabilities (Bereiter \& Scardamalia; Heller \& Swinehart-Jones, 2003; Sandberg).

Individuals with physical disabilities often have additional impairments. In terms of learning issues, often there are other associated learning difficulties with individuals 
with physical disabilities. Mental retardation, developmental delays, and learning disabilities can accompany various physical disabilities. These learning issues obviously affect students’ participation and success in school. Because of these learning issues, specialized instructional strategies as well as an adapted or enhanced curriculum are sometimes necessary to effectively teach individuals with physical disabilities. Vision impairments as a secondary impairment also can have a tremendous impact on individuals' writing and participation in academic activities. For example, an individual with physical disabilities and vision loss might not be able to read a standard textbook or be able to see what the teacher is writing on the board. This can have a negative impact on not only how the individual learns but also what the individual learns.

Psychosocial and environmental factors, such as motivation, self-concept and self-esteem, and behavioral and emotional functioning also must be considered. Some individuals may have limited social interaction or distorted social interaction. How a student feels about himself also can impact his education. Low self-esteem can be common. For example, an individual with muscular dystrophy or spinal muscular atrophy may feel depressed about the loss of physical function. This depression may affect motivation to engage in academic activities such as writing.

All of these functional, psychosocial, and environmental factors can have a tremendous impact on the education of individuals with physical disabilities. Depending on the type and the extent of the physical disability, writing ability may be affected. Writing

Writing processes. Flower and Hayes (1981) formulated the cognitive processes of writing and characterized writing as thinking processes in which writers organize their 
thoughts as they construct their composition. They suggested that writers utilize the following processes when writing: planning, sentence generation, and revision. They noted that during the revising process, planning and generation also occur (Flower \& Hayes; Hayes \& Flower, 1987). Flower and Hayes described prewriting as the time the writer spends before putting words on paper. Writing includes producing a product, and rewriting is rewording the composition. They stated that writers pan and revise constantly as they write and that the stages of writing overlap (Flower \& Hayes). Male (2003) described the process approach to writing in a similar manner, adding a sharing/publication stage. In alignment with Flower and Hayes, Male (2003) agreed that these processes are not linear; rather they are cyclical and interactive.

Planning involves idea generation and organization (Hayes \& Flower, 1987) and is viewed as the most important process of writing (Reece \& Cumming, 1996). Planning involves retrieval and shaping of knowledge (Hayes \& Flower). Pre-writing, which includes brainstorming and planning, is a time in which the student may generate ideas about which to write. In this stage, the student may think of ideas, discuss ideas with a teacher or peer, write down thoughts, utilize a graphic organizer, or create an outline. For individuals with physical disabilities, motoric difficulties can be seen in the pre-writing process. Therefore it is important that they have an effective means of physically organizing information, such as writing notes, creating outlines, or rehearsing what they plan to compose. Otherwise, thoughts and ideas can be lost in the planning stage.

In the next stage, the student writes a first draft. During the writing stage, not only do individuals have to determine how the text should be organized and structured, they also have to choose the words and phrases to generate sentences that clearly and 
accurately communicate what they are trying to convey (Dale, 1999). During draft writing, sentence generation occurs, and the writer forms the plans into formal sentences. As multiple sentences are generated, the writer is producing a draft (Hayes \& Flower, 1987). Even when writing a first draft, the writer is always evaluating while generating based on his goal for writing and may revise his plan, affecting word choice, sentence order, or many other aspects of the composition. Strum and Koppenhaver (2000) discussed that because of the cognitive demands on writing, it is important for writers to compose multiple drafts.

Finally, the process of reviewing involves evaluating and revising what has been written. In this stage, the student usually expands upon the draft, corrects errors, reorganizes thoughts, and adds or removes segments of what was written in the draft. Writing strategies. One of the strategies to promote composition of a written product is to concentrate first on getting the desired content on paper in a draft format and then on revising the draft, making necessary corrections. For example, Kellogg (1996) described a writing strategy in which the writer would plan and generate text without monitoring it for errors or reformatting. After the initial draft was completed, the writer would read the draft and begin the editing process. However, other writing strategies exist in which writers devote much attention to editing as they write their draft and therefore produce a polished and complete document (Kellogg). Rhodes, DudleyMarling, and Mowder (1986) described a strategy for increasing writing fluency using a draft format that they called free writing. In free writing, which also can be combined with journal writing, writers were timed, typically for five to ten minutes. The writers 
simply wrote about anything that occurred to them and did not stop to edit or make any corrections.

Effects of working memory. Due to the complexity of writing, working memory is involved heavily in all stages of writing. In order to understand better the impact that memory processes have on writing, a review of the Information Processing Theory (Atkinson \& Shiffrin, 1968) is necessary. In Atkinson and Shiffrin’s dual store model of memory, the central executive system regulates the flow of information through different phases of information processing. Information is sent first to the sensory register, where it spends only a few seconds. The information in the sensory register is either lost or is transferred to short-term memory, otherwise known as working memory. In working memory, information is held for under one minute and either needs to be used or moved to long-term memory. Information that does not transfer from working memory to longterm memory is forgotten. In order to move information from working memory to longterm memory, the individual must attend to the information in order to sufficiently process it.

Working memory can hold five to nine units of information at one time, although the amount of information in each unit can vary and affects the storage capacity. Consequently, some of the capacity of working memory may be devoted to cognitive processing, therefore leaving less room for information storage. Working memory consists of a visuospatial sketchpad, which is for retention of visual material. Working memory also consists of the phonological loop where auditory information is stored through constant repetition (Baddeley \& Wilson, 1985). Repeating information, known as maintenance rehearsal, keeps information in working memory and is often accomplished 
through subvocal rehearsal. Information disappears once the rehearsal stops. Decay and interference also can cause information in working memory to disappear or to be replaced by other information. Organizational processes that can help working memory include chunking, or placing like information together (Atkinson \& Shiffrin, 1968). Planning prior to writing may help individuals chunk and organize their information better (Bereiter \& Scardamalia, 1987; Honeycutt, 2003; Reece \& Cumming, 1996).

Working memory has implications in the transcription process, the act of generating text (Barnes et al., 2004; Berninger, 1999), and editing (Kellogg, 1996). The concept of cognitive load on working memory is related to activity interference, with low-level activities interfering with higher-level activities (Bourdin \& Fayol, 2000). For example, if handwriting and spelling, which should be low-level activities, interfere with the production of cohesive text, which is a higher-level activity, interference is occurring in working memory, causing additional strain to the central executive system. As Bourdin and Fayol stated, "the graphomotor component interferes with textual production” (p. 185). Writing utilizes resources and therefore increases the load on working memory. Therefore, individuals do not have as many working memory resources for planning and writing (Bourdin \& Fayol).

Kellogg (1996) suggested that typing and handwriting are not as taxing on the central executive system when the skills are well-practiced. In their experiment, Bourdin and Fayol (2000) tested the hypothesis that working memory load is increased when primary tasks, such as recall, are paired with secondary tasks, such as drawing, tapping, or sorting. They found this to be true for younger children as opposed to older children because older children had "at least partially automated graphic transcription" (Bourdin 
\& Fayol, p. 192). Graham and Harris (2000) indicated that if writers are not fluent or efficient with transcription, it can be taxing on attention. Additionally, having to attend to transcription, considered a lower level of skill, can interfere with content generation (Graham, 1990). Moreover, Flower and Hayes (1981) indicated that the process of translating or transcribing ideas into written words can be a burden that may overwhelm working memory. They stated, "if the writer must devote conscious attention to demands such as spelling and grammar, the task of translating can interfere with the more global processes of planning what one wants to say” (Flower \& Hayes, p. 373).

The implications of working memory concerns for individuals with physical disabilities are that they often do not have automated graphic transcription (Bourdin \& Fayol, 2000) due to their motor limitations, and because of this, there may be additional strain on working memory. Handwriting, typing, or spelling is not necessarily a low-level task due to the motor and learning issues that these individuals often experience. Therefore, the physical act of transcribing their thoughts could have a tremendous impact on the working memory load. Because individuals with physical disabilities have to devote so much physical energy and attention to the motor act of typing or handwriting, the central executive system is highly taxed.

Finally, the most significant demand on working memory, Kellogg (1996) described, is when editing, not when reading the writing. Therefore, it is more taxing on working memory for writers to edit as they compose as opposed to editing and then revising later. Editing while composing adds just one more layer to burdens on working memory (Kellogg). 
Bourdin and Fayol (2000) discussed that children from ages six to nine produced more coherent and elaborate texts orally as opposed to in written format. However, they reported that once individuals reached the age of 9 or 10, the opposite was true, with written texts becoming more coherent and elaborate than oral ones. Often, younger children's texts are choppier because they go from idea to idea and compose without planning the entire text. Bourdin and Fayol hypothesized:

that the greater or lesser degree of efficiency of certain low-level operations (orthography, graphic activity, etc.) modulates the quantity of resources available and thus has an indirect impact on the quantity and quality of the written compositions. We postulate that the children allocate less attention to conceptual planning because they have to devote attentional resources to the management of certain low-level activities specific to writing (e.g., spelling, handwriting). This conception is consistent with a capacity theory of writing. (p. 184)

Reece and Cumming (1996) found that higher quality work was produced when the writers planned prior to writing. Because writers did not have to pay attention to spelling, punctuation, handwriting, and other distracters when dictating, there were more cognitive resources that they could allocate to the other processes of writing, such as planning, composing, and revising. Reece and Cumming also found quality increased when planning involved using an outline prior to composing. Finally, Graham and Harris (2000) stated that when writers dictated their work, they did not have to deal with the transcription process, which removed the mechanical demands of writing. Consequently, their quantity, in terms of length, and quality improved.

Speed and accuracy issues. Due to interference of motor planning issues with working memory and the writing process, it is important that students with physical disabilities use the most efficient method for text input. Efficiency can be measured by speed and accuracy. One way to examine speed and accuracy is to target the draft phase 
of writing. Lewis, Graves, Ashton, and Kieley (1998) analyzed three minute writing samples for speed and accuracy for students without disabilities and students with learning disabilities. The researchers analyzed first drafts of writing samples for writing speed and accuracy. First drafts were selected for analysis because the focus of the study was text input, not the revising and editing stages of writing. Students were given a prompt based on the classroom writing program. Speed was reported in number of characters per minute. Errors were analyzed in terms of mechanics, spelling, and syntax. The number of errors per 100 words was reported. The pre-test consisted of both groups using handwriting only. The post-test consisted of five out of the six groups using different treatments on the computer (e.g., systematic keyboarding instruction, alternative keyboard, word processing alone, word prediction, and word prediction with speech). The results indicated that speed was faster during the pre-test for students with learning disabilities, with all students using handwriting. The word prediction with speech group had the largest decrease in speed between pre-test and post-test, and the word prediction alone group had the least amount of decrease in speed compared to handwriting. The traditional handwriting group’s speed was virtually unchanged from pre-test to post-test. When compared to students without disabilities, students with learning disabilities had a slower speed at both pre-test and post-test. The writing accuracy of the students with learning disabilities, however, improved from pre-test to post-test. The authors speculated that the students with learning disabilities were able to identify their errors better on the computer screen as opposed to their handwriting. Other authors have noted that the neat copy that the computer produces can be advantageous for individuals with learning disabilities (MacArthur \& Shneiderman, 1986). 
The standard writing process may be difficult for students with physical disabilities when there are speed and access issues. A slower speed may result in less written material and less revising that is needed. DuBois, Klemm, Murchland, and Ozols (2004) utilized parent and teacher surveys to discuss and analyze the handwriting of students with hemiplegia cerebral palsy. They noted that students with physical disabilities are typically expected to keep up with the general curriculum and with their peers; however, their handwriting speed often holds them back and causes them to fall behind when completing written activities. The motor dysfunction typical for individuals with hemiplegia often causes abnormal muscle tone, spasticity, an increase in fatigue, and slower movement, thus making handwriting difficult. Based on 72 questionnaires from parents and teachers about the handwriting of children with hemiplegia cerebral palsy ages 8 -13, DuBois et al. found that $75 \%$ of the parents indicated handwriting problems in their children and $69 \%$ of the teachers indicated handwriting difficulties. The surveys assessed areas of functional writing, organization of writing, speed, and neatness. In the area of speed, parents indicated that $52 \%$ of their children had difficulties with speed; teachers indicated $42 \%$. It was noted that some students experienced frustration due to the time it took them to write and because they fatigued while handwriting. Other findings of interest indicated that one-third of the students experienced pain when writing, posture was an issue during the handwriting task, children often engaged in atypical pencil grasps, and fatigue and tiring occurred frequently during longer writing sessions. Almost two-thirds of the children were said to have difficulties with neatness. Because of difficulty with handwriting for students with physical disabilities and its impact on speed and accuracy, it has been suggested students type their assignments. 
Other modifications may include giving extended time to complete assignments and reducing the length of the assignment (Heller, 2003). This could lead to students completing tests or assignments over two days, writing fewer or shorter assignments, or using a laptop computer or assistive technology in class (Heller). Additional types of modifications and assistive technology are available.

\section{Modifications and Assistive Technology}

Fortunately, many assistive technology adaptations exist that can assist in circumventing writing problems (Bruce, Edmundson, \& Coleman, 2003). Making accommodations for writing is important, because long papers are difficult to produce. These assistive technology solutions range from no-tech to high-tech. Low-tech adaptations are often necessary to help the individual compensate for the physical disability in the educational environment. Some adaptations can be as simple as modifying writing or simply changing how individuals hold their pencils. Different types of writing instruments, such as markers or felt-tipped pens can be used in order to change the amount of resistance the writer experiences on the paper. For others, building up writing instruments to provide a better grasp can help. Sometimes, it is necessary to use a different body part, such as toes, to hold writing instruments and to write.

Modifications to paper also can be made. Paper guides, such as typoscopes also can be used to define writing boundaries. Dark or raised lines on the paper can provide the writer with clearly defined boundaries. Positioning of the paper is also important. Sometimes, simply altering the angle or placement of the paper can help, and slant boards are often used. Stabilization of the paper is sometimes necessary and can be accomplished by using tape or placing the paper on a non-slip surface, such as Dycem. 
Finally, the size of the paper is important and should be within the writer's range of motion.

Some writers may need to use the computer due to illegible handwriting or lack of ability to write. Most individuals without disabilities utilize the direct select method of keyboarding (i.e., they make contact with the keys on the keyboard, typically using all ten fingers). However, individuals with physical disabilities may need modifications for direct select, such as using a mouth stick on a standard keyboard. If direct select is not possible, alternate methods of selection, such as scanning, are available. For students with motor problems who cannot use the standard keyboard, adapted computer keyboards can be used. Alternate keyboards are available, such as IntelliKeys, mini keyboards, and onscreen keyboards. Other adaptations may be necessary such as enlarging keyboard letters, using keyguards, using a TouchWindow, and using specialized software to enhance rate, such as word or letter prediction. Accessibility options also can be changed easily, making changes to the repeat rate or using sticky keys for users who cannot use two hands simultaneously. Solutions as simple as changing keyboard layout (such as DVORAK), using one-handed keyboards, using switches, or using different pointer devices (such as a mouth stick) are available. Audio taping responses instead of inputting directly (Best et al., 2005) or utilizing spell check and grammar check for editing may be helpful. Finally, word processing, word prediction, dictation, and speech recognition may provide better writing access for some individuals with physical disabilities.

Word processing. Word processing is of little value without specific instruction (MacArthur, Schwartz, \& Graham, 1991). Male (2003) suggested the following writing instructional strategies for using word processing: provide sufficient time; use a variety of 
writing tasks (e.g., narratives, journaling, problem solving, compare/contrast); create an environment of writing; integrate writing activities across all academic subjects; provide opportunities to practice keyboarding and basic writing tasks (e.g., paragraph construction); and do not over-emphasize errors. Instead, offer suggestions for improvements in just a few areas.

When trying to determine useful features of word processing, it is necessary to determine the size of the print and whether or not certain features will be enabled or disabled (e.g., speech synthesis, grammar check, spell check). Teacher prompts are important because they initiate the process of writing. How the student will access the computer is also important. Will he or she utilize the standard keyboard or need an adapted keyboard? Can the individual utilize the standard mouse or will he or she need to utilize switches or a touch screen? Male (1997) reported that at times, it is useful to have the teacher type for a student when the student is

unable to type fast enough to get his or her ideas down or when the student is stuck. Teachers can type short phrases on the computer, based on what the child says aloud, which the student can then expand into complete sentences. (p. 94)

A review of the research on word processing yielded mixed results (BangertDrowns, 1993; Male, 1997). MacArthur and Shneiderman (1986) indicated that word processing has three benefits that can potentially affect the way individuals write. The benefits include the ability to produce a neat copy of their work, which in turn, elicits perceptions of quality. They stated that the neat output can increase motivation. Second, word processing allows for easy editing and revision. Finally, it takes away the physical aspect of handwriting, which can reduce the physical demand and aid in the transcription process, circumventing the mechanical aspects of writing (Graham, 1990; MacArthur \& 
Graham, 1987). However, MacArthur and Shneiderman cautioned that students must have some keyboarding skills and knowledge of basic functions, such as editing and commands, of the word processor in order to utilize it successfully.

MacArthur, Schwartz, and Graham (1991) discussed advantages to typing, in that it is easier and neater than handwriting for students with fine motor problems. They recommend that students should be able use correct fingering while looking at the keyboard (MacArthur et al.). Students should also be able to type as fast or faster as they write by hand (Best et al., 2005; MacArthur et al.). After one school year of participating in the Computers and Writing Instructive Project (CWIP), which consisted of a process approach to writing, word processing instruction, and strategy instruction, 180 students with learning disabilities, in comparison to the control group, improved on quality of narrative and informative writing, increased the number of words, and decreased the percentage of spelling errors (MacArthur et al.).

Lifshitz (1999) taught 25 individuals with mild mental retardation word processing skills using two different instructional techniques: task analysis and cognitive processes. Word processing skills taught included basic functions, including letter and punctuation keys, use of action keys, including spacebar, enter, delete, backspace and error keys, and use of commands, such as moving and copying text and saving and printing. Participants were taught the letter keys by copying familiar texts. They began typing only two-letter words and slowly increased word length, then moved to typing sentences, and finally, moved to typing paragraphs. While typing the texts, the participants were taught to use the spacebar accurately. The commands of moving text were then taught. The results showed that regardless of whether the participants were 
taught through task analysis or cognitive processes, they were able to type simple text. However, when learning to use the enter and spacebar keys, the use of cognitive processes to teach the skills was more effective. Only a few participants were able to successfully use the move commands. This study demonstrated that individuals with mental retardation can learn basic word processing skills effectively but may be limited in their understanding of higher-level functions and commands (Lifshitz).

Langone and Willis (1994-1995) found that when comparing word processing with paper and pencil for teaching writing skills to children with learning disabilities in elementary school, individual differences accounted for the effectiveness of both strategies. As cited in Hetzroni and Shrieber, (2004) Margalit and Roth (1989) found that word processing could help improve the writing of children with learning disabilities and mild intellectual disabilities in elementary school once they learned keyboarding skills.

MacArthur and Graham (1987) and MacArthur and Shneiderman (1986) indicated that through the use of word processing, problems associated with handwriting and spelling were no longer present, and this, in turn, could lead to motivation for writing. The word processor allowed students to edit and spell-check the product and to present a legible document.

Hetzroni and Shrieber (2004) investigated the effects of word processing on the writing of students with writing difficulties. All participants had learning disabilities and had difficulty with spelling, legibility, and copying text. The authors reported that the participants had basic knowledge of typing and were able to perform basic word processing tasks. Percentage of spelling errors (number of errors divided by total number of words, not including repeated mistakes) and total number of words regardless of 
spelling errors were of interest. All three participants made fewer spelling mistakes using word processing, and two out of three participants consistently wrote a higher total number of words when using word processing. Participants were able to use the spellcheck feature on the word processor. Because the product on word processing was more legible, students were able to read their own writing better when using the word processing product as opposed to the handwritten product. The authors noted that the red line under the spelling errors helped students become aware of spelling mistakes. When they returned to handwriting, they initially searched the document more thoroughly for spelling mistakes, but because there was no visual reminder, they soon stopped searching as the session progressed. It was found that word processing increased the readability of the product and might, therefore, lead to greater motivation and confidence when writing. Englert, Wu, and Zhao (2005) noted the advantage of technology, stating that “technology can be used to offload some of the cognitive work from the inexperienced writer onto the computer, just as a calculator might be used to offload some of the cognitive demands on students in mathematics” (p. 185). Another advantage of the use of technology is the accessibility of spelling assistance. Many word processors provide spell-checking assistance, which can have a positive impact on the output of the user's writing. In their study, Englert et al. taught students to utilize a web-based program to write detailed narratives. In one condition, the researchers scaffolded the assignment based on topic and structure. The program also offered a text-to-speech function, which was utilized. Another condition, the unscaffolded condition, did not allow students free access to prompts and help during their writing. Finally, there was a paper and pencil condition in which students wrote. Papers were scored for quality, readability, and 
productivity (word counts and line counts). The results indicated that the scaffolding helped with text structure, but the length did not vary much among conditions.

Outhred (1989) assessed the creative writing of children with learning disabilities. She compared the stories written by hand with stories written using the word processor in the areas of story length and misspellings. Over time, the length of the stories increased in both the handwriting condition and the word processing condition. However, the students who had the shorter handwritten stories wrote more when using the word processor. In the area of spelling, students with low rates of spelling errors on handwritten stories made approximately the same number of spelling errors when using the word processor. Again, however, students who had severe spelling problems in the handwriting condition (60\% errors) made fewer errors when using the word processor (30\% errors). The results indicated that the word processor could be a positive choice for students who have severe spelling problems or who are concerned with the mechanics of writing and therefore produce less handwritten output.

Word prediction. Another solution that may help students circumvent spelling problems and slow rate of production using a standard or alternate keyboard is word prediction software. Word prediction software was developed to help reduce the number of keystrokes it takes to type a word and works in the following way. When the student types the first letter of a word, a list of numbered words appears in a separate window on the screen. If the word the student is trying to type is on the list, the student can select the word by typing the corresponding number or by clicking on the word with the mouse. If the word is not on the list, the student continues to type, and the list of potential words changes accordingly. When the student types a period or presses enter, the words from 
the word prediction screen transfer to the selected word processor. Options such as predict ahead and flexible spelling are features that also are available. Predict ahead works when the user selects a word from the list or types a word and enters a space. Before typing the first letter of the next word, a list of predicted next words appears. Newer versions of word prediction software have flexible spelling, so if the student types a letter that the word does not begin with, but that has a similar sound, the word may appear in the list (e.g., student types f-o- and the word "phone” appears on the list). Some word prediction programs can learn new words that the user inputs (Lewis et al., 1998). Because of the many features of word prediction software, it could be a helpful tool for writing for some individuals.

There are potential benefits and limitations to using word prediction software. MacArthur (1999a) stated that "word prediction software was originally developed for individuals with physical disabilities to reduce the number of keystrokes required to type words” (p. 178). Because the user theoretically can press fewer keys to type a word, students who have motor problems or who are slow typists potentially can increase their typing rate. It also has the potential to help students with spelling because they do not have to type or spell the entire word (MacArthur, 1998b, 1999b; Merbler, Hadadian, \& Ulman, 1999; Mezei, \& Heller, 2004). Additionally, MacArthur (2000) suggested that word prediction software could be beneficial for students who had poor handwriting or whose spelling was so poor that they could not read their work. Other benefits include expanding vocabulary (MacArthur, 1999a, 1999b). There are limitations, however, including difficulty of use (MacArthur, 1999b), the amount of time it takes to scan the list for the correct word (Golden, 2001), and the potential that the student will have to type 
the whole word because it does not appear in the list, taxing both the physical component of writing as well as spelling. Consequently, it could take effort for some students to type using word prediction software. The possibility also exists that the students might choose the wrong word simply because it is available in the list.

A number of researchers have performed studies on the use of word prediction software. Many of these studies have included participants with learning disabilities. Lewis et al. (1998) assessed the writing of students with learning disabilities and found that they could handwrite the fastest and use word prediction the second fastest. They were slowest using word processing. Lewis et al. reported that teachers believed that word prediction actually slowed down the typing rate for more advanced typists. However, Lewis et al. also discussed that students may have had slower typing rates using word processing and word prediction because of lack of practice and keyboard familiarity. They recommended more typing practice for the students with learning disabilities. However, for students with physical disabilities, more typing practice may not help because these students may never be able to increase their typing rate due to motor issues.

In another study with students with learning disabilities, the typing rate of the student who had the highest words per minute rate and good knowledge of the keyboard and keyboarding skills decreased when using word prediction software (Golden, 2001). Golden discussed that the time to search the word prediction list could have impeded the student's ability to type faster, thus decreasing typing speed.

In relationship to spelling, MacArthur (1999b) found that only one out of three students with learning disabilities spelled better with word prediction. However, when 
given a more advanced writing task that called for the use of more complex words, two out of three students improved their spelling using word prediction. MacArthur (1999b) noted, however, that the word prediction software was difficult to use and required significant demands on attention. In another study, however, all four participants with learning disabilities significantly increased their correctly spelled words (MacArthur, 1998b).

Finally, Tumlin and Heller (2004) conducted a study with individuals with physical disabilities using word prediction software. Tumlin and Heller found that the two students with the most severe physical disabilities showed improvement in rate (words per minute) when using word prediction software compared to word processing alone. One student showed no difference in rate, and the fourth student decreased in rate when using word prediction software. The student who decreased in rate had the fastest baseline typing rate. However, Mezei and Heller (2004) found that for individuals with physical disabilities, typing rate increased from word processing to word prediction for three students with physical disabilities, and all of the participants decreased their spelling errors.

The mixed results of the use of word prediction software indicate that individual characteristics can influence the success of the use of assistive technology. As these studies suggest, word prediction performance can rely on several factors. Student characteristics such as the amount of time it takes to press a key (keypress time) and the amount of time it takes for a student to search the word prediction list can influence writing rate (Koester \& Levine, 1997, 1998). For students with physical disabilities, the keypress time will be the factor that is most divergent from students with other 
disabilities. Because word prediction has yielded mixed results, especially for individuals with higher initial typing rates, other solutions must be considered.

Dictation. Some students have such severe physical disabilities that their production rate is very slow when using word processing, even with enhancements. When individuals have difficulty with writing due to access issues, dictation is an option (MacArthur, 1999a, 2000). Reece and Cumming (1996) offered an increase in speed of production as an advantage to any form of dictation. De La Paz (1999) noted that dictating is faster than writing or typing because people speak at a rate of 125 to 160 words per minute, write 15 to 25 words per minute, and depending on typing abilities, typically type at a rate somewhat faster than writing. Therefore, dictation can be quite efficient. De La Paz and Graham (1997) indicated that dictation can not only affect the speed of writing but also the amount of work produced and the quality of the dictated product. In their study, they found that advanced organization training paired with dictation had a positive effect on the quality of the writing. De La Paz and Graham found when comparing dictation to handwriting, dictation had a higher entry rate and the students produced longer, more complete, more cohesive, and quantitatively better essays. They also found that dictation was 250\% faster than handwriting. Graham (1990) and MacArthur and Graham (1987) found that students with learning disabilities were able to compose longer, higher quality papers when using dictation instead of handwriting or word processing. MacArthur and Graham found that dictation was nine times faster than handwriting and twice as fast as word processing when assessing the writing of fifth and sixth grade students with learning disabilities. Finally, Bereiter and Scardamalia (1987) reported that when removing the mechanics of writing through 
dictation, students with learning disabilities wrote $163 \%$ more when using normal dictation to a transcriber.

Dictation removes the transcription process and consequently keeps the student from having to worry about the mechanics of writing (MacArthur, 1999a, 1999b). Possible reasons for the success of dictation could be that the cognitive demands of handwriting and /or typing along with the mechanics may get in the way of the fluency and quality of the writing (Wetzel, 1996). Limitations to dictation include that it takes tremendous teacher time and develops dependence in the dictator (MacArthur, 1999a, 1999b).

Speech Recognition Systems

Another solution for writing is speech recognition software. Instead of relying on another person, speech recognition systems take the burden off of using human transcribers and allow students to independently dictate work (Higgins \& Raskind, 1995). Hux, Rankin-Erickson, Manasse, and Lauritzen, (2000) and Rosen and Yampolsky (2000) discussed that due to motor constraints, the hands-free speech recognition system is attractive. It has been suggested that students with physical disabilities could benefit from using speech recognition due to motor difficulties (Duhaney \& Duhaney, 2000).

Description of speech recognition software. Speech recognition is a separate program loaded onto a computer that allows the user to speak instead of type. Using a microphone, the user dictates directly into the computer. The user must complete training so the software can create voice files and thus recognize the specific user's speech patterns. Once training is complete, the user speaks into the microphone and the words are transcribed onto the screen. The spoken words appear in print anywhere the cursor is 
located. The user can open a word processor along with speech recognition software and use all of the features of word processing with his voice.

Not only does speech recognition software transcribe the spoken words into print, it also allows the user to navigate the computer and execute commands. For example, if the user wants to save the file, instead of having to navigate through the saving process with the mouse or keyboard, the user can use speech commands, specific to the speech recognition software, to save the document. Speech recognition software users also can navigate through documents by speaking commands such as, "move to next line” or "move to end of paragraph." Capitalization and formatting is also possible using speech recognition software, using commands such as "cap that” and "copy that.” Speech recognition users can access computer functions such as creating documents, letters, and memos, working on spreadsheets, sending e-mail messages, working on the Internet, and starting programs and opening menus. Users also can dictate into handheld recorders for later transcription. Speech recognition software allows users many different ways to create, navigate, and format documents hands-free. The use of the mouse and keyboard in addition to speech recognition software might be helpful or necessary (Karat, Horn, Halverson, \& Karat, 2000). However, if using the keyboard or mouse is not an option, the user can use voice commands.

Many speech recognition programs offer some of the features discussed previously, but there are a number of different types of speech recognition programs that warrant discussion. There are three different types of speech that can be used with various speech recognition programs: discrete-utterance, connected word, and continuous speech (Goette \& Marchewka, 1994; Koester, 2001). Discrete speech requires the user to 
speak words individually, pausing between each word. Connected-word systems allow the user to speak in short phrases before pausing. Finally, continuous speech systems allow the user to speak in complete, uninterrupted sentences or groups of sentences. Other terms related to speech recognition include speaker-dependent, speakerindependent systems, and speaker-adaptive systems (Goette \& Marchewka; Koester, 2001). In speaker-dependent systems, the user must train the system to recognize his speech patterns. Speaker-independent systems, however, do not require specific user training. Finally, in speaker-adaptive systems, the user participates in limited training, but does not train an extensive group of words. Instead, the user trains syllabic utterances from which the software will piece together speech patterns for recognition (Goette \& Marchewka).

Speech recognition has been in development since the early 1970s (Koester, 2001). Through the 1980s, discrete speech recognition systems continued development, improving the technology and increasing the vocabulary size (Koester, 2001). In 1997, however, the first commercial speech recognition system with continuous speech became available. Consequently, there are a number of early studies that review discrete speech recognition systems and a few recent studies reviewing the use of continuous speech recognition systems.

According to De La Paz (1999), there are five components of speech recognition software that are important. These components include training requirements, whether or not the software can effectively recognize continuous speech, the system's vocabulary size, error-correction procedures, and the system's overall accuracy rate. The training and instructional components of learning to use speech recognition software are very 
important. Vocabulary size has increased over the years due to the improved memory capacities of computers. Some systems will allow users to train new words that are not already in the system's repertoire. Some vocabulary systems are restricted; others are quite large, housing over 60,000 words (Kambeyanda, Singer, \& Cronk, 1997).

Because speech recognition software is a relatively new technology, and as with all technologies, has gone through many software revisions to refine it, there is not an extensive literature base. Some literature does exist that addresses the benefits, barriers, recognition accuracy, error correction capacity, rate enhancement, and use with dysarthric speakers.

Positive attributes of speech recognition. Several benefits have been attributed to using speech recognition software. Speech recognition software has been advertised as allowing individuals to write more quickly, creating documents by voice. Speech recognition can also potentially reduce the stress associated with keyboarding. Cavalier and Ferretti (1996) stated, “for many people with disabilities, alternate access to computers through speech recognition technology holds the promise of lessening their dependence on others and promoting the development of their adaptive abilities” (ף 1). They also indicated that for speech recognition to be advantageous to users, the user characteristics, type of task, and the specific speech recognition system must be considered (Cavalier \& Ferretti). Speech recognition can be a good choice for individuals with physical disabilities because it may require less physical demands and may be less tiring because it takes less effort to speak than to write (Kotler \& Tam, 2002). However, Kotler and Tam indicated that continuous speech recognition may not be effective for all 
individuals with physical disabilities because they may not be able to use it effectively without using their hands in some cases.

Speech recognition also may improve the writing process through its ability to bypass the mechanism of writing. Composing orally

permits thinking to unfold in a natural and unimpeded way...[and therefore] we are more likely to capture fleeting thoughts and sequences of thoughts than if we had been writing by hand or a typewriter - thus avoiding the uncomfortable feeling that some brilliant idea was irretrievably lost while we were typing. (Gardner, 1980, p. 19)

Some of the advantages of dictating through speech recognition software include the ability for one to speak faster than he can write if there is good recognition accuracy. Instead of having to take the time to write things down, speaking allows individuals to capture those thoughts that might otherwise be lost in the transcription time. When writing, often, it is not possible to write down ideas fast enough and they therefore are lost. When an individual composes via an inefficient means, motivation can be affected. With dictation, the user can bypass the mechanics of writing and focus more on what he wants to say (De La Paz, 1999).

In order for writing to be effective with speech recognition software, the initial phase of writing, which is the brainstorming and planning stage, needs to be addressed. A number of studies indicated the importance or rehearsal and planning prior to composing using dictation (De La Paz \& Graham, 1997; Higgins \& Raskind 1995; Reece \& Cumming, 1996; Wetzel, 1996) because participants in these studies improved writing skills through dictation only when planning first. In the studies, all students with learning disabilities had difficulty handwriting, spelling, punctuating, and with rate of production. 
Feng, Karat, and Sears (2005) had 15 participants dictate a 400-word essay for up to one hour using speech recognition. They determined the words per minute, with five characters equaling one word. They found that as participants became more experienced with the software, their productivity increased. The average rate in trial one was 10.6 words per minute, as compared to 18.1 words per minute by the eighth trial. Feng et al. indicated that participants spoke between 120 -125 words per minute, and there was a discrepancy between documented words per minute produced using speech recognition and the rate at which the participants spoke. However, participants spent the discrepant time checking and correcting errors.

Although speech recognition software has been considered beneficial to improve students' writing, it has been suggested that speech recognition technology should only be used for first drafts (Honeycutt, 2003). Honeycutt indicated that the first draft is the easiest, in terms of the writing process. Because the revision process is so difficult, it has been recommended that students do not edit their draft as they dictate. Honeycutt also stated that some speech recognition manuals suggest that the users not look at the screen as they dictate to discourage them from editing as they dictate. When revising, Honeycutt speculated that using the keyboard would be more efficient than using speech. He also described the importance of planning prior to writing, stating that formal planning is to be extremely important prior to dictating in order to avoid stream-of-consciousness writing (Honeycutt). Planning prior to dictating will help in producing a logical and orderly document, representing all of the thoughts the author intended.

Another area that has been addressed as a possible benefit of speech recognition use is quality of output when compared to handwriting and dictation. Reece and 
Cumming (1996) described three strategies that may ease the demands of writing:

outlining, dictating to a tape recorder for later transcription, and using speech recognition systems. Reece and Cumming discussed the listening word processor (LWP), a system in which a writer dictated and a hidden typist inputted the dictation into a word processor. The writer/dictator could view the screen as the hidden typist transcribed the dictation. Reece and Cumming conducted five studies on the effects of planning, dictation, and use of the listening word processor on text quality. They found that the use of the listening word processor improved the quality of the compositions, as opposed to handwriting, for normally achieving students. They also found, however, that with poor writers, dictation and use of the listening word processor were superior to handwriting, with little difference between dictation and the listening word processor. Reece and Cumming also found the listening word processor to be superior to dictation because the writer could see a written record of his dictated text, whereas dictating into a tape recorder did not provide that. Therefore, Reece and Cumming stated that using the listening word processor, the writer does not need to utilize high levels of working memory to compose and can therefore concentrate on the higher level aspect of composing.

Higgins and Raskind (1995) compared discrete speech recognition to handwriting and dictation to a human transcriber for college students with learning disabilities. Although it took the participants an average of six hours to learn to use the speech recognition system, the authors found that essays that were produced using speech recognition were of higher quality than those written using handwriting. However, there were only slight differences between the speech recognition essays and the essays dictated to a human transcriber. Students produced slightly better essays when using 
speech recognition than when dictating to a human transcriber. One reason for this may be the dependency issue of someone else completing the writing task for the individual. Also, some students had more difficulty reading transcriber's handwriting than recognizing on the screen what they had dictated. The authors found that when using speech recognition, students used longer words. They explained this by surmising that because students did not have to worry about spelling when using speech recognition, they were free to use longer words. The speech recognition program was more accurate when transcribing longer words as opposed to shorter words. This may explain why students chose to use longer words. Students reported that they were free from the distraction of having to continuously check their spelling. This was reported to be one of the most positive features of the software. Higgins and Raskind therefore noted that speech recognition helped students with learning disabilities to compensate for writing deficits. In another study, three students with learning disabilities in the fifth and sixth grade used VoiceType speech recognition software, using discrete speech (Wetzel, 1996). The participants wrote personal narratives using oral rehearsal and a word bank. The authors wanted to determine if fifth and sixth grade students could learn to use the program, if the program was accurate, and if the program could improve the quality and quantity of students' writing. One participant had a dictation rate of only 2.5 words per minute in early sessions and 5.5 words per minute in later sessions. That participant reached 74\% recognition accuracy, although VoiceType indicates that rates over 90\% recognition accuracy can be achieved. Throughout the study, the participant had difficulty with VoiceType's recognition accuracy. Twenty-six percent of the time, the participant had to use the keyboard to clarify words misinterpreted by the program. The 
accuracy rate and error rate were found unacceptable. Wetzel noted that if the accuracy rate was closer to $90 \%$, it might have been beneficial for participants to ignore recognition errors and continue to dictate. Some recognition problems occurred because of breathiness and coughing. When one participant went to make corrections, he had difficulty spelling many of the words when he had to type. The participant became frustrated because of lack of recognition.

Cognitive costs of speech recognition. The literature also reports several drawbacks to speech recognition systems, including the amount of training and the inaccuracy of the word recognition. Higgins and Raskind (1995) reported that students spent an average of six hours of training on the speech recognition software.

Additionally, people have to modify the way they talk (De La Paz, 1999). They cannot speak naturally, and often, they have to slow their speech and over-pronounce words. Recognition errors can occur, causing many word errors and frustration with users. Finally, there is mixed evidence in the literature on whether the use of speech recognition software benefits users because of issues of error correction, accuracy, and depth of training.

Koester (2001) discussed the memory burden on the use of speech recognition. MacArthur (1999a) noted that because there are many commands that must be learned in order to effectively use speech recognition software, there is an increased burden on memory. Koester (2001) described additional burdens on memory by stating that there are special words that an individual must know in order to effectively dictate. These include speech recognition commands for dictating punctuation marks, commands for editing, and program operation commands. 
Another cognitive cost that Koester (2001) described using speech recognition is that of identifying and correcting recognition errors. Koester (2001) also discussed how the consequences of errors are different between keyboard use and speech recognition. In order to identify recognition errors, the user must look at the screen, whereas with keyboarding, the user can look at the screen or base his detection of the error on the keyboarding itself (finger placement mistake). Karat et al. (2000) indicated that when keyboarding, it takes an average of three seconds to repair an error, compared to at least 25 seconds to repair speech recognition errors. This shows that large time costs can be associated with correcting speech recognition errors.

Physical and emotional costs of speech recognition. Not only are there some cognitive costs to speech recognition use, there are also physical and emotional considerations. A possible physical problem that can be associated with the use of speech recognition technology is voice fatigue. Especially with discrete speech when the user is starting and stopping speech frequently, fatigue of the vocal systems has been noted (Kambeyanda et al., 1997; Koester, 2001). Goette and Marchewka (1994) cautioned that speech recognition may not be as effective if the user experiences voice fatigue or when the user speaks with emotion or emphasis. Kambeyanda et al. also discussed voice problems and assessed speech recognition users through a survey questionnaire. After extended use, participants experienced some throat dryness and irritation. It was reported that fluids and rest helped. They determined that the use of discrete speech recognition can lead to moderate to severe voice problems (Kambeyanda et al.). Another factor when considering the use of speech recognition software is that of background noise (Koester, 
2001). Users need to be aware of their environment and make sure that the noise level in their environment does not interfere with the use of speech recognition software.

Emotional considerations can include frustration with the use of speech recognition due to the time it takes to train and due to issues with recognition accuracy. Users also may experience frustration when correcting multiple errors due to low rates of recognition accuracy. Although speech recognition is advertised as being totally handsfree, some users may find that in order to successfully or efficiently use the software, they have to make corrections by hand as opposed to by voice (Karat et al., 2000). Therefore, some users may experience frustration or disappointment that the software does not always work for them in the way it is advertised.

Recognition accuracy. Recognition accuracy is defined as how well the speech recognition software recognizes the user’s speech. However, Hux et al. (2000) indicated that an accuracy rate as low as $65 \%$ may be acceptable for individuals with motor and speech disabilities. Kotler and Tam (2002) interviewed six participants with physical disabilities and intelligible speech, ages 19 to 35 about their experiences using discrete speech recognition software. Kotler and Tam found that the average speed ranged from 8.6 to 15.4 words per minute, with five characters counting as a word. Recognition accuracy ranged from $62.4 \%$ to $84.4 \%$. In their interview with the participants, Kotler and Tam noted that participants indicated that one of the advantages of speech recognition was that they could generate text faster than with their other, nonhands-free methods. However, they noted that the increase in speed still was not adequate to complete their work. Additionally, they all agreed that speech recognition software was an appropriate alternative to word processing. However, participants cited low 
recognition accuracy, voice problems, and fatigue as disadvantages of speech recognition software use. Because of the low recognition accuracy, the authors estimated that participants had to "generate double the number of utterances to produce the required text” (Kotler \& Tam, p. 143).

Koester (2004) studied participants who had used speech recognition technology for at least six months. The participants were given two text entry tasks to measure speed. One was transcribing a paragraph from a copy and the other was composing a short piece on a subject provided by the researcher. Eleven of the 18 participants were able to achieve higher text entry rates using speech recognition and were an average of 8.9 words per minute faster than without. Koester (2004) noted that for individuals who typed slower than 15 words per minute, speech recognition improved their text entry rate. Recognition errors also were calculated by taking the total number of recognition errors divided by the total number of words spoken. Recognition accuracy raged from $72 \%$ to 94\%, averaging 85\%. Koester (2004) indicated that participants spent an average of 56\% of their text entry time correcting recognition errors, averaging 23 seconds and 1.8 attempts to correct the error. In a survey of the participants, $75 \%$ indicated that they found the speed of entry of the speech recognition system to be acceptable. In contrast, only $54 \%$ indicated that the recognition accuracy was acceptable. They also noted that there was a lack of privacy when using the technology because they had to speak out loud and bystanders could overhear their dictation. Koester (2004) noted the benefits of speech recognition, indicating that it can reduce pain and fatigue commonly experienced by other manual text entry methods. The participants in the study typically used speech recognition in addition to another input method instead of using it completely in isolation. 
The most limiting barrier to speech recognition technology, according to Koester (2004) is that of recognition accuracy and the consequences of having to repair recognition errors because the finished products using speech recognition software were less accurate than those completed without speech recognition.

Koester (2003) reported additional results on data collected on text entry rate and recognition accuracy. In the dictation phase, Koester (2003) measured the recognition accuracy. In the correction phase, she was able to get a true measurement of the participant's text entry rate because it calculated the time required to correct recognition errors. Initial recognition accuracy averaged 86\% (range 69 - 95\%) and 83\% (range 6099\%) after 4-6 weeks. Initial text entry rate, calculated in words per minute, averaged 16.9 words per minute (range 1.9 - 39.0) and 19.8 words per minute (range 1.5 - 72.6) after four to six weeks. At a six-month follow up, however, only one user was still using speech recognition.

Error correction. Karat et al. (2000) stated that developers of speech recognition often misrepresent the ability of the technology, especially in the area of rate of input (claims up to 140 words per minute). Early in users' experience, problems with error correction typically occur more frequently compared to normal text entry. In the study by Karat et al., the researchers found that individuals who typed were more productive when measuring corrected words per minute (revising while writing) than those using speech recognition software. Individuals who typed averaged a rate of 32 corrected words per minute, as compared to those who used speech recognition software, averaging 14 corrected words per minute. The authors reiterated that it was not the rate of entry that produced the results; rather, it was the time it took to correct the dictation errors as 
opposed to the time it took to correct the typing errors. Karat et al. summarized their data, making some important observations. It appeared that as speech recognition users became more proficient users, their rate of speech input, defined in terms of corrected words per minute, increased. Novices were reported to use speech to input at a rate of 13.6 corrected words per minute, whereas expert users were reported to input at a rate of 31.0 corrected words per minute. Whereas it took novice users an average of 7.3 steps to correct their work, expert users were able to complete the correction task in 3.3 steps. The authors noted that as speech recognition users gained more experience, they began using the keyboard and mouse more frequently than speech to correct errors. For example, novice users used keyboard corrections $2 \%$ of the time, whereas they used speech corrections $90 \%$ of the time, with multimodal corrections (mouse and keyboard) accounting for the other $8 \%$. Conversely, expert users used keyboard corrections 38\% of the time, speech corrections only $2 \%$ of the time, and multimodal corrections the remaining $60 \%$. The authors concluded that more advanced users preferred keyboard-mouse correction techniques over speech techniques for correcting errors when using speech recognition software.

Koester (2001) described a number of ways to prevent errors, given that the cost of errors is high when using speech recognition software. One preventative method is to use speech entry methods, such as speaking at a constant pace and volume. It is important to enunciate each word and avoid unnecessary sounds. However, Koester (2001) pointed out that cognitive energy and time are required to adapt speech patterns, even slightly. Another suggestion for avoiding recognition errors is to anticipate them before they occur. Koester (2001) suggested spelling out words, such as acronyms, proper nouns, or 
other words that might be easily misrecognized. In order to spell words, the user must use a command specific to the software (such as SPELL) and then spell the word letter-byletter. This may be a strategy that is more efficient for experienced users.

Speech recognition with dysarthric speakers. Because students with physical disabilities often have dysarthric speech, a further investigation explored the use of speech recognition software for this population (Kotler \& Thomas-Stonell, 1997). Speech problems that limit the use of speech recognition include decreased intelligibility, phonemic limitations, slower speech rate, variable speech patterns, involuntary sounds, and inconsistency (Kotler \& Thomas-Stonell; Rosen \& Yampolsky, 2000). Additionally, environmental factors, such as fatigue and time of day need to be considered due to adverse affects on speech (Hux et. al., 2000). Because individuals with dysarthria have more difficulty speaking than persons without dysarthria, they often have more difficulty with speech recognition systems. However, Rosen and Yampolsky indicated that some individuals with severely dysarthric speech have had some success with speech recognition.

Hux et al. (2000) compared three commercially available speech recognition systems using two participants. One participant was an individual with traumatic brain injury and mild dysarthric speech. The individual at the time of the study was using word processing for writing. She had tremors, ataxia, and her handwriting was illegible and laborious. The other participant did not have a disability and had normal speech. The authors compared three speech recognition systems and found that with the participant with dysarthric speech, one system outperformed the other two substantially. In contrast, the quality of all three programs was comparable at the end of the intervention for the 
participant with normal speech. This finding indicates that the quality of the software is correlated to the success with users with dysarthria.

Kotler and Thomas-Stonell (1997) conducted a study with an individual with spastic cerebral and mild dysarthria. They found that the amount of speech training was correlated to the accuracy of speech recognition with people with dysarthria. In addition, they produced guidelines for determining recognition of speech sounds that can be used in future research. It appears that as technology improves, speech recognition is a possible option for individuals with physical disabilities and possibly with dysarthric speech. With the hands-free approach, speech recognition is a potential solution for producing written work for individuals with dysarthria.

\section{Conclusions}

Due to the motor, learning, and environmental influences on individuals with physical disabilities, it is apparent that modifications for writing are often needed to help these individuals overcome barriers to writing. Assistive technology solutions, such as low-tech modifications, word processing, word prediction, and dictation do not always remove all of the barriers to writing for individuals with physical disabilities for a variety of reasons. One assistive technology solution that may be a solution for individuals with physical disabilities is speech recognition software. It is apparent, based on the review, that speech recognition software comes with many potential benefits but also with potential costs for individuals with physical disabilities. Because it is hands-free, speech recognition can allow the user to operate it independently and can potentially increase the rate of input to the rate of speaking. However, due to low rates of recognition accuracy that some users experience, the amount of time and effort required to successfully use the 
software may cause users to not view it as an effective or efficient alternative to their current method of writing. More research is therefore needed in order to determine whether speech recognition software can be a viable writing accommodation for individuals with physical disabilities. 


\section{REFERENCES}

Atkinson, R. C., \& Shiffrin, R. M. (1968). Human memory: A proposed system and its control processes. In K. W. Spence \& J. T. Spence (Eds.), The psychology of learning and motivation: Advances in research and theory (pp. 89-195). New York: Academic Press.

Baddeley, A. D., \& Wilson, B. (1985). Phonological coding and short-term memory in patients without speech. Journal of Memory and Language, 24, 490-502.

Bangert-Drowns, R. L. (1993). The word processor as an instructional tool: A metaanalysis of word processing in writing instruction. Review of Educational Research, 63(1), 69-93.

Barnes, M., Dennis, M., \& Hetherington, R. (2004) Reading and writing skills in young adults with spina bifida and hydrocephalus. Journal of the International Neuropsychological Society, 10, 655-663.

Bereiter, C., \& Scardamalia, M. (1987). The psychology of written composition. Hillsdale, NJ: Lawrence Erlbaum Associates.

Berninger, V. W. (1999). Coordinating transcription and text generation in working memory during composing: Automatic and constructive processes. Learning Disability Quarterly, 22, 99-112.

Best, S. J., Heller, K. W., \& Bigge, J. L., (2005). Teaching individuals with physical or multiple disabilities (5th ed.). Upper Saddle River, NJ: Pearson/Merrill Prentice Hall. 
Bourdin, B., \& Fayol, M. (2000). Is graphic activity cognitively costly? A developmental approach. Reading and Writing: An Interdisciplinary Journal, 13, 183-196.

Bruce, C., Edmundson, A., \& Coleman, M. (2003). Writing with voice: An investigation of the use of a voice recognition system as a writing aid for a man with aphasia. International Journal of Language \& Communication Disorders, 38(2), 131-148.

Cavalier, A. R., \& Ferretti, R. P. (1996). Talking instead of typing: Alternate access to computers via speech recognition technology. Focus on Autism \& Other Developmental Disabilities, 11, 79-85. Retrieved June 8, 2005, from the Academic Search Premier database.

Dale, R. (1999). Content determination in natural language generation. In M. Torrance, \& D. Galbraith (Eds.), Knowing what to write (pp. 51-64). Amsterdam: Amsterdam University Press.

De La Paz, S. (1999). Composing via dictation and speech recognition systems: Compensatory technology for students with learning disabilities. Learning Disability Quarterly, 22, 173-182.

De La Paz, S., \& Graham, S. (1997). Effects of dictation and advanced planning instruction on the composing of students with writing and learning problems. Journal of Educational Psychology, 89, 203-222.

DuBois, L., Klemm, A., Murchland, S., \& Ozols, A. (2004). Handwriting of children who have hemiplegia: A profile of abilities in children aged $8-13$ years from a parent and teacher survey. Australian Occupational Therapy Journal, 51, 89-98. 
Duhaney, L. M. G., \& Duhaney, D. C. (2000). Assistive technology: Meeting the needs of learners with disabilities. International Journal of Instructional Media, 27, 393-402.

Englert, C. S., Wu, X., \& Zhao, Y. (2005). Cognitive tools for writing: Scaffolding the performance of students through technology. Learning Disabilities Research \& Practice, 20, 184-198.

Feng, J., Karat, C-M, \& Sears, A. (2005). How productivity improves in hands-free continuous dictation tasks: Lessons learned from a longitudinal study. Interacting with Computers, 17, 265-289.

Flower, L., \& Hayes, J. R. (1981). A cognitive process theory of writing. College Composition and Communication, 32, 365-387

Gardner, H. (1980, December). On becoming a dictator. Psychology Today, 14, 14-19.

Goette, T., \& Marchewka, J. T. (1994). Voice recognition technology for persons who have motoric disabilities. Journal of Rehabilitation, 60(2), 38-41.

Golden, S. (2001). Word prediction and students with $L D$ and severe spelling difficulties. Unpublished Ed.S. thesis, Georgia State University, Atlanta.

Graham, S. (1990). The role of production factors in learning disabled students' compositions. Journal of Educational Psychology, 82, 781-791.

Graham, S. \& Harris, K. R. (2000). The role of self-regulation and transcription skills in writing and writing development. Educational Psychologist, 35(1), 3-12.

Hayes, J. R., \& Flower, L. S. (1987). On the structure of the writing process. Topics in Language Disorders, 7(1), 19-30. 
Heller, K. W. (2003). Persons with physical or health disabilities. In R. M. Gargiulo, Special education in contemporary society: An introduction to exceptionality (pp. 533-598). Belmont, CA: Wadsworth/Thompson Learning.

Heller, K. W., Alberto, P. A., Forney, P. E., \& Schwartzman, M. N. (1996). Understanding physical, sensory, and health impairments: Characteristics and educational implications. Pacific Grove, CA: Brooks/Cole Publishing Company.

Heller, K. W., \& Swinehart-Jones, D. (2003). Supporting the educational needs of students with orthopedic impairments. Physical Disabilities: Education and Related Services, 22(1), 3-24.

Hetzroni, O. E., \& Shrieber, B. (2004). Word processing as an assistive technology tool for enhancing academic outcomes of students with writing disabilities in the general classroom. Journal of Learning Disabilities, 37, 143-154.

Higgins, E. L., \& Raskind, M. H. (1995). Compensatory effectiveness of speech recognition on the written composition performance of postsecondary students with learning disabilities. Learning Disability Quarterly, 18, 159-174.

Honeycutt, L. (2003). Researching the use of voice recognition writing software. Computers and Composition, 20, 77-95.

Hux, K., Rankin-Erickson, J., Manasse, N., \& Lauritzen, E. (2000). Accuracy of three speech recognition systems: Case study of dysarthric speech. AAC Augmentative and Alternative Communication, 16, 186-196.

Kambeyanda, D., Singer, L., \& Cronk, S. (1997). Potential problems associated with use of speech recognition products. Assistive Technology, 9, 95-101. 
Karat, J., Horn, D. B., Halverson, C. A., \& Karat. C. -M. (2000, April). Overcoming unusabilty: Developing efficient strategies in speech recognition systems. Poster session presented at CHI 2000, the AMC Conference on Human Factors in Computer Systems, The Hague, Netherlands.

Kay Elemetrics (1993). Multi-Dimensional Voice Program (MDVP). [Computer program.] Pine Brook, NJ: Author

Kellogg, R. T. (1996). A model of working memory in writing. In C. M. Levy, \& S. Ransdell (Eds.), The Science of writing: Theories, methods, individual differences, and applications (pp. 57-71). Mahwah, NJ: Lawrence Erlbaum Associates.

Koester, H. H. (2001). User performance with speech recognition: A literature review. Assistive Technology, 13, 116-130.

Koester, H. H. (2003). Abandonment of speech recognition by new users. Paper presented at the RESNA $26^{\text {th }}$ International Annual Conference, Atlanta, GA.

Koester, H. H. (2004). Usage, performance, and satisfaction outcomes for experienced users of automatic speech recognition. Journal of Rehabilitation Research \& Development, 41, 739-754.

Koester, H. H., \& Levine, S. P. (1997). Keystroke-level models for user performance with word prediction. AAC Augmentative and Alternative Communication, 13, 239-257.

Koester, H. H., \& Levine, S. P. (1998). Model simulations of user performance with word prediction. AAC Augmentative and Alternative Communication, 14, 25-35. 
Kotler, A.-L., \& Tam, C. (2002). Effectiveness of using discrete utterance speech recognition software. AAC Augmentative and Alternative Communication, 18, 137-146.

Kotler, A.-L., \& Thomas-Stonell. (1997). Effects of speech training on the accuracy of speech recognition for an individual with a speech impairment. AAC Augmentative and Alternative Communication, 13, 71-80.

Langone, J., \& Willis, C. (1994-1995). Effects of computer-based word processing versus paper/pencil activities on the paragraph construction of elementary students with learning disabilities. Journal of Learning Disabilities, 31, 16-26.

Lewis, R. B., Graves, A. W., Ashton, T. M., \& Kieley, C. L. (1998). Word processing tools for students with learning disabilities: A comparison of strategies to increase text entry speed. Learning Disabilities Research \& Practice, 13, 95-108.

Lifshitz, H. (1999). Comparison of two methods of teaching word-processing skills to persons with mental retardation. Education and Training in Developmental Disabilities, 34, 90-98.

MacArthur, C. A. (1998a). From illegible to understandable: How word recognition and speech synthesis can help. Teaching Exceptional Children, July/Aug, 66-71.

MacArthur, C. A. (1998b). Word processing with speech synthesis and word prediction: Effects of the dialogue journal writing of students with learning disabilities. Learning Disability Quarterly, 21, 151-166.

MacArthur, C. A. (1999a). Overcoming barriers to writing: Computer support for basic writing skills. Reading \& Writing Quarterly, 15, 169-192. 
MacArthur, C. A. (1999b). Word prediction for students with severe spelling problems. Learning Disability Quarterly, 22, 158-172.

MacArthur, C. A. (2000). New tools for writing: Assistive technology for students with writing difficulties. Topics in Language Disorders, 20(4), 85-100.

MacArthur, C. A., \& Graham, S. (1987). Learning disabled students’ composing under three methods of test production: Handwriting, word processing, and dictation. The Journal of Special Education, 21(3), 22-42.

MacArthur, C. A., Schwartz, S. S., \& Graham, S. (1991). A model for writing instruction: Integrating word processing and strategy instruction into a process approach to writing. Learning Disabilities Research \& Practice, 6, 230-236.

MacArthur, C. A., \& Shneiderman, B. (1986). Learning disabled students’ difficulties in learning to use a word processor: Implications for instruction and software evaluation. Journal of Learning Disabilities, 19, 248-253.

Male, M. (1997). Technology for inclusion: Meeting the special needs of all students ( $^{\text {rd }}$ ed.). Boston: Allyn and Bacon.

Male, M. (2003). Technology for inclusion: Meeting the special needs of all students $\left(4^{\text {th }}\right.$ ed.). Boston: Allyn and Bacon.

Merbler, J. B., Hadadian, A., \& Ulman, J. (1999). Using assistive technology in the inclusive classroom. Preventing School Failure, 34, 113-118.

Mezei, P., \& Heller, K.W. (2004). Evaluating word prediction software for students with physical disabilities. Journal of Physical Disabilities and Related Services, 23(2), 96-113. 
Outhred, L. (1989). Word processing: Its impact on children’s writing. Journal of Learning Disabilities, 22, 262-264.

Reece, J. E., \& Cumming, G. (1996). Evaluating speech-based composition methods: Planning, dictation and the listening word processor. In C. M. Levy, \& S. Ransdell (Eds.), The Science of writing: Theories, methods, individual differences, and applications (pp.361-380). Mahwah, NJ: Lawrence Erlbaum Associates.

Rhodes, L. K., Dudley-Marling, C. C., \& Mowder, B. A. (1986). Intervention strategies for developing student reading and writing fluency. Journal for Remedial Education and Counseling, 2, 256-262.

Rosen, K., \& Yampolsky, S. (2000). Automatic speech recognition and review of its functioning with dysarthric speech. AAC Augmentative and Alternative Communication, 16, 48-60.

Sandberg, A. D. (2001). Reading and spelling, phonological awareness, and working memory in children with severe speech impairments: A longitudinal study. AAC Augmentative and Alternative Communication, 17, 11-26.

Shaer, C. (1997). The infant and young child with Spina Bifida: Major medical concerns. Infants and Young Children, 9(3), 13-25.

Strum, J., \& Koppenhaver, D. A. (2000). Supporting writing development in adolescents with developmental disabilities. Topics in Language Disorders, 20, 73-92.

Tumlin, J., \& Heller, K. W. (2004). Using word prediction software to increase typing fluency with students with physical disabilities. Journal of Special Education Technology, 19(3), 5-14. 
Wetzel, K. (1996). Speech-recognizing computers: A written-communication tool for students with learning disabilities. Journal of Learning Disabilities, 29, 371-380. 


\title{
CHAPTER 2
}

\section{USING SPEECH RECOGNITION SOFTWARE TO INCREASE WRITING FLUENCY FOR INDIVIDUALS WITH PHYSICAL DISABILITIES}

\author{
Statement of the Problem
}

It is important for individuals to be able to write efficiently and accurately in school and life activities. Students with physical disabilities often have difficulties writing efficiently due to decreased motor control in their hands. Handwriting is often not an option, and typing rate can be extremely slow. Writing accuracy also can be affected by poor spelling performance (Sandberg, 2001) and extraneous motor movements, which can cause unintended keystrokes (Best, Heller, \& Bigge, 2005). Although there are several different adaptations and assistive technology interventions available, many of them result in dependence on another person or may not increase both writing rate and accuracy. One type of assistive technology that may increase both rate and accuracy of written production for students with physical disabilities is speech recognition software. Impact of Physical Disabilities on Writing

There are many types of physical disabilities that may affect written production rate and accuracy. Individuals with physical disabilities, such as cerebral palsy, spina bifida, and degenerative diseases, may have motor coordination issues. These motor issues make handwriting and typing slow, inefficient, or not possible. Fine motor coordination problems may lead to reduced mobility in the hands and fingers and cause problems with producing written work. Unintended motor patterns may cause individuals 
with physical disabilities to have difficulty controlling movement and reaching an intended target, such as a piece of paper or a keyboard. This can cause a decrease in rate and an increase in errors when producing written work. Limited range of motion may make it difficult for the individual to access the materials. Muscle fatigue, endurance, and weakness are other physical characteristics that accompany some physical disabilities, decreasing the rate at which individuals can produce work and the amount of work they can produce. Medical side effects can cause lack of attention to the task or fatigue and therefore also have implications on writing. Finally, if the physical task is so great that it is difficult for the individual, impeded concentration can negatively affect typing rate and accuracy.

In addition to the physical issues with writing, sometimes there are also associated cognitive or learning issues that accompany physical disabilities that can affect writing. Mental retardation sometimes is present in individuals with cerebral palsy and spina bifida. This affects cognitive abilities, which can affect writing. Learning issues, such as auditory or visual processing and perceptual issues also can affect writing. Issues of organization, attention, memory, unbalanced cognitive load, transcribing, thinking about spelling, mechanics, and syntax are common problems that individuals with physical disabilities and learning issues experience (Best et al., 2005; MacArthur, 2000; Sandberg, 2001; Shaer, 1997). Working memory also may be affected when a physical disability is present. This occurs when the student has to direct his attention towards controlling motor movements needed to access a keyboard or to write by hand, while at the same time trying to compose written work. The attention needed to control the motor movements may interfere with the ability of the student to effectively maintain his 
thoughts in working memory (Bourdin \& Fayol, 2000). All of these learning issues, along with the physical aspect of writing, can result in thoughts being lost (De La Paz, 1999).

Due to the physical and learning issues that can be related to physical disabilities, it is apparent that rate and accuracy of writing can be affected. Rate and accuracy are important components of writing. The physical disabilities that cause the slow rate can make writing difficult. The faster an individual can input information, the more work he can complete in a given amount of time. If the rate of production is hampered by a disability, the individual will produce less and therefore fall behind in work completion. Accuracy is important because it is related to the need for revisions. If written work has multiple errors or needs substantial revision, that takes time and, paired with a slow rate due to a physical disability, can be quite laborious.

Adaptations and Assistive Technology Interventions

There are several types of adaptations and assistive technologies (AT) that may be used to increase written production rate and accuracy. In order to make writing more accessible to students with physical disabilities, different solutions are available. Options such as adapting writing instruments, choosing different types of paper, or using slant boards can improve handwriting ability. Dictating to a scribe can help individuals produce their work at a much faster rate (De La Paz, 1999); however, it makes the writer dependent on another person to complete the work (MacArthur \& Cavalier, 2004). Another option is using assistive technology, such as word processors, word processors with alternate access, or word prediction software.

Students for whom handwriting is not an option often use word processors (Bangert-Drowns, 1993). Using word processing can pose both advantages and 
disadvantages for individuals with physical disabilities. Advantages can include access to spell and grammar check, which may assist some users in recognizing errors (Hetzroni \& Shrieber, 2004). Readability of the product and motivation when writing using a word processor can improve (Hetzroni \& Shrieber). MacArthur and Shneiderman (1986) indicated that benefits of word processing include production of a neat copy, easy editing and revision, and removal of the physical aspect of handwriting, which can be difficult. However, disadvantages also exist for word processing. Using word processing requires inputting the information into the program, and keyboarding is often difficult or inefficient for individuals with physical disabilities. Using word processing also requires instruction on the use of its components and accessories, which some instructors neglect to recognize (MacArthur, Schwartz, \& Graham, 1991).

Because the standard keyboard is often difficult for individuals with physical disabilities to use, additional adaptations may be necessary for an individual to utilize word processing effectively and efficiently. Alternate access with word processing can include the use of mouth sticks, alternative keyboard arrangement (such as DVORAK), alternate keyboards, and use of on-screen keyboards. Most individuals without disabilities utilize the direct select method of keyboarding (i.e., they make contact with the keys on the keyboard, typically using all ten fingers). However, individuals with physical disabilities may need modifications for direct select, such as using a mouth stick on a standard keyboard. If direct select is not possible, alternate methods of selection, such as scanning, are available. Although using alternate access can improve access to the word processor and computer, some of these solutions are user-specific and cannot easily transfer to different computers or environments. 
Another writing option for individuals with physical disabilities is the use of word prediction software (Tumlin \& Heller, 2004). Most word prediction programs can be used with any word processor, with the user typing in a window separate from the word processor. As the user types, the program begins predicting the word and provides a list from which the desired word can be selected. The user can then select the word by either clicking on it with the mouse or by typing the number of the corresponding word. If the correct word is not in the list, the user continues to type and the list of predicted words changes accordingly. When the user types a period or presses enter, the sentence is transferred from the word prediction software to the word processor (MacArthur, 1999a, 1999b). Because word prediction theoretically decreases the number of keystrokes needed to type a word, it can improve the rate of production for individuals with physical disabilities. However, it should be noted that if the word prediction program incorrectly predicts the user's intended word by not displaying the target word, it may take longer and require more effort to have the desired word displayed. MacArthur (1998a, 1998b) stated that word prediction could support correct spelling as well as expand the use of vocabulary. Lewis, Graves, Ashton, and Kieley (1998) assessed students’ writing and found that students with learning disabilities could handwrite the fastest, with word prediction next, and typing in a word processor last. They reported that teachers believed that for more advanced typists, word prediction software slowed down their typing rate. Tumlin and Heller also found this for individuals with physical disabilities.

The assistive technology solutions discussed have included access to the computer still using keyboard modifications. However, it is sometimes necessary to utilize access 
that does not require as much physical manipulation. One such option that has recently become available is speech recognition software.

Speech Recognition Software

Speech recognition software, which provides hands-free access to the computer, was developed to facilitate the production of written work (Kotler \& Thomas-Stonell, 1997). As the user speaks into a microphone, the words are transformed into text on the screen. According to Bruce, Edmundson, and Coleman (2003), using speech recognition software allows individuals to "circumvent” spelling and writing difficulties. Most literate adults without disabilities typically write 15 - 25 words per minute and can speak at 125 - 160 words per minute (De La Paz, 1999; Feng, Karat, \& Sears, 2005). Speech recognition software, therefore, has the ability to transcribe speech significantly faster than handwriting (De La Paz). Speech recognition software has the potential to make writing more efficient and accurate for individuals with physical disabilities, but it also has some limitations that users must consider.

Speech recognition allows users to bypass the mechanics of writing and loss of ideas in the transcription process (De La Paz, 1999). Speaking is faster and less laborious than manual text entry and is less fatiguing (Koester, 2001). Although speech recognition can decrease the load on working memory by removing the transcription of thoughts into written words, Koester (2001) discussed potential memory burdens associated with the use of speech recognition. The commands and special words and formats that are necessary when using speech recognition software can add additional cognitive load to speech recognition use. 
Speech recognition also requires training to reach an acceptable level of recognition accuracy. Recognition accuracy is important because some researchers have found that speech recognition software can be difficult to use because some users spend so much time correcting errors that it becomes inefficient (Karat, Horn, Halverson, \& Karat (2000). Higgins and Raskind (1995) noted that it took participants with learning disabilities in their study an average of six hours to learn the system. In Kotler and Tam's (2002) study, because of low recognition accuracy, ranging from $62 \%$ to $84 \%$, the authors noted that the participants with physical disabilities and intelligible speech had to "generate double the number or utterances to produce the required text” (p. 143) due to error correction.

Improved rate of input is one of the potential benefits of speech recognition. Once recognition accuracy is acceptable, the rate of writing can increase. Koester (2004) found that for individuals with physical disabilities who typed slower than 15 words per minute, speech recognition helped improve their text entry rate. However, for individuals who were faster typists, speech recognition may not improve rate. Koester (2003) collected data on text entry rate and recognition accuracy. In the dictation phase, Koester (2003) measured the recognition accuracy. In the correction phase, she was able to obtain a true measurement of the participant's text entry rate because it calculated the time required to correct recognition errors. Initial recognition accuracy averaged 86\% (range 69 - 95\%), and after four to six weeks averaged 83\% (range 60 - 99\%). Initial text entry rate, calculated in words per minute, averaged 16.9 words per minute (range 1.9 - 39.0) and after four to six weeks, averaged 19.8 words per minute (range $1.5-72.6$ ). At a sixmonth follow up, however, only one out of the eight participants was still using speech 
recognition. Out of eight participants, two discontinued use due to technical problems using speech recognition; four students preferred using a standard keyboard with various methods of access; and one discontinued use due to personal problems.

Karat et al. (2000) indicated that when keyboarding, it takes an average of three seconds to repair an error, compared to at least 25 seconds to repair speech recognition errors for individuals without disabilities. When measuring corrected words per minute (text entry and editing) of individuals without disabilities, Karat et al. found that due to the time it took to correct dictation errors as opposed to the time it took to correct typing errors, typing was more efficient, yielding 32 corrected words per minute, as opposed to 14 corrected words per minute using speech recognition. Karat et al. discovered that as individuals became more proficient users of speech recognition, they tended to use more multimodal means of error correction (i.e., using the keyboard and/or mouse in addition to speech commands to repair errors). Feng et al. (2005) found that as participants became more experienced with the software, their productivity increased. However, Koester (2003) found the opposite, citing inconsistent and variable performance with speech recognition. Koester (2003) indicated that only three out of seven participants with physical disabilities improved their text entry rate over a six-week period and only two out of seven participants improved their recognition accuracy over six weeks.

Finally, Honeycutt (2003) stated that speech recognition should only be used in first draft writing because it is the easiest stage of writing and students do not have to edit as they dictate. The research supports this, indicating that users spend a tremendous amount of time editing their work when using speech recognition software (Feng et al., 2005; Karat et al., 2000; Koester, 2004; Kotler \& Tam, 2002). Honeycutt (2003) also 
discussed the importance of planning, stating that writers who have time to plan prior to writing produce more organized documents. Others (De La Paz \& Graham, 1997; Higgins \& Raskind, 1995; Reece \& Cumming, 1996; Wetzel, 1996) have found that planning prior to writing can improve the quality of work produced using speech recognition software.

Given the potential benefits of speech recognition software for individuals with physical disabilities, it is thought that it could have a positive impact on the writing access of these individuals because it takes the physical component out of writing. Providing instruction on the use of speech recognition software could lead to writing becoming more accessible and efficient for writers with physical disabilities. This is especially the case with first draft writing where students do not have to contend with error correction caused by the speech recognition software misinterpreting what they say. However, because recognition errors can be made with speech recognition software, the accuracy of the written product could be affected. More research is needed to determine the best method to assist individuals with physical disabilities to write efficiently and accurately.

\section{Purpose}

The purpose of this study was to compare the effects of speech recognition software to word processing across written production rate (fluency) and accuracy on first draft writing. Also of interest was the length of the draft, the type of errors participants made, and the students' ability to recognize errors and recall what they intended to write when they identified mistakes in their writing. Because speech recognition offers handsfree access to a computer, it may aid individuals with physical disabilities in improving 
their rate of input and in decreasing errors if the recognition accuracy is sufficient. Because assistive technology is typically a necessary component of work production for individuals with physical disabilities, the results of this study will add much-needed information on the use of speech recognition software for writing within the research base of physical disabilities.

\section{Research Questions}

1. To what extent does the use of speech recognition software affect the fluency rate compared to word processing for individuals with physical disabilities in writing a first draft of a paper?

2. To what extent does the use of speech recognition software affect the writing accuracy rate compared to word processing for individuals with physical disabilities?

3. To what extent does the use of speech recognition software affect the production of different types of errors compared to errors produced using word processing?

4. To what extent does the use of speech recognition software affect the students' ability to recall the intended meaning when they begin to identify the errors in their first draft as compared to word processing?

5. To what extent does the use of speech recognition software affect the length of the draft compared to word processing?

\section{Methodology}

\section{Participants and Setting}

Students of high school age with physical disabilities that affect hand use were selected to participate in this study. They were selected based on the following criteria: 
(a) having a physical disability with fine motor impairments (that still allowed them to use direct select to access a keyboard); (b) meeting the Georgia requirements for orthopedic impairments (i.e., students with physical disabilities having mild intellectual disabilities or normal or gifted intelligence); (c) receiving services through an orthopedic impairments (OI) special education program; (d) not having a diagnosed articulation or voice disorder or being served through the Speech and Language program for articulation or voice disorders; (e) being high school age; (f) having had prior experience with accessing a computer for a minimum of two years (either with standard keyboard or alternate access devices); (g) having utilized word processing for completion of writing tasks for a minimum of two years; (h) not receiving services from the visual impairments program (but may have a visual impairment with visual adaptations in place); (i) not currently using speech recognition software and not having used it successfully in the past to complete school work; and (j) parental consent and student assent. Potential participants were asked if they were willing to use word processing and speech recognition software prior to the study to ensure that either or both programs were not aversive to the students. If they indicated that they were willing to use both programs, they were eligible to be selected as participants. The sample size included five participants who met the criteria. The first five participants who qualified and had consent and assent were chosen to participate in the study

The five participants selected for participation were Ann, Beau, Cady, Dana , and Emma (see Table 1). Ann was an 18 year old Caucasian female who was a $10^{\text {th }}$ grader at the time of the study. Her diagnosis was spina bifida and mild intellectual disability. She wore glasses and used a power wheelchair for mobility, and had a manual wheelchair that 
Table 1

Student Information

\begin{tabular}{|c|c|c|c|c|c|}
\hline Name & $\begin{array}{l}\text { Age } \\
\text { Grade } \\
\text { Placement }\end{array}$ & Disability & $\begin{array}{l}\text { Equipment \& } \\
\text { Adaptations }\end{array}$ & $\begin{array}{l}\text { HW Rate }^{\mathrm{a}} \\
\text { Typing Rate } \\
\text { Flesh/Kincaid }^{\mathrm{b}} \\
\text { WRAT-3 }^{\mathrm{c}}\end{array}$ & $\begin{array}{l}\text { Microsoft } \\
\text { Word \& } \\
\text { SR History } \\
\text { of Use } \\
\end{array}$ \\
\hline Ann & $\begin{array}{l}18 \\
10^{\text {th }} \text { Grade } \\
\text { MID Self } \\
\text { Contained } \\
\text { OI Consult }\end{array}$ & Spina Bifida & $\begin{array}{l}\text { Dell Latitude } \\
\text { D600 } \\
\text { Glasses }\end{array}$ & $\begin{array}{l}7.0 \text { wcpm HW } \\
8.4 \text { wcpm T } \\
6.1 \text { grade level } \\
\text { High School }\end{array}$ & $\begin{array}{l}5 \text { years } \\
\text { No prior use }\end{array}$ \\
\hline Beau & $\begin{array}{l}15 \\
9^{\text {th }} \text { Grade } \\
\text { OI } \\
\text { Resource } \\
\text { General } \\
\text { Education }\end{array}$ & $\begin{array}{l}\text { Duchene's } \\
\text { Muscular } \\
\text { Dystrophy }\end{array}$ & $\begin{array}{l}\text { Dell Latitude } \\
\text { D600 } \\
\text { Mini Keyboard } \\
\text { Roller ball } \\
\text { Mouse } \\
\text { Pen for typing } \\
\text { Glasses }\end{array}$ & $\begin{array}{l}8.4 \text { wcpm HW } \\
8.6 \text { wcpm T } \\
7.2 \text { grade level } \\
\text { High School }\end{array}$ & $\begin{array}{l}3 \text { years } \\
\text { Minimal } \\
\text { use }^{\mathrm{e}}\end{array}$ \\
\hline Cady & $\begin{array}{l}15 \\
10^{\text {th }} \text { Grade } \\
\text { OI } \\
\text { Resource } \\
\text { General } \\
\text { Education }\end{array}$ & Spina Bifida & $\begin{array}{l}\text { Dell Latitude } \\
\text { D600 }\end{array}$ & $\begin{array}{l}17.2 \text { wcpm HW } \\
15.5 \text { wpm T } \\
7.3 \text { grade level } \\
\text { High School }\end{array}$ & $\begin{array}{l}\text { Approx. } 5 \\
\text { years } \\
\text { No prior use }\end{array}$ \\
\hline Dana & $\begin{array}{l}17 \\
12^{\text {th }} \text { Grade } \\
\text { OI } \\
\text { Resource } \\
\text { General } \\
\text { Education }\end{array}$ & $\begin{array}{l}\text { Cerebral } \\
\text { Palsy, } \\
\text { Aspergers } \\
\text { Syndrome, } \\
\text { Vision } \\
\text { Impairment }\end{array}$ & $\begin{array}{l}\text { Dell Latitude } \\
\text { D600 } \\
\text { Text enlarged to } \\
16 \text { point font } \\
\text { Glasses }\end{array}$ & $\begin{array}{l}23.0 \text { wcpm HW } \\
30.3 \text { wcpm T } \\
10.4 \text { grade level } \\
\text { Post High } \\
\text { School }\end{array}$ & $\begin{array}{l}>10 \text { years } \\
\text { No prior use }\end{array}$ \\
\hline Emma & $\begin{array}{l}17 \\
12^{\text {th }} \text { Grade } \\
\text { OI Consult } \\
\text { General } \\
\text { Education }\end{array}$ & $\begin{array}{l}\text { Spinal } \\
\text { Muscular } \\
\text { Atrophy }\end{array}$ & $\begin{array}{l}\text { Dell Inspiron } \\
\text { E1505 for } \\
\text { Typing } \\
\text { Dell Latitude } \\
\text { D600 for Speech } \\
\text { Recognition } \\
\text { Glasses }\end{array}$ & $\begin{array}{l}29.9 \text { wcpm HW } \\
37.9 \text { wcpm T } \\
9.9 \text { grade level } \\
\text { Post High } \\
\text { School }\end{array}$ & $\begin{array}{l}>8 \text { years } \\
\text { Minimal }_{\text {use }}\end{array}$ \\
\hline
\end{tabular}

Note. ${ }^{\mathrm{a}} \mathrm{HW}$ Rate refers to handwriting rate. ${ }^{\mathrm{b}}$ The Flesch-Kincaid Grade Level is Microsoft

Word's tool to approximate the grade level of the writing. ${ }^{~}$ The WRAT-3 is the Wide 
Range Achievement Test, $3^{\text {rd }}$ Edition. It reports grade level of spelling. ${ }^{\mathrm{d}}$ SR History of Use is the speech recognition history of use. It indicates any prior history with speech recognition software. ${ }^{\mathrm{e}}$ Used for less than 1 week approximately 4 years ago. ${ }^{\mathrm{f}}$ Used for approximately 2 months approximately 5 years ago. 
she could also use. Ann was served through the Mild Intellectual Disabilities (MID) selfcontained program for functional curriculum classes and received OI consult services for physical modifications to her environment. Her handwriting was very legible, but slow (7.0 words correct per minute (wcpm) due to impaired hand functioning or processing due to the spina bifida. Ann wore glasses and typed at a rate of 8.4 wcpm prior to the study. Ann had used a computer since elementary school, Microsoft Word for the past five years, and had no prior use of speech recognition software. She completed most of her schoolwork using handwriting, although sometimes she typed on the computer. Ann had a nasal sounding voice and did not speak confidently, often changing her mind or starting words and not completing them.

Beau was a 15 year old Caucasian male who was a ninth grader. He was diagnosed with Duchene’s Muscular Dystrophy (MD). He wore glasses and used a power wheelchair for mobility. He was served through OI resource for study skills and took academic and elective classes in general education. His handwriting rate was 8.4 wcpm, and his typing rate prior to the study was 8.6 wcpm. Due to his decreased muscle functioning because of the MD, he had very limited gross motor abilities, and his fine motor functioning was impaired. Beau had used a computer for schoolwork for the past 3 years, including using Microsoft Word for the past three years. He had used Dragon NaturallySpeaking around four years ago but discontinued use because it did not work well for him at the time. He reported, however, that he was willing to try it again. He had a laptop computer that he could use to complete his schoolwork, but dictated to a scribe most of the time because typing or handwriting long assignments was inefficient for him. Beau spoke in short phrases, due to the need to take shallow breaths frequently. 
Cady was a 15 year old African-American female who was a $10^{\text {th }}$ grader with a diagnosis of spina bifida. She used a manual wheelchair for mobility and was served through the OI resource room for study skills and in general education for academic and elective classes. Her pre-study handwriting rate was 17.2 wcpm, and her typing rate was 15.5 wcpm. Cady had used a computer for school since the $6^{\text {th }}$ grade and had used Microsoft Word for school since she started using the computer. She had no prior use of speech recognition software but indicated that she was willing to try it for the purpose of the study. She had a low, southern voice. Her handwriting was legible, and she completed most of her schoolwork by handwriting.

Dana was a 17 year old Caucasian female who was a high school senior at the time of the study. She was diagnosed with cerebral palsy, Asperger's Syndrome, and a vision impairment. She used a manual wheelchair for mobility, although she could walk short distances without assistance. Her vision impairment was corrected with glasses although she required enlarged print text to 14 point font. Dana did not qualify for vision services. Her fine motor coordination was affected by her cerebral palsy, and her handwriting was illegible at times. Dana’s handwriting rate was 23.0 wcpm, and her typing rate was 30.3 wcpm prior to the study. To complete her schoolwork, Dana used a combination of a laptop computer and handwriting. Dana was served through OI resource and took team taught general education classes. Her voice was clear, and she spoke confidently. Dana had used a laptop computer and Microsoft word since elementary school and had no prior use of speech recognition software.

Finally, Emma was a 17 year old Caucasian female who was a senior in high school diagnosed with Spinal Muscular Atrophy. She received OI consult services and 
took all of her classes in general education. Her pre-study handwriting rate was 29.9 wcpm, and her typing rate was 37.9 wcpm. Because SMA is degenerative, it was thought that it would be good to train her on speech recognition software. She had used a computer for schoolwork since middle school and had tried Dragon NaturallySpeaking five years prior to the study for a couple of months. She reported that the purpose was just to try it out, although she did not intend to use it at the time. She stated that she was willing to try it again. She had access to a laptop computer for work, and completed her schoolwork with a combination of using her laptop and handwriting.

The study was conducted in the OI classroom of a public high school during study skills class. Training was conducted in two different types of groupings. Demonstration of speech recognition software was conducted in a small group setting in two different study skills class periods. Three students received simultaneous demonstration in one study skills class and the other three received it in the other class. Voice file training and dictation of compositions, however, were conducted on a one-on-one basis because of the importance of the room being quiet and so that individual concerns could be addressed when participants were creating their voice files. Some researchers have found that speech recognition users typically need guided practice and support during the training phases (MacArthur \& Cavalier, 2004; Quinlan, 2004); therefore, it was important that participants had sufficient access to the teacher or researcher during the training phase. Both the small group instruction and individual instruction for training occurred in the OI classroom. Intervention also occurred in the OI classroom on a one-on-one basis. The researcher worked with participants individually until they completed the writing session. 


\section{Operational Definitions}

The independent variables in this study were the use of word processing and speech recognition software during first-draft writing. The dependent variables were writing fluency, accuracy, type of word errors, recall of intended meaning, and length of the document. Writing fluency was of primary interest and was defined as the number of words correct per minute (wcpm) of the composition. A correct word was defined as a word that was correctly spelled (since misspelling, keyboarding errors or additional keystrokes often occur with the use of word processing) and was the intended word (not a substituted or additional word or group of words due to misinterpretation by speech recognition software).

Due to the variance in word length that can occur across writing samples, a more accurate measure was needed than counting whole words. Because the length of the word affects the writing speed, the word length needs to be consistent across passages and across students. Students who are functioning on a higher level may be using larger and more complex words than lower-functioning students. Therefore, it was important to standardize word length. Computation of writing fluency (wcpm) in which one word equaled 5 characters, therefore, was used (Feng et al., 2005; Kotler \& Tam, 2002). A character was defined as a letter, space, punctuation mark, or symbol. Using this formula, the number of characters in the written product was determined and divided by five to determine the number of words per passage. To aid in this calculation, Microsoft Word's character count with spaces tool was used to determine the total number of characters in each of the written passages. 
When determining the writing fluency (wcpm), the following formula was used: (Total characters produced - all characters in each incorrect word) $\div 5$ $\mathrm{wcpm}=$

\section{Number of minutes}

This was calculated by removing words that were incorrect from the writing sample, obtaining the character count, and dividing by 5 (to get the number of correct words). Next, this number was divided by the number of minutes to get the rate (wcpm).

Accuracy, defined in terms of percent correct, was calculated by subtracting the number of word errors from the total number of words divided by the total number of words times 100. In this formula, whole words were counted, not five characters equaling one word. The following formula was used:

Total Number words - number of word errors

$$
\% \text { Correct }=
$$

Total number of words

If the same word error was made more than once, it was counted each time the error was made. For example, if speech recognition misrecognized a word five times (e.g., I scream for ice cream), it was counted as five separate errors. In word processing, if the student misspelled a word consistently five times (e.g., their for there), it was counted as five errors. Also, if the student spelled a word correctly but it was not the correct word, it was counted as an error (e.g., to for too). Word errors were counted each time the error was made because of their impact on fluency and because later when the student goes back to correct the mistakes, the student would have to correct the mistake each time it is made. 
Data also reflected the type of word errors students made. When the student wrote with the word processor the following errors were counted: (a) spelling/keyboarding errors, (b) keypress errors, and (c) incorrect words. When using speech recognition software, the errors that were counted were: (a) substituted incorrect words (words that the computer types out that the student did not say); (b) additional unintended words (computer puts in different or more words than the student said); (c) omission of a word; and (d) command errors (e.g., spelling out "period” instead of placing a period at the end of a sentence, or not executing the command) (MacArthur \& Cavalier, 2004).

Punctuation and capitalization errors were not counted as errors in either word processing or speech recognition software use unless the student gave a command for punctuation or capitalization in speech recognition that did not occur (hence a command error).

It was necessary to distinguish between so many types of word errors because different types of errors occurred with the use of speech recognition software versus word processing software. For example, speech recognition software will not misspell a word; however, the program might misinterpret the user's intended word and substitute another word or group of words or omit a word or group of words. Using word processing, however, the student might misspell a word or might use the incorrect word. Because speech recognition is hands-free, users must dictate punctuation marks, capitalization, and basic navigation requests. This provides the opportunity for punctuation, capitalization, and navigation command errors to occur when using speech recognition software.

In addition to the different types of word errors that can occur in speech recognition and word processing software, other composing considerations must be 
made. If the participant speaks quickly in order to produce a longer composition, more errors could be made. The same is true for word processing. If the user types fast to increase the rate but makes a high percentage of errors, this must be considered. This is one reason that fluency was calculated, taking into consideration not only the rate but also the errors made when composing.

Recall of intended meaning also was documented. Recall of intended meaning occurred when the student read back the writing sample and identified errors in word processing or misinterpretations made by the speech recognition software. Upon completion of the draft writing, the researcher instructed the student to read back what was written. See Appendix A for recall of intended meaning script. In the word processing component, of interest was whether or not the student could read correctly the misspellings or incorrect words. During the speech recognition component, of interest was whether or not the students could recall what they meant to say given the potential recognition misinterpretations of the speech recognition software. It was documented whether the student was able to recall the intended meaning immediately, with a delay, differently without changing the meaning, or was not able to recall intended meaning at all.

Finally, the length of document was calculated. Length was defined as the number of words in the draft. The original document was analyzed for length by taking the number of characters and dividing them by five to obtain the number of words. Materials

Participants used word processing software, speech recognition software, and a computer with a headset microphone attached. The word processing software was 
Microsoft Word 2003. Spell check and grammar check were turned off during writing sessions. This is because when writing a draft, it is important for students to write for content and then go back later for revisions (Honeycutt, 2003). Additionally, the auto correct and auto complete features were turned off.

Dragon NaturallySpeaking 7 Preferred was the speech recognition software used. Hux, Rankin-Erickson, Manasse, and Lauritzen, (2000) found that when comparing three different brands of speech recognition software, Dragon NaturallySpeaking was more accurate than the other two. The Preferred version was selected because it has special compatibility with Microsoft Word (www.nuance.com/naturallyspeaking/home/). Passages using speech recognition software were dictated directly into Microsoft Word. The microphone headsets used by all participants were ones provided with the Dragon NaturallySpeaking software. Individual headsets were assigned to each participant before the study and were used consistently throughout.

Speech recognition software works in the following way: the user, wearing a microphone headset connected to the computer, speaks into the microphone. As the user speaks, the words appear on the word processing screen. Speech recognition software can be completely hands-free. Speech recognition software also encompasses a complete list of correction commands. For example, if users make a mistake and need to change the text, they can speak a correction command such as "scratch that," deleting the last phrase spoken. If the speech recognition software misinterprets speech and the user needs to make a correction, the user can select specific words or phrases by speaking a command such as "select goes to the score" and re-dictating "go to the store." The program also recognizes navigation commands so the user can move around the document without 
using the mouse or keyboard (e.g., page up, move to end of line, or move the cursor before or after a specific word or phrase). In addition to correction and navigation commands, users can also dictate punctuation marks and capitalization, save documents, cut and paste, and perform all functions of the word processor hands-free. Users can also open and close files, access the Internet, and compose email using speech recognition software.

Dragon NaturallySpeaking allows the user to select specific settings during setup. The vocabulary for Dragon NaturallySpeaking was set to General - Large and the language was set to US English. The Speech model was set to BestMatch III. Participants were required to speak the punctuation commands that they desired in their composition. Although Dragon NaturallySpeaking does have automatic punctuation completion, it was necessary for participants to dictate the punctuation because the comparison was made with word processing, where they also had to input the punctuation manually. Microsoft Word and Dragon NaturallySpeaking automatically will capitalize the first word of each sentence. Dragon NaturallySpeaking also automatically capitalizes proper nouns. Dragon NaturallySpeaking was set to place one space, as opposed to two spaces, after a period for all users because all participants only placed one space after periods in word processing.

The computers that were used were determined individually. The computer that the participant most often used at school was the computer that the participant used for this study. In the absence of the participant having an assigned or preferred computer, or a computer that had the internal memory to support Dragon NaturallySpeaking, the researcher's computers were used. Therefore, Ann, Cady, and Dana used the researcher's 
Dell Latitude D600. Dana had the text enlarged to 16 point font. Beau used his Dell Latitude D600 computer with a mini keyboard, rollerball mouse, and a pen for typing, and Emma used the researcher's Dell Inspiron E1505 and D600.

Procedures

Pre-intervention measures. Prior to intervention, the following measures were collected and reported: (a) initial spelling achievement measure, (b) handwriting rate, (c) typing rate, (d) writing level, and (e) voice quality. All participants completed the spelling sub-test of the Wide Range Achievement Test 3 (WRAT3) (Wilkinson, 1993) in order to determine a baseline for spelling ability. With assistance from the occupational therapist, the classroom teacher and researcher obtained measures of handwriting rate and typing rate. Handwriting rate was determined by timing the participant for three minutes during a handwriting task. The total number of correct words written (with five characters, including spaces, equaling one word) was divided by the total number of minutes of writing. The same procedure was used in order to calculate typing rate. Participants were given three minutes to type in response to a writing topic, and their typing rates were calculated by dividing the total number of correct words typed (with five characters, including spaces, equaling one word) by the total number of minutes writing. The writing level measure was conducted by taking three samples of participants’ previously typed work and running it though Microsoft Word's FleschKincaid grade level tool. All writing samples were converted to 12 point Times New Roman font for consistency prior to obtaining the grade level measure. A measure of voice quality, the Multi-Dimensional Voice Program (MDVP) (Kay Elemetrics, 1993) was utilized to obtain a measure of each student's voice. This was obtained by having the 
student participants say “ahhh” for three to five seconds into a digital audio recorder. The digital recording of their voices was analyzed using the MDVP (Kay Elemetrics). Examples of additional measures the MDVP (Kay Elemetrics) may take include voice breaks, voice tremors, noise-related measures, amplitude perturbations, and frequency perturbations. Reporting this measure may provide useful information about voice characteristics for discussion purposes. Additional pre-intervention measures, including the length of time students had used word processing were reported. Student participants also were asked if they found word processing aversive or if they had prior experience with speech recognition software (but were not currently using it), if they found it aversive.

Spelling ability, handwriting rate, typing rate, writing level, and voice quality provided information that was useful in making inferences about the results and that contributed to the discussion of results. The word errors in the word processing phase could be compared to spelling ability if spelling was problematic. The other preintervention measures were important for comparison with intervention outcomes.

Finally, prior to the study, all students compiled a list of broad topics of interest to them. The purpose of this list was to ensure that each student was writing about a topic of personal interest and that it was a topic that each student could sustain for at least three minutes of continuous typing or dictation. During writing sessions, the students chose a topic about which to write from their lists.

Speech recognition training. In order for individuals to be able to use speech recognition, training of voice files had to be completed successfully prior to intervention. Training occurred over multiple sessions in the following manner, as recommended by 
MacArthur and Cavalier (2004) and Quinlan (2004). Speech recognition training consisted of: a) an explanation of the purpose of the software and modeling its use, b) instruction in creating voice files, c) creation of voice files through reading two training passages, d) completion of the Dragon NaturallySpeaking tutorial, e) completion of command probes (e.g., dictating punctuation and basic navigation commands), and f) completion of pre-intervention skill probes (e.g., turning on computer, starting program). See checklist in Appendix A.

First, the researcher provided an introduction to Dragon NaturallySpeaking to the students. The purpose of this introduction was to demonstrate the capabilities of Dragon NaturallySpeaking and to demonstrate to the students the end result of their training. The researcher explained the purpose of the software, which is to provide hands-free access to the computer and to provide an alternative to typing by using voice instead of hands. The researcher also modeled clear dictation of a short paragraph (including basic punctuation, capitalization, and navigation commands) using a computer and LCD projector, with the computer image projected on a screen. As the researcher demonstrated dictation, students were able to see on the projection screen that, as the researcher spoke, the words appeared in Microsoft Word. The researcher also showed the participants the different toolbars and commands associated with Dragon NaturallySpeaking.

Voice file instruction occurred next with a demonstration of the reading of a brief training passage. The researcher demonstrated proper dictation strategies and had the participants practice saying sentences clearly and enunciating each word. Students learned proper microphone placement and were encouraged to speak naturally and to enunciate clearly when training voice files (Quinlan, 2004). 
The next phase of speech recognition training consisted of individuals creating user-voice files. The researcher met with participants individually in this phase. As part of the software training exercises, Dragon NaturallySpeaking offers a selection of different training passages that appear on the screen that students read into the microphone. As the user reads the passage provided by Dragon NaturallySpeaking, the program updates its understanding of the user's speech patterns and creates specific uservoice files. As recommended by Dragon NaturallySpeaking, users read two training passages, and all training exercises utilized the training passages provided by Dragon NaturallySpeaking. For example, users were given a list of training passages from which to choose. The participants were instructed to read Talking to your computer (Easy Reading: Instructional) as the first passage. The second training passage selected was Product Manager's Mail Messages (Easier Reading: Business). The researcher sat next to the participant during the reading of training passages to ensure that the participant was enunciating clearly and reading each word in the passage. If necessary, the researcher paused the training and provided additional guidance. Because there is a high incidence of individuals with physical disabilities and vision impairments, the researcher ensured, prior to training, that the participants could see the training passages. When the font of the training passage was too small for the participant to read, the researcher enlarged the training passages ahead of time and presented them to students at the time of training. This occurred with two participants, Dana and Ann.

After completion of reading training passages, Dragon NaturallySpeaking offers users the opportunity to take its tutorial. The Dragon NaturallySpeaking tutorial takes users through 14 lessons. Lessons include learning about the Dragon toolbar, turning the 
microphone on and off, using punctuation, dictation suggestions, navigation commands, correction commands, spelling words instead of dictating them, deleting, inserting, and formatting words. The tutorial provided instruction on the skill, a video demonstration, and opportunity for users to practice the skills that had been demonstrated. After users completed their second voice-file reading, they were instructed to complete Lessons 1 14 of the Dragon NaturallySpeaking tutorial.

The final component of speech recognition training consisted of teaching basic punctuation, capitalization, and navigation procedures. Because punctuation, capitalization, and navigation occur hands-free, it is important for participants to demonstrate these commands effectively. The researcher taught the students the following punctuation commands: period, question mark, exclamation mark, comma, semicolon, colon, and dash. Although Dragon NaturallySpeaking capitalizes the first letter of a sentence and proper nouns, other words may need to be capitalized (e.g., title of a book). Therefore, the participants were taught capitalization commands. The researcher also taught the students the following navigation commands: new line, new paragraph, and tab. Due to the cognitive load of memorizing commands, as discussed by Koester (2001), the students had a list of commands available next to the computer that they could reference while dictating their draft.

Students were required to demonstrate competency using Dragon NaturallySpeaking software. They had to meet $100 \%$ accuracy for three consecutive trials in a session on the designated skills before they could move on to intervention. As seen in Appendix A, a protocol for training was developed. Its purpose was to ensure procedural 
integrity. The protocol was set up in a checklist format and clearly defined each step the researcher took when conducting training sessions.

Intervention: writing sessions. Writing sessions consisted of first-draft writing. The students were instructed to type a short passage about a general, familiar topic using either word processing or speech recognition. The first-draft writing passage was selected so the students would not have to concern themselves with the writing process or what they were going to write about; rather, they could concentrate on composing processes such as typing (word processing) and clearly dictating (speech recognition). This has implications for working memory. Like decoding and comprehending at the same time, composing and transcribing imposes a great deal of strain on working memory. It is difficult to remember thoughts when transcription issues are consuming the resources of working memory (Bourdin \& Fayol, 2000). Also, stopping to correct errors while composing can place additional strain on working memory (Kellogg, 1996).

At the beginning of each session, students set up all of the materials necessary to write (e.g., turn on computer, open programs). The students set up materials first in order to decrease interference in the writing so that everything was prepared when they were ready to type. During individual sessions, participants were provided with a choice of writing topics from their list (e.g., dogs). Once the writing topic was chosen, the researcher discussed the topic with the participants and had them write some words or phrases depicting key ideas of what they were planning to compose. This is supported by Reece and Cumming (1996) who discussed the need of having an outline prior to having a draft to decrease working memory load. Written notes could be completed by handwriting or keyboarding and were printed out and displayed for the students to refer 
to when they began the actual writing task. Additionally, a list of navigation and punctuation commands were posted next to each participant's computer for reference in order to prevent possible memory-related issues.

Participants spent approximately five minutes brainstorming, writing notes, and rehearsing their responses to the topic. Planning is an important step because it can potentially eliminate pauses and ensure that there will be a continuous flow so the students will not have to stop to think about what they will be writing. Most students concentrate on getting their thoughts down on paper when writing a draft and then go back later to make changes (Honeycutt, 2003). Aligning with this method of draft writing, students were told to write and correct later. Also for the purposes of this study, it was important to obtain a true measure of fluency and to analyze the errors the participants made. If the participants corrected as they composed, it would have been impossible to determine a true measure of fluency and to determine specific word errors. Therefore, participants were instructed not to correct mistakes as they composed using both speech recognition and word processing. Students also were not taught the correction commands for Dragon NaturallySpeaking during the time of the study to eliminate this from occurring. Students also were observed while using the word processing condition to monitor that corrections were not made while being timed. If corrections were made during word processing or speech recognition use, the researcher documented their occurrence on the procedural fidelity checklist (See Appendix A).

After planning was complete, the students were instructed to write on the given topic. The researcher timed the students for three minutes. The time began when the student pressed the first key or spoke the first word. At the end of three minutes, the 
student was directed to stop composing and draw a line under the written work. The student then had the opportunity to complete the draft with as much additional time as necessary. The researcher continued to time the writing session through the student's completion of writing. This method of timing is consistent with research conducted by Lewis et al (1998) on draft writing using various AT tools, where they had the students initially write for three minutes, then draw a line and continue writing until the students wanted to stop. In this study, when the draft was complete, the students immediately were asked to re-read what they had written. When word processing, the students' drafts were checked for any discrepancies between what was spoken and what was written. The same occurred for the speech recognition treatment, providing the opportunity for the student to point out word substitutions or other word errors. This allowed the researcher to determine whether the students were able to remember what they initially meant when the speech recognition put in unintended words or made other errors. It was documented whether the students were able to recall the error or what they meant to say immediately, with a delay in recall of the error or what they meant to say, differently than they stated it but without changing the meaning, or were not able to identify the error at all or know what they meant. Koester (2001) noted the importance of this, stating, “one drawback, especially when recognition accuracy is not above 95\%, is that risk of forgetting the original intent when there is a significant time delay between when the error occurred and when it is identified" (p. 124).

For increased data collection accuracy, the students were audio taped when composing using speech recognition software. Audio taping also occurred when students reread their paragraphs in order to point out corrections in word processing and speech 
recognition. The researcher analyzed the first three minutes of the product for fluency, accuracy, type of word errors, recall of intended meaning, and length. The researcher then analyzed the audio tapes for discrepancies between what the students actually said and what the speech recognition software wrote for the first three minutes, as well as discrepancies between what the students wrote using word processing and what they read back during the first three minutes.

Finally, after the session was complete, and before the next speech recognition session occurred, the researcher guided the participants in correcting the mistakes that speech recognition made. The researcher assisted participants in using voice commands to select the errors and to replace the errors with the correct words. Also, if there were word omissions, the participants were guided in inserting the omitted words into the document. This helped not only to create a correct document, but also to allow updates to be made to voice files. Although this was not an official part of the study, it was important, because if corrections are not made, and voice files are not updated to reflect the words that the student dictated that the program misrecognized, the accuracy of the speech recognition program will not be able to improve. Because the correction process can be difficult, requiring knowledge of additional commands that are not necessary in the draft-writing phase, the researcher assisted the students in making the corrections.

\section{Data Collection}

Data were collected during each session from permanent products on writing fluency (wcpm). Data were collected in the following manner. In order to calculate writing fluency, the permanent product of the writing session was assessed. As described in the Operational Definitions section, writing fluency is defined as the number of correct 
words produced in one minute. The character count tool on Microsoft Word was used in order to count the number of characters (including spaces) in the passage. To calculate fluency, incorrect words were removed from the writing sample, obtaining the character count, and were then divided by 5 (to get the number of correct words). Next, this number was divided by the number of minutes (three) to obtain the rate (wcpm). Once writing fluency was calculated and documented on the data sheet (see Appendix B), it was plotted on the graph for visual inspection and analysis.

In addition to fluency, accuracy also was calculated. The total number of word errors was subtracted from the total number of words produced and then divided by the total number of words produced. The number of total words produced was provided by the word count tool on Microsoft Word. Accuracy was then documented on the data sheet and plotted on the graph for visual inspection and analysis. Once the accuracy was determined, the length of the document was noted on the data sheets. Word errors were coded based on the type of error (see Appendix B). Again, word errors were defined as spelling errors, substituted incorrect word(s), additional unintended word(s), omission of a word, and command errors (see Table 2). The type of word error was coded on the data collection sheet based on the following categories: $\mathrm{S}$ = spelling error; $\mathrm{I}$ = substituted incorrect (unintentional) words; $\mathrm{A}=$ additional unintended word; $\mathrm{O}=$ omission of a word; $\mathrm{C}=$ command error. Finally, recall of intended meaning was coded and documented on the data sheet.

Research Design

An alternating treatments design (Barlow \& Hayes, 1979) was used to compare word processing with speech recognition. An alternating treatments design was chosen 
Table 2

Coding for Word Errors across Word Processing and Speech Recognition

\begin{tabular}{llll}
\hline Word Processing Error & \multicolumn{2}{l}{ Speech Recognition Error } \\
\hline S & $\begin{array}{l}\text { Spelling/Keyboarding } \\
\text { WORD Error }\end{array}$ & I & $\begin{array}{l}\text { Substituted Incorrect } \\
\text { word(s) }\end{array}$ \\
K & $\begin{array}{l}\text { Keypress Error (extra characters } \\
\text { not associated with a word) }\end{array}$ & A & $\begin{array}{l}\text { Additional unintentional } \\
\text { (didn't say it but the } \\
\text { program wrote it }\end{array}$ \\
& & $\begin{array}{l}\text { OR environmental sound, } \\
\text { stutter, or extraneous sound } \\
\text { (ie., thinking sound, um, } \\
\text { sneeze, etc.)) }\end{array}$ \\
& & O & $\begin{array}{l}\text { Omission of a word (said it } \\
\text { but the program didn't write } \\
\text { it) }\end{array}$ \\
& & C & Command Error \\
\hline
\end{tabular}

because of the ability to compare two different conditions clearly. In this case, two independent variables, speech recognition software and word processing were compared.

Because motor patterns of individuals with physical disabilities can be erratic due to many factors such as fatigue, motor control, and environmental influences (Heller \& Swinehart-Jones, 2003), it is potentially difficult to reach stability with motor response behaviors, such as composition rate. Poling, Methot, and LeSage (1995) indicated that an advantage of using an alternating treatments design over a multiple-baseline design or withdrawal design is that when behaviors are potentially highly variable, phase changes might not be appropriate. Additionally, Poling et al. stated,

With the alternating-treatments design, conditions change regardless of the subject's behavior, and a comparison can legitimately be made between performance in two conditions (e.g., treatment and baseline) even though the target behavior improves or worsens during each. So long as behavior 
is consistently and appreciably better (or worse) during treatment than during baseline, variability across time does not preclude making a gross statement about the effects of the treatment. (p. 96)

The presentation of the use of word processing and speech recognition was counterbalanced and presented in random order. For example, a rotation such as A B A A B A B B A B, with A representing word processing and B representing speech recognition, was used (Alberto \& Troutman, 2006). This phase continued until a clear fractionation of the data was seen in the area of fluency, within a minimum of 10 sessions and a maximum of 20 sessions.

In addition to the alternating treatments phase, a replication phase was added. Alberto and Troutman (2006) discussed that an alternating treatments phase does not include a replication phase and is therefore relatively weak. The replication phase consisted of using the more effective treatment with the less effective treatment's writing topic area. The writing topics were general enough that when asked to write about them in the replication phase, although the prompt was the same, the content could be different. The replication phase continued for two sessions.

\section{Data Analysis}

Data were analyzed through visual inspection of the graph in terms of fractionation between the effects of word processing use and speech recognition use on fluency and accuracy. Fractionation is defined as vertical separation between the two writing conditions (Poling et al., 1995). For fluency, when one condition is vertically higher than the other for three consecutive data points, it would be determined that the condition is more effective for fluency. 
Accuracy was calculated for each session, and an examination of the accuracy (percent correct) between independent variables occurred. This included session-bysession comparisons, as well as ranges and means. Errors also were graphed for visual inspection. In addition, specific types of errors were coded and were analyzed based on frequency of the specific types of errors made. Finally, recall of intended meaning was coded and analyzed based on frequency and type of recall (immediate, delayed, different or incorrect/no recall). Reliability, Procedural Fidelity, and Social Validity

Interobserver reliability (IOR). IOR was calculated in $20 \%$ of the sessions for both word processing and speech recognition use and in 50\% of the replication sessions. Another adult with experience with individuals with physical disabilities and assistive technology was trained and served as the second observer. The second observer calculated fluency, accuracy, and length and checked the list of errors against the written product to ensure that all errors were found. IOR was calculated as (the number of agreements divided by the number of agreements plus disagreements) times 100 .

Number of agreements

$\mathrm{IOR}=$ $\mathrm{x} 100$

Number of agreements plus disagreements

Procedural fidelity. As seen in Appendix A, a protocol for the writing sessions was developed. Its purpose was to ensure procedural integrity. The protocol was set up in a checklist format and clearly defined each step the researcher was to take when conducting writing sessions. Procedural fidelity checklists for training and writing sessions were followed $100 \%$ of the time by the researcher in order to ensure that the 
procedures were carried out in a consistent manner. The researcher trained an adult in the classroom on the treatment integrity and procedures and the checklist and checked it $20 \%$ of the time in conjunction with the other observer to ensure that the researcher was following the outlined procedures.

Social validity. Social validity was assessed through a post-treatment questionnaire with the participants. The questionnaire consisted of questions assessing the participants' perceptions of the use of speech recognition software and word processing as well as their perceptions about writing and composition in school. Additionally, after the social validity questionnaire was given, participants were asked to respond to a writing prompt related directly to their participation in the study and their feelings about speech recognition. They were given the choice of responding via handwriting, word processing, or speech recognition.

\section{Results}

The purpose of this study was to compare the effectiveness of word processing compared to speech recognition software across the five dependent variables of (a) writing fluency, (b) accuracy, (c) type of word error, (d) recall of intended meaning, and (e) length of the document. The results demonstrated that all five students involved in the study were able to use speech recognition software for writing draft papers.

As seen in Figure 1, all five students had higher writing fluency rates (as calculated by wcpm) using speech recognition software compared to word processing. In terms of errors, all five students had higher accuracy rates and lower error rates using word processing (see Figure 2). Out of three different word error types (spelling/ keyboarding word errors, keypress errors, and substituted incorrect words), the 
Figure 1. Writing fluency across participants.

\section{Writing Fluency}

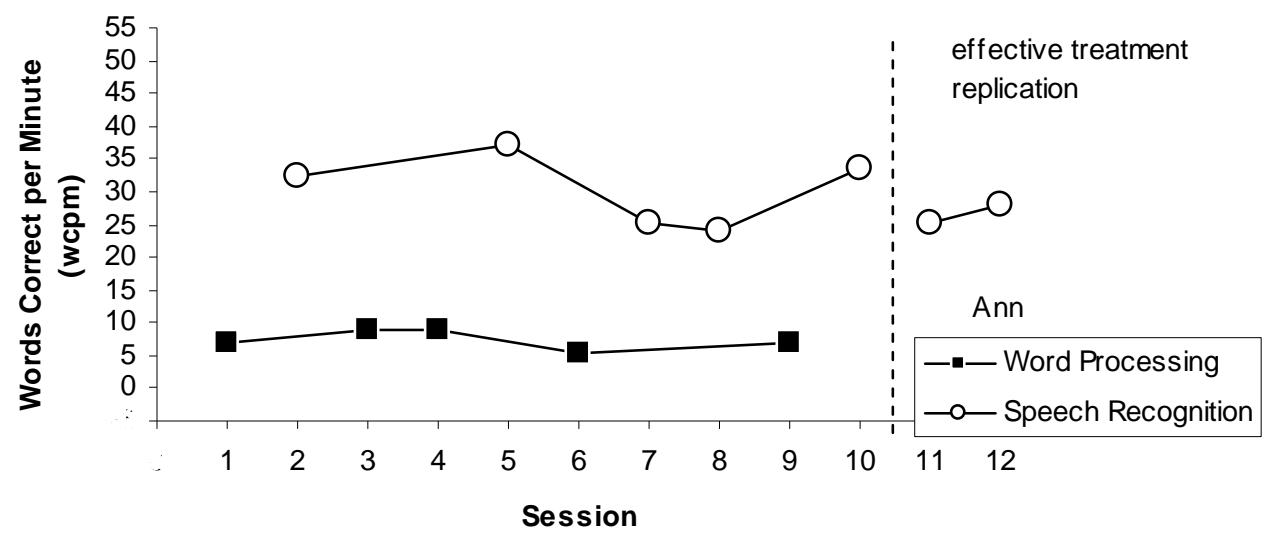

Writing Fuency

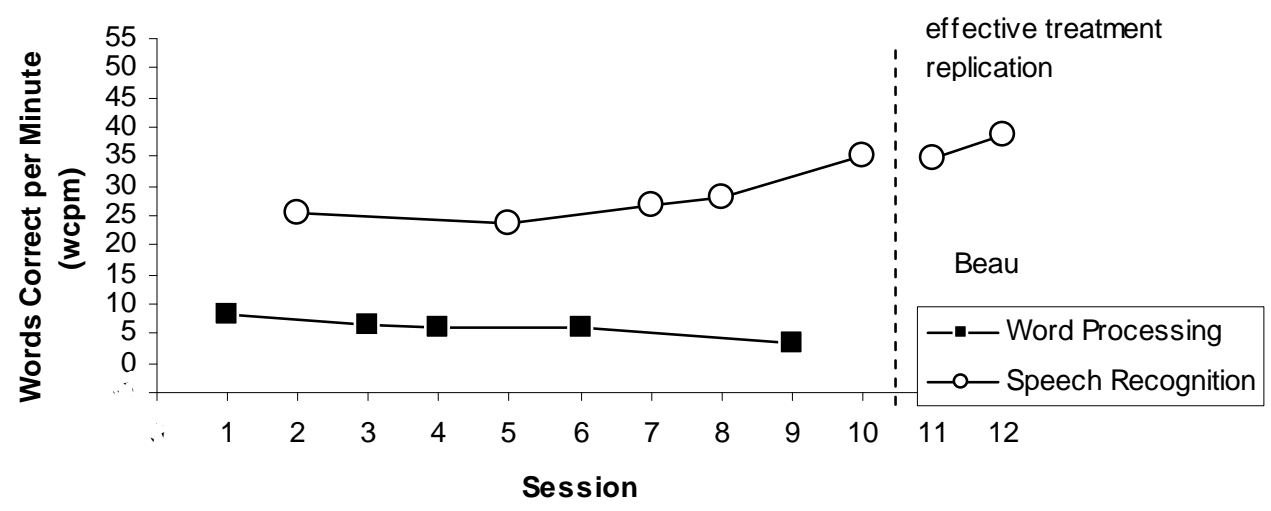

Writing Fuency

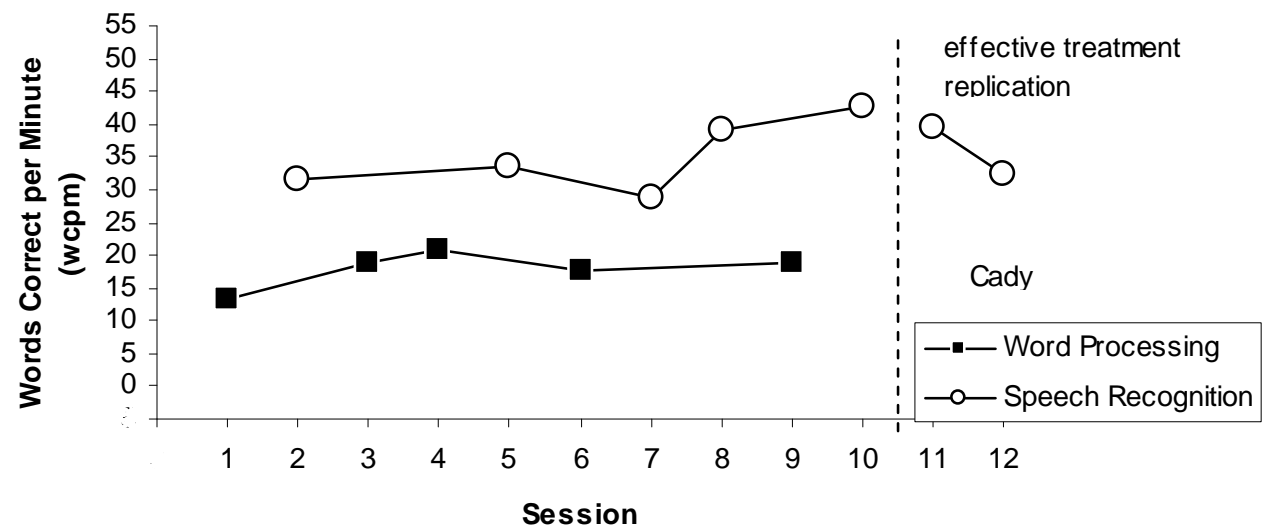


Figure 1 continued. Writing fluency across participants.
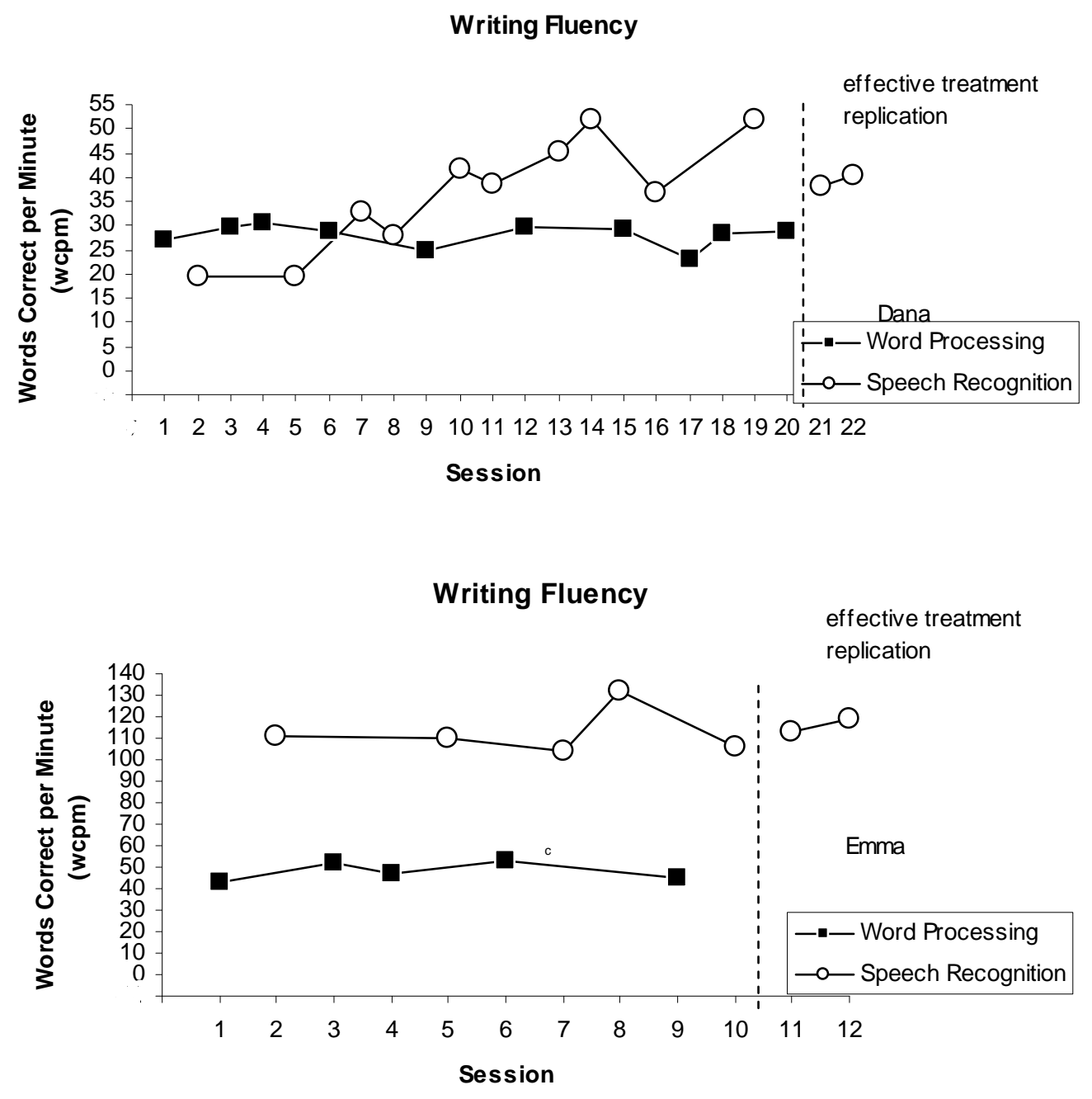
Figure 2. Accuracy across participants.

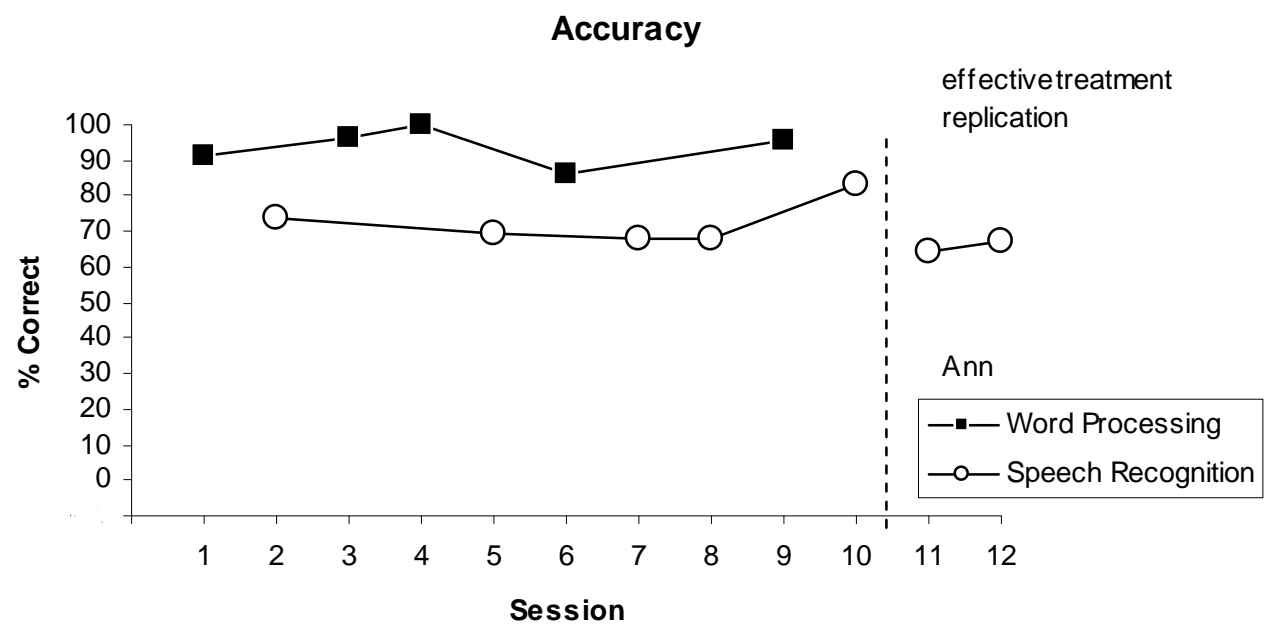

Accuracy
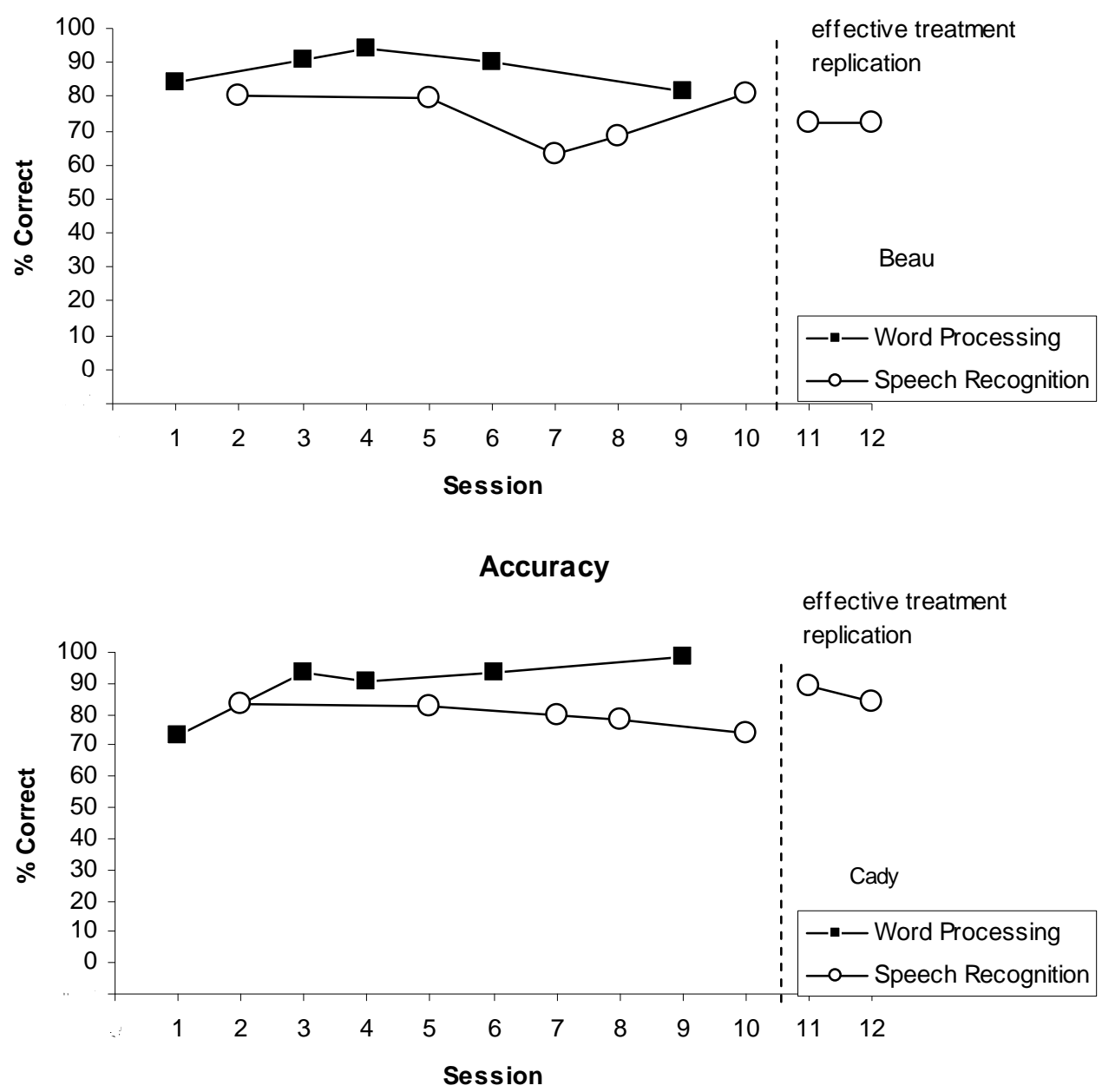
Figure 2 continued. Accuracy across participants.
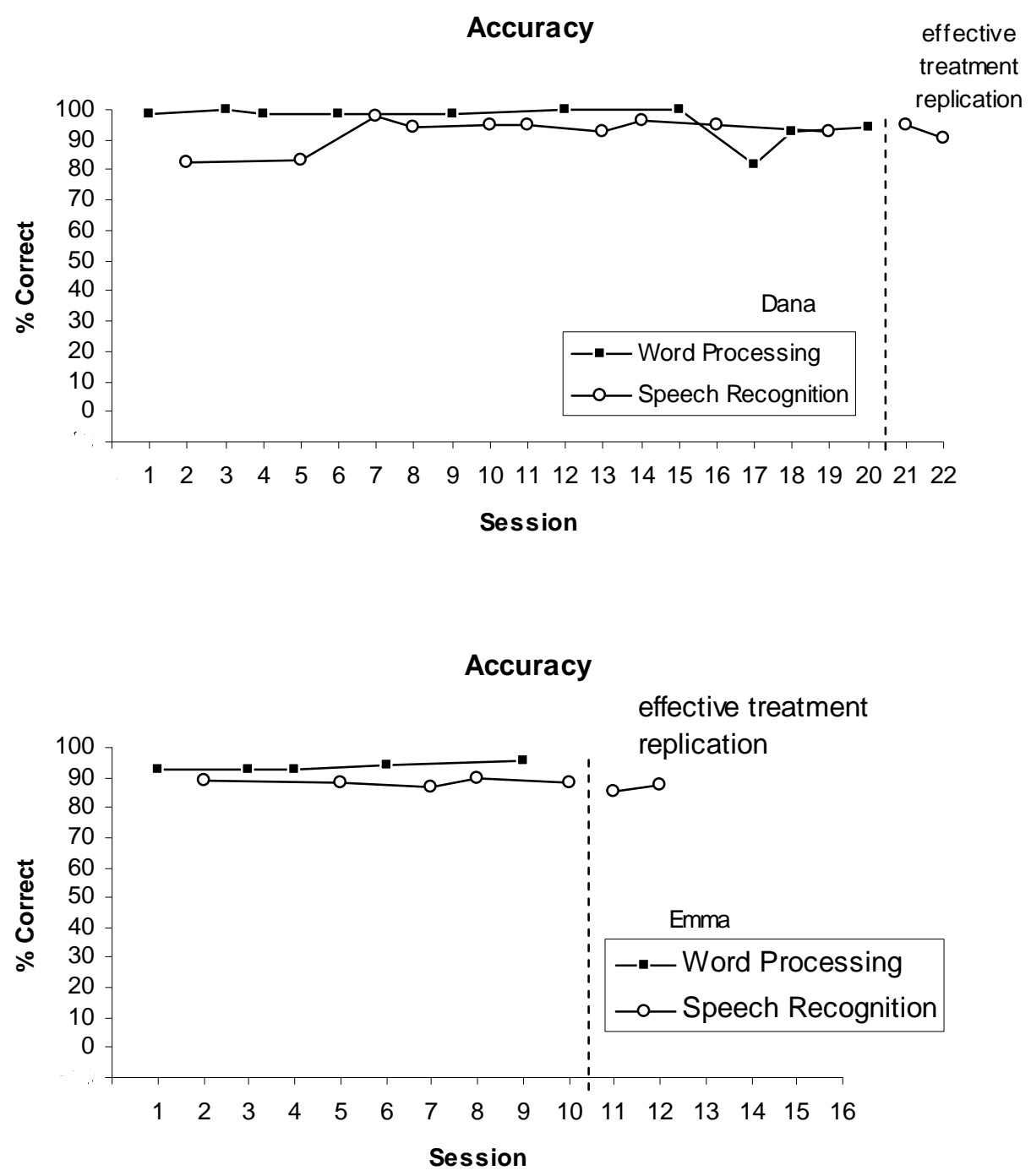

Note: The data represented on Dana's graph depicting word processing accuracy is divergent from the other graphs because she tended to correct as she typed. Therefore, the data showing word processing accuracy can not be considered a true measure of accuracy, unlike the other participants. 
most common type of word error using word processing were spelling/keyboarding errors. Out of four types of errors for speech recognition (substituted incorrect word(s), additional unintended words, omissions, and command errors), the most common type of word error using speech recognition was substituted incorrect words (see Table 3). The students’ abilities to recall intended meaning varied across students and treatments. In terms of length, all students wrote longer drafts using speech recognition software (see Figure 3). Individual results are reported for each participant.

Ann

Writing fluency (wcpm). As seen in Figure 1, Ann had a clear bifurcation of the data, with a higher fluency rate (as determined by words correct per minute) using speech recognition software compared to word processing. There were no overlapping data points between the two treatments. Throughout the five speech recognition sessions, Ann’s writing fluency ranged from 24.1 wcpm to 37.2 wcpm, with an average of 30.4 wcpm. Throughout the five word processing sessions, Ann's writing fluency ranged from 5.5 wcpm to 8.9 wcpm, with a mean of 7.5 wcpm. For Ann, speech recognition improved her writing fluency an average of 22.9 wcpm.

Replication of the most successful treatment occurred for two sessions. This replication used speech recognition. Ann wrote about two topics that she had written about in previous word processing sessions. The effective treatment replication showed similar writing fluency rates.

Accuracy and word error type. As seen in Figure 2, Ann's accuracy was higher using word processing. Ann’s accuracy using speech recognition ranged from $68.0 \%$ to $83.5 \%$, with an average of $72.6 \%$. Word processing accuracy ranged from $86.4 \%$ to 
Table 3

Percent of Word Errors across All Words

\begin{tabular}{lccccc}
\hline \multicolumn{1}{c}{ Ann } & Beau & Cady & Dana & Emma \\
\hline Word Processing & & & & & \\
\hline Accuracy & $93.9 \%$ & $88.0 \%$ & $91.3 \%$ & $96.3 \%$ & $93.8 \%$ \\
Errors & $6.1 \%$ & $12.0 \%$ & $8.7 \%$ & $3.7 \%$ & $6.2 \%$ \\
Error type S & $6.1 \%$ & $6.9 \%$ & $8.4 \%$ & $3.7 \%$ & $6.2 \%$ \\
Error type K & $0 \%$ & $4.6 \%$ & $0 \%$ & $0 \%$ & $0 \%$ \\
Error type I & $0 \%$ & $.6 \%$ & $.3 \%$ & $0 \%$ & $0 \%$ \\
Recall Imm & $4.4 \%$ & $11.4 \%$ & $8.7 \%$ & $3.6 \%$ & $6.2 \%$ \\
Recall Del & $1.7 \%$ & $0 \%$ & $0 \%$ & $.1 \%$ & $0 \%$ \\
Recall Diff & $0 \%$ & $0 \%$ & $0 \%$ & $0 \%$ & $0 \%$ \\
Recall X & $0 \%$ & $.6 \%$ & $0 \%$ & $0 \%$ & $0 \%$ \\
\hline Speech Recognition & & & & & \\
\hline Accuracy & $72.6 \%$ & $74.2 \%$ & $79.9 \%$ & $92.5 \%$ & $88.3 \%$ \\
Errors & $27.4 \%$ & $25.8 \%$ & $20.1 \%$ & $7.5 \%$ & $11.7 \%$ \\
Error type I & $23.1 \%$ & $18.3 \%$ & $15.8 \%$ & $5.5 \%$ & $9.6 \%$ \\
Error type A & $3.2 \%$ & $5.2 \%$ & $1.0 \%$ & $5.8 \%$ & $1.5 \%$ \\
Error type O & $.6 \%$ & $1.1 \%$ & $1.4 \%$ & $1.0 \%$ & $.6 \%$ \\
Error type C & $.6 \%$ & $1.1 \%$ & $1.8 \%$ & $.3 \%$ & $.1 \%$ \\
Recall Imm & $11.4 \%$ & $16.3 \%$ & $15.1 \%$ & $6.5 \%$ & $8.5 \%$ \\
Recall Del & $3.7 \%$ & $2.6 \%$ & $2.2 \%$ & $.5 \%$ & $1.0 \%$ \\
Recall Diff & $2.9 \%$ & $4.0 \%$ & $1.0 \%$ & $.1 \%$ & $1.0 \%$ \\
Recall X & $9.4 \%$ & $2.9 \%$ & $1.8 \%$ & $.5 \%$ & $1.2 \%$ \\
\hline Replication & & & & & \\
\hline Accuracy & $66.1 \%$ & $72.4 \%$ & $86.5 \%$ & $92.9 \%$ & $86.5 \%$ \\
Errors & $33.9 \%$ & $27.6 \%$ & $13.5 \%$ & $7.1 \%$ & $13.5 \%$ \\
Error type I & $26.7 \%$ & $20.9 \%$ & $7.8 \%$ & $5.8 \%$ & $11.8 \%$ \\
Error type A & $2.9 \%$ & $4.6 \%$ & $1.6 \%$ & $0 \%$ & $.8 \%$ \\
Error type O & $.7 \%$ & $1.0 \%$ & $0 \%$ & $.9 \%$ & $.9 \%$ \\
Error type C & $3.6 \%$ & $1.0 \%$ & $4.2 \%$ & $.4 \%$ & $0 \%$ \\
Recall Imm & $7.2 \%$ & $16.9 \%$ & $8.8 \%$ & $5.3 \%$ & $9.7 \%$ \\
Recall Del & $3.6 \%$ & $3.1 \%$ & $.5 \%$ & $1.3 \%$ & $1.9 \%$ \\
Recall Diff & $3.6 \%$ & $4.1 \%$ & $3.6 \%$ & $.4 \%$ & $1.5 \%$ \\
Recall X & $19.5 \%$ & $3.6 \%$ & $.5 \%$ & $0 \%$ & $.4 \%$ \\
\hline Note: For word & & & $0 \%$ & $\mathrm{I} \%$ \\
\hline
\end{tabular}

Note: For word processing, $\mathrm{S}=$ Spelling/Keyboarding Error; K = Keypress Error; I =

Substituted incorrect word(s). For speech recognition, I = Substituted Incorrect Word; A = Additional unintended word; $\mathrm{O}=$ Omission of a word; $\mathrm{C}=$ Command error. For Recall of intended meaning, Imm = Able to recall the error immediately; Del = Able to recall the 
error after delay; Diff = Read differently without changing meaning; $\mathrm{X}=$ Incorrect (changed meaning) or no recall. 
Figure 3. Length across participants.

\section{Length}

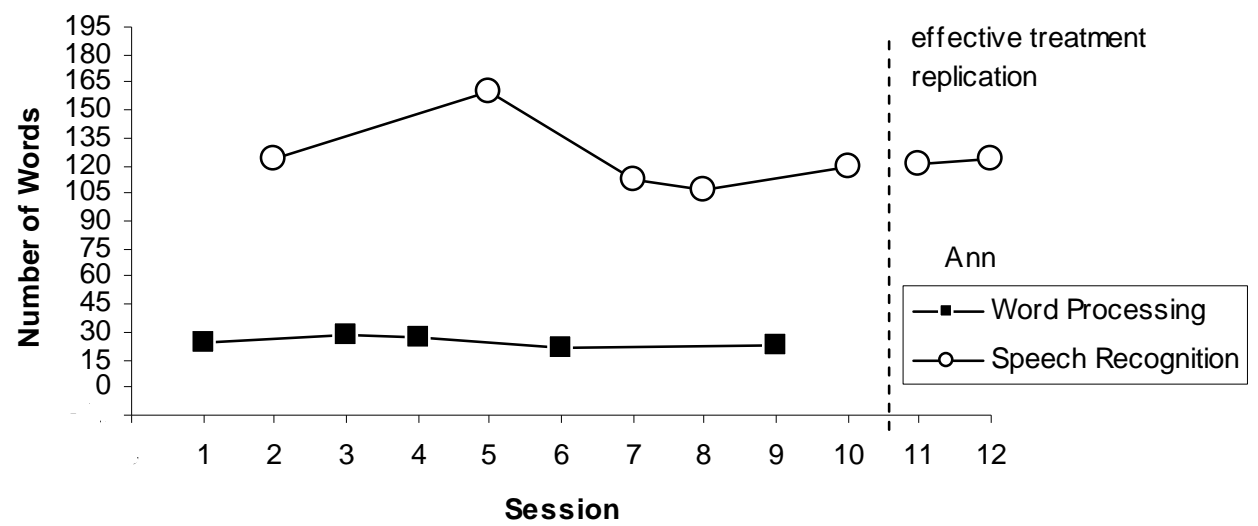

\section{Length}

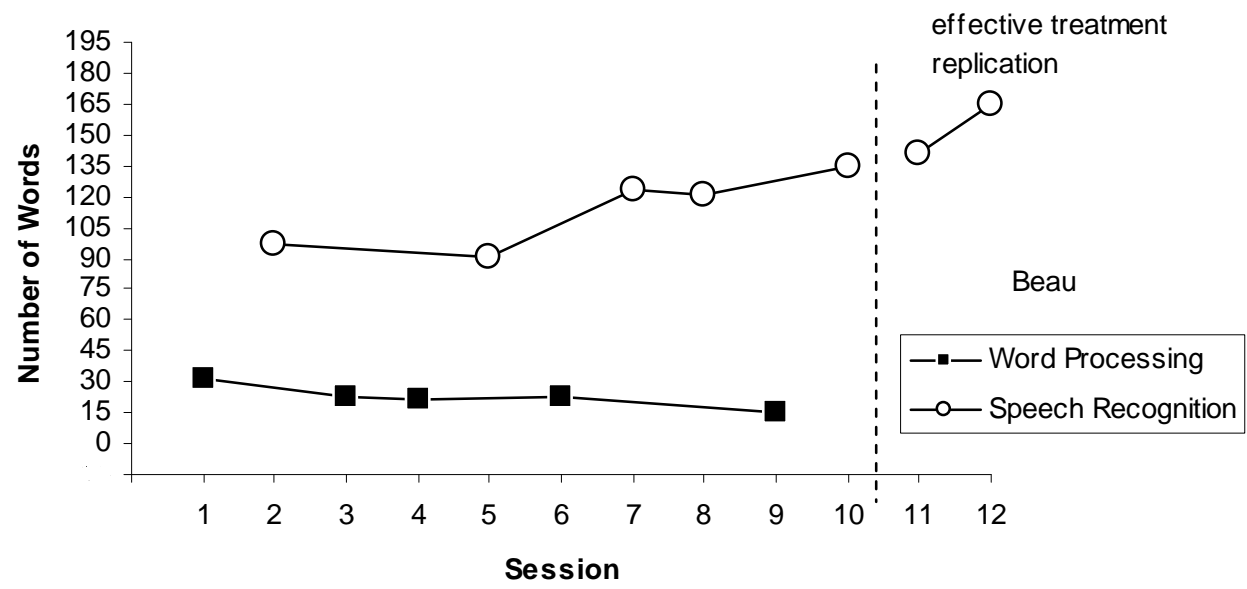

Length

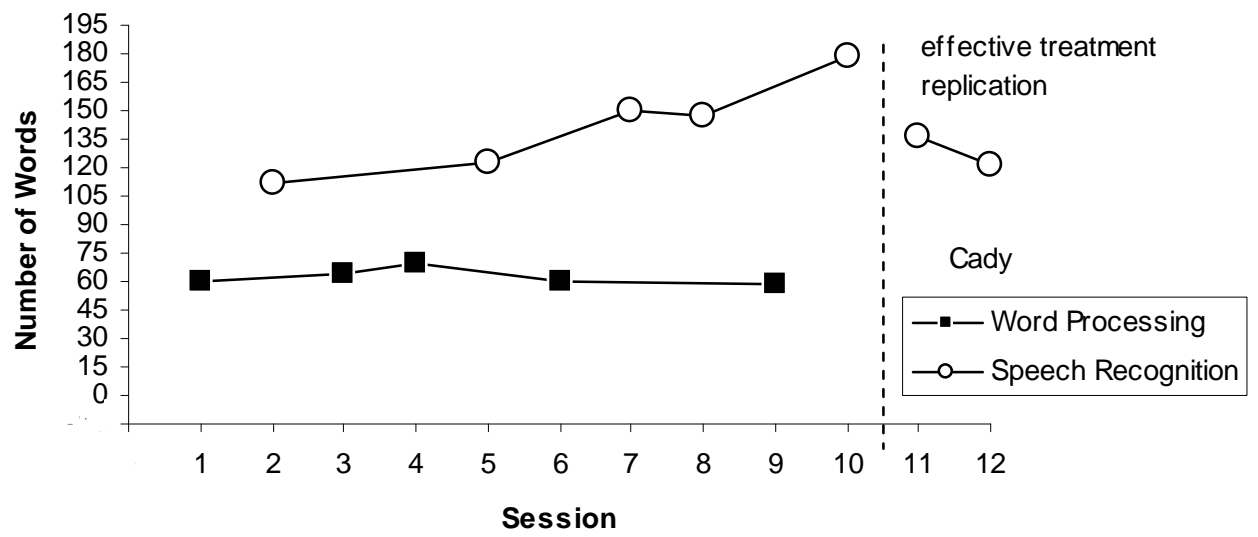


Figure 3 continued. Length across participants.

\section{Length}

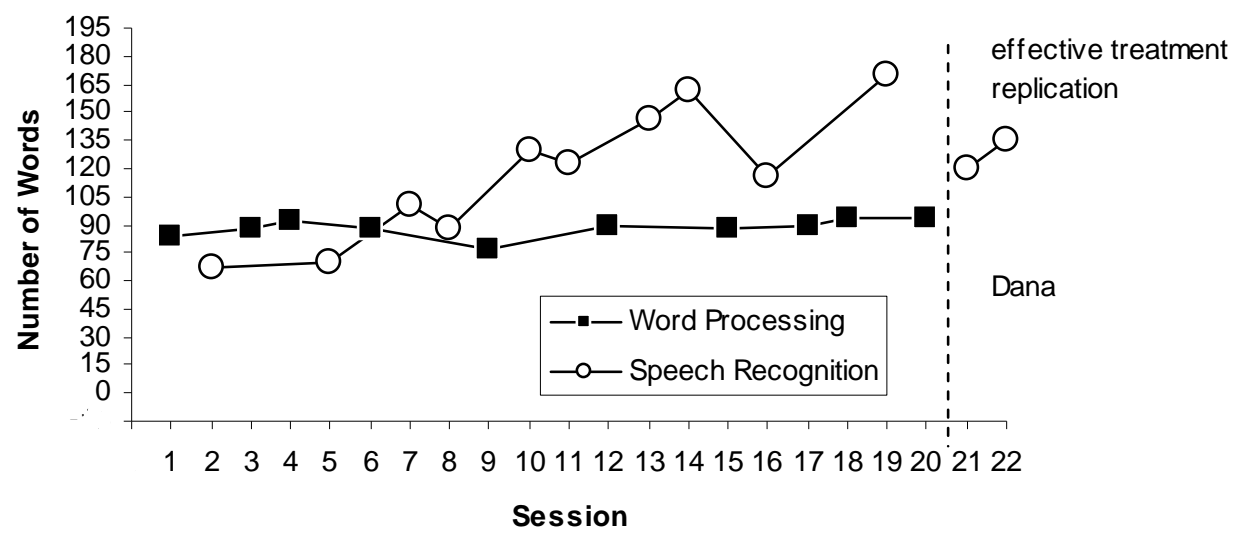

Length

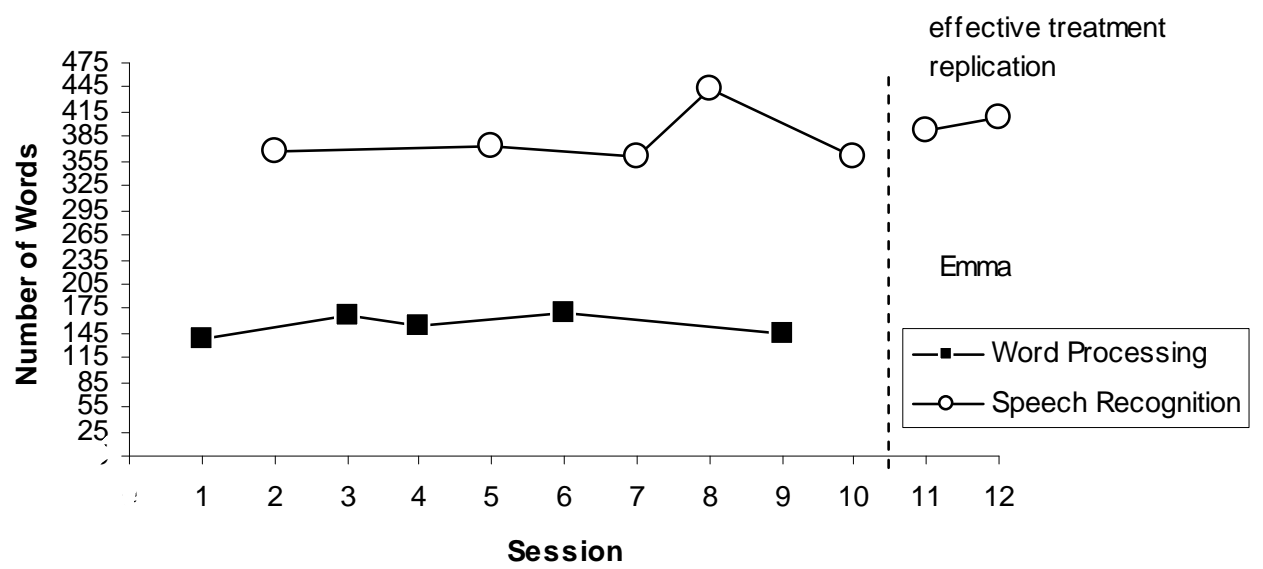


$100 \%$ over the five sessions with a mean of 93.9\%. Accuracy was higher when using word processing by an average of $21.3 \%$. Effective treatment replication resulted in a lower accuracy average (66.1\% in replication compared to $72.6 \%$ in intervention).

Ann’s error rate was $27.4 \%$ for speech recognition. As seen in Table 3, for speech recognition, 23.1\% of her draft consisted of incorrect word errors. The incorrect word error category had the highest percentage of errors across all error types. The second highest category of errors was additional unintended words at 3.2\%. The other error types, omissions and command errors, were both at .6\%.

In addition to examining the percentage of errors occurring in the draft, the percentage of each type of error was also calculated (in which errors add up to 100\%). Ann had a total of 7 spelling/keyboarding word errors across the five word processing sessions. Number of word errors ranged from 0 to 3 errors. Ann had no keypress errors and no substituted incorrect word errors. Therefore, $100 \%$ of her errors were spelling or keyboarding errors. Out of all of the errors across the five speech recognition sessions, $84.4 \%$ of them were substituted incorrect word(s), $11.5 \%$ were additional unintended words, $2.1 \%$ were omissions, and 2.1\% were command errors. Effective treatment replication showed slightly fewer substituted incorrect words and additional unintended words and an increase in command errors.

Recall of intended meaning. Ann was able to recall immediately her intended meaning using word processing $71.4 \%$ of the time. She had delayed recall $28.6 \%$ of the time. There were no instances where she recalled her word processing draft differently, incorrectly, or not at all. When recalling intended meaning using speech recognition, Ann was able to recall $41.7 \%$ of the errors immediately, $13.5 \%$ of the errors with delayed 
recall, $10.4 \%$ of the errors differently, and was not able to recall $34.4 \%$ of the errors correctly or at all. In terms of recall of intended meaning when using word processing, effective treatment replication showed a decrease in immediate and delayed recall and an increase in incorrect or no recall. Different recall remained about the same.

Length. As seen in Figure 3, Ann wrote longer drafts using speech recognition software. Using speech recognition, the length of Ann's drafts ranged from 107.2 words to 159.4 words, with an average of 124.3 words per draft. Length of the drafts for word processing ranged from 21.4 words in length to 28.8 words, with an average of 24.8 words. Ann's draft was longer when she used speech recognition software by an average of 99.5 words. Effective treatment replication showed that Ann's length was within the intervention ranges.

Beau

Writing fluency (wcpm). As seen in Figure 1, Beau had a clear bifurcation of the data with a higher fluency rate using speech recognition over word processing. Further examination of the graph shows no overlapping data between the two treatments, and an upward trend in the data is present under the speech recognition treatment.

In the speech recognition treatment, writing fluency ranged from 23.5 wcpm to 35.0 wcpm, with an average of $27.8 \mathrm{wcpm}$ as compared to the word processing treatment range of 3.2 wcpm to 8.1 wcpm, with a mean of 6.0 wcpm. For Beau speech recognition improved his writing fluency an average of 21.8 wcpm. During effective treatment replication, similar high writing fluency rates were found, with the final session being the highest. 
Accuracy and word error type. As seen in Figure 2, Beau had a higher accuracy rate under the word processing treatment. One hundred percent of the sessions were higher for accuracy under the word processing treatment. In the word processing treatment, accuracy ranged from $81.3 \%$ to $94.1 \%$ over the five sessions with a mean of 88.0\%. In the speech recognition treatment, his accuracy ranged from $62.9 \%$ to $80.6 \%$, with an average of $74.2 \%$. Accuracy was better when using word processing by an average of $13.8 \%$. The effective treatment replication of speech recognition for accuracy showed that it was in the same range as the intervention data (72.5\% and $72.3 \%)$, with the replication being $1.8 \%$ lower than intervention.

Beau's error rate was $25.8 \%$ for speech recognition. As seen in Table 3, for speech recognition, $18.3 \%$ of his draft consisted of incorrect word errors. The incorrect word error category had the highest percentage of errors across all error types. The second highest category of errors was additional unintended words at 5.2\%. The other error types, omissions and command errors, were both at $1.1 \%$.

The percentage of each type of error was also calculated (in which errors add up to $100 \%)$. Types of errors were calculated across the five word processing sessions, and Beau had a total of $57.1 \%$ spelling/keyboarding errors, 38.1\% keypress errors, and $4.8 \%$ substituted incorrect words. Keypress errors were made often by holding a key down and getting a repeated key error. When calculating types of word errors across the five speech recognition sessions, Beau had 71.1\% substituted incorrect word(s) errors, 20.0\% additional unintended word errors, 4.4\% omission errors, and 4.4\% command errors. In the effective treatment replication phase, using speech recognition, Beau’s word error types were similar to those in the intervention phase. 
Recall of intended meaning. Beau was able to recall immediately the intended meaning using word processing $95.2 \%$ of the time, and could not recall the intended meaning at all $4.8 \%$ of the time. Using speech recognition, Beau was able to recall $63.3 \%$ of the errors immediately, $10.0 \%$ of the errors with a delay, $15.6 \%$ of the errors differently, and was not able to recall $11.1 \%$ of the errors correctly or at all. During the effective treatment replication, Beau was able to recall intended meaning about the same as in the intervention phase.

Length. As seen in Figure 3, Beau clearly wrote more words in his draft under the speech recognition condition than in the word processing condition. There is a clear bifurcation of the data. In the speech recognition sessions, the length of his drafts ranged from 91.2 words to 135.0 words, with an average of 113.4 words. In the word processing sessions, length ranged from 15.2 words to 32.0 words, with an average of 22.8 words over the five word processing sessions. Beau's draft was longer by an average of 90.6 words when he used speech recognition software. His treatment replication phase showed longer drafts than the intervention phase.

Cady

Writing fluency (wcpm). As seen in Figure 1, there was clear bifurcation of Cady’s data when comparing word processing sessions to speech recognition sessions, with speech recognition having higher writing fluency. There was no overlap of the data throughout the 10 sessions for writing fluency.

In the five speech recognition sessions, Cady’s writing fluency ranged from 31.4 wcpm in session 2 (first speech recognition session) to 42.6 wcpm in session 10 (last speech recognition session), for an average of 37.1 wcpm. Her writing fluency improved 
every session. In the five word processing sessions, Cady's writing fluency ranged from 13.1 wcpm in the first session to 21.0 wcpm in session four (third word processing session), with a mean of 18.0 wcpm. The results for Cady indicated that her writing fluency was higher when using speech recognition software than when writing with word processing by an average of $19.1 \mathrm{wcpm}$. Effective treatment replication showed that writing fluency was within the same range of the speech recognition intervention data.

Accuracy and word error type. As seen in Figure 2, there was clear bifurcation of the data, showing that Cady's accuracy was higher when she used word processing compared to speech recognition. Cady's accuracy with word processing was 91.3\%. Her accuracy in the speech recognition treatment decreased every session, ranging from $83.2 \%$ in session 2 to $74.0 \%$ in session 10 , with an average of $79.9 \%$. Accuracy was better when using word processing by an average of $11.4 \%$. In the effective treatment replication phase, Cady's speech recognition accuracy improved to $86.5 \%$.

Cady's error rate was $20.1 \%$ for speech recognition. As seen in Table 3, for speech recognition, $15.8 \%$ of her draft consisted of incorrect word errors. The incorrect word error category had the highest percentage of errors across all error types. The second highest category of errors was command errors at 1.8\%. Omissions errors accounted for $1.4 \%$ of the draft while additional unintended word errors accounted for $1.0 \%$ of the draft.

The percentage of each type of error was also calculated (in which errors add up to $100 \%$ ). For word processing, her accuracy ranged from $73.2 \%$ (session 1) to $98.4 \%$ ( $9^{\text {th }} /$ last word processing session). Spelling/keyboarding word errors accounted for $96.8 \%$ of all word processing errors. Of the total errors, only one of them was a substituted 
incorrect word (3.2\%). Throughout the speech recognition sessions, $78.6 \%$ of the errors were substituted incorrect word(s). Additional unintended words accounted for $5.1 \%$ of all errors. Omissions were 7.1\%, and command errors were 9.2\%. Effective treatment replication showed that her accuracy was higher during replication than in intervention.

Recall of intended meaning. When recalling intended meaning with word processing, Cady was able to recall 100\% of the errors with immediate recall. With speech recognition, Cady was able to recall $75 \%$ of the errors immediately, $11 \%$ with delayed recall, $5 \%$ differently, and was not able to recall $9 \%$ of the errors correctly or at all.

Length. As seen in Figure 3, there is clear bifurcation of the data for length, and drafts were longer when Cady used speech recognition. Using speech recognition, her length ranged from 112.4 words to 178.0 words, with an average of 142.1 words. When using word processing, her mean length was 62.4 words, with a range from 58.6 to 70.2 words. Her drafts were longer when using speech recognition software by an average of 79.7 words. Effective treatment replication showed that length was within the same range as in intervention.

Dana

Dana wrote a total of 20 sessions, with two additional replication sessions. It was necessary to continue beyond 10 sessions because clear bifurcation of the wcpm data did not occur in the first 10 sessions.

Writing fluency (wcpm). As seen in Figure 1, by the end of the intervention, there was clear bifurcation of the data. Dana started off with a faster writing fluency rate when using word processing. During the course of the study, however, speech recognition 
became more effective for writing fluency than word processing. Overlap occurred in $10 \%$ of the sessions, and in $70 \%$ of the sessions, speech recognition writing fluency was higher than that of word processing, while $20 \%$ were lower.

In the speech recognition treatment, writing fluency ranged from 19.5 wcpm to 52.1 wcpm with an average of 36.6 wcpm, as compared to the word processing treatment of 23.1 wcpm to 30.4 wcpm, with a mean of 28.0 wcpm. For Dana speech recognition improved her writing fluency an average of 8.6 wcpm.

During effective treatment replication, similar high writing fluency rates of 37.9 wcpm and 40.3 wcpm, for an average of 39.1 wcpm, were found. When comparing the replication sessions with the intervention sessions, Dana's wcpm average was higher in the replication sessions by an average of $2.5 \mathrm{wcpm}$.

Accuracy and word error type. As seen in Figure 2, Dana had a slightly higher average accuracy rate under the word processing treatment. When using word processing, Dana’s accuracy ranged from $81.5 \%$ to $100 \%$, with an average of $96.3 \%$. When using speech recognition, Dana’s accuracy ranged from $82.5 \%$ to $98.0 \%$, with an average of 92.5\%. Accuracy was better in the word processing treatment by an average of $3.8 \%$. Throughout the intervention phase, Dana was the only student who persisted in correcting errors as she typed. Beginning in session 17, she decreased doing this, which resulted in a decrease in accuracy for word processing. Prior to Session 17, four probes were taken on the number of words on which she was making self corrections. She was self correcting an average of $13.4 \%$ with a range of $10.5 \%$ to $15.9 \%$. Although the researcher continually attempted to have her stop correcting her work for consistency in the study and reminded her before every session not to correct, as verified by the procedural 
integrity checklist, Dana persisted, and it was not until session 17 that she decreased the self corrections. Data on the number of words she corrected were taken every session after that point. After session 17, she decreased her self corrections to an average of $5.9 \%$, with a range of $3.2 \%$ to $8.4 \%$.

Dana's error rate was 7.5\% for speech recognition. As seen in Table 3, for speech recognition, $5.8 \%$ of her draft consisted of additional unintended word errors. The additional unintended word error category had the highest percentage of errors across all error types. The second highest category of errors was incorrect word errors at $5.5 \%$. The other error types, omissions and command errors, were at $1.0 \%$ and $0.3 \%$, respectively.

In addition to examining the percentage of errors occurring in the draft, the percentage of each type of error was also calculated (in which errors add up to 100\%). Across the 10 word processing sessions, Dana had no keypress errors and no substituted incorrect word errors. Therefore, $100 \%$ of her errors were spelling or keyboarding errors. When calculating types of word errors in the speech recognition treatment, out of all of the errors, Dana had 73.8\% substituted incorrect word(s) errors, 7.7\% additional unintended word errors, $13.8 \%$ omission errors, and $4.6 \%$ command errors. In the replication phase, Dana's accuracy was $95.1 \%$ and $90.7 \%$, for an average of $92.9 \%$. This was within the range of her accuracy during the alternating treatments but was higher in the replication session by an average of $4.0 \%$.

Recall of intended meaning. In terms of recall of intended meaning for word processing, Dana was able to recall immediately intended meaning $96.7 \%$ of the time. The one time she could not recall it immediately (3.3\%), she stumbled over the re-read and therefore had delayed recall. There were no instances where she recalled her word 
processing draft differently, incorrectly, or not at all. For recall of intended meaning for speech recognition, Dana was able to recall $86.2 \%$ of the errors immediately, $6.2 \%$ of the errors with delayed recall, $1.5 \%$ of the errors differently, and was not able to recall $6.2 \%$ of the errors at all.

During effective treatment replication, Dana was able to recall 12 out of the 16 errors with immediate recall (75\%), 3 with delayed recall (18.8\%), 1 differently (6.3\%), and had no instances of not being able to recall the error correctly or at all (0\%). When recalling intended meaning, Dana was able to recall $11.2 \%$ more errors immediately in the speech recognition intervention sessions, $12.6 \%$ more errors with delayed recall in the replication sessions, $4.8 \%$ more errors differently in the replication sessions, and $6.2 \%$ more no or incorrect recall in the speech recognition intervention sessions.

Length. As seen in Figure 3, as with writing fluency, Dana started out writing more words in her draft with word processing. The first two speech recognition sessions, Dana wrote less using speech recognition software. However, as the study progressed, there was a clear bifurcation of the data with Dana writing more using speech recognition than using word processing starting with session 7, she wrote faster using speech recognition. Starting with session 10, her length increased to 129.6 words, and she started writing over 100 words consistently using speech recognition. Over the 10 speech recognition sessions, length ranged from 66.4 words to 169.4 words, with a mean of 145.4 words. Over the 10 word processing sessions, length ranged from 77.4 words to 93.4 words, with an average of 88.2 words. During effective treatment replication using speech recognition, her length was 119.4 words, and 134.8 words, for an average of 127.1 
words. Therefore, her length was higher in the intervention sessions by an average of 18.3 words.

Emma

Writing fluency (wcpm). As seen in Figure 1, there was clear bifurcation of the data, and writing fluency was higher for speech recognition. Please note the scale change in Emma’s graph due to her high writing fluency. There was no overlap across treatments. Across the five speech recognition sessions, Emma's writing fluency ranged from 104.5 wcpm to 132.1 wcpm, with a mean of 112.7 wcpm. Emma had the highest writing fluency of all of the participants. Emma's writing fluency in the five word processing sessions ranged from 42.6 wcpm to 53.1 wcpm, with an average of 48.0 wcpm. Overall, the results for Emma indicated that her writing fluency dictating with speech recognition was significantly higher than typing with word processing, with a 64.7 wcpm difference between the independent variables. Effective treatment replication showed that Emma's writing fluency was within the same range as in intervention.

Accuracy and word error type. As seen in Figure 2, there was clear bifurcation of the data, and accuracy for word processing was higher than for speech recognition. Emma’s accuracy with word processing ranged from $92.6 \%$ to $95.5 \%$ with a mean of 93.8\%. Emma’s accuracy using speech recognition was very consistent, ranging from $88.2 \%$ to $89.6 \%$, with an average of $88.3 \%$. Her accuracy was lower when using speech recognition, by 5.5\% when compared to word processing. Effective treatment replication showed that Emma’s accuracy was within the same range as in intervention.

Emma’s error rate was $11.7 \%$ for speech recognition. As seen in Table 3, for speech recognition, 9.6\% of her draft consisted of incorrect word errors. The incorrect 
word error category had the highest percentage of errors across all error types. The second highest category of errors was additional unintended words at $1.5 \%$. The other error types, omissions and command errors, were $0.6 \%$ and $0.1 \%$ respectively

In addition to examining the percentage of errors occurring in the draft, the percentage of each type of error was also calculated (in which errors add up to 100\%).Out of all of Emma's word errors in word processing, 100\% of them were spelling/ keyboarding errors. When analyzing errors across all five speech recognition sessions, $81.7 \%$ of them were substituted incorrect word(s), $12.8 \%$ were additional unintended words (12.8\%), 4.9\% were omissions, and $0.6 \%$ were command errors.

Recall of intended meaning. Emma was able to recognize 100\% of the word errors in word processing with immediate recall. When using speech recognition, Emma was able to recall $72.4 \%$ of the errors immediately, $8.6 \%$ with delayed recall, $8.6 \%$ differently than dictated, and was not able to recall $10.4 \%$ correctly or at all.

Length. As seen in Figure 3, there was clear bifurcation of the data, and length was higher for speech recognition. Again, note the scale change in Emma's graph due to her high length. The length of the drafts written with speech recognition ranged from 359.6 words to 444.0 words, with an average of 380.9 words. The length of her draft using word processing ranged from 139.4 words to 170.6 words, with an average of 155.0 words. Length was higher for speech recognition, by 225.9 words compared to word processing.

IOR and Procedural Fidelity

Inter-observer reliability was calculated in $20 \%$ of all word processing and speech recognition sessions for each participant. IOR was calculated for fluency, accuracy, and 
length. In addition, the second observer compared the word error lists to the writing samples in order to verify that all errors had been recorded. The results of the IOR indicate an agreement range of $98.7 \%$ to $100 \%$ for fluency, accuracy, and length.

In addition to IOR, the Procedural Fidelity Checklist was filled out by the researcher in $100 \%$ of the sessions. In $20 \%$ of the sessions, a second observer checked to ensure that the researcher was following the checklist. The results indicated that the researcher followed all steps of the Procedural Fidelity Checklist 93\% of the time. In 7\% of the sessions, although all of the steps were followed, they were either followed out of order for various reasons, or there was a brief delay during the session due to a classroom interruption, announcements, class change, or other uncontrollable school-related event. Additionally, the second observer was in agreement with the researcher on the checklist $100 \%$ of the time.

\section{Social Validity}

A social validity survey was given to each participant upon completion of the second replication session. The survey was in the form of a questionnaire and included multiple choice items with a Likert scale as well as open-ended items. Additionally, each participant was given the opportunity to complete one final writing prompt that stated, “Think about your experiences using speech recognition software. Let me know what you thought about using it, what you liked about it, what you didn't like about it, if you thought it was easy or hard, if you think you'll use it again, how you felt about the training, how you felt about making corrections, and if you'd recommend it to others. Write a paragraph (or more if you'd like) about your experiences using speech recognition software.” 
Results of the social validity information, displayed in Table 4, indicated that all students liked using speech recognition software and agreed that speech recognition helped them produce their work faster. In terms of accuracy of work, four of the students indicated that when compared to word processing, their work had fewer errors when they used speech recognition, and one student said that the work had the same amount of errors.

Four of the students indicated that speech recognition training was very easy or easy. One student indicated that it was hard. All students agreed that speech recognition recognized most of what they said. They all agreed that making corrections was easy and only took a little time. In terms of frustration, four of the participants indicated that speech recognition was not frustrating, while one student indicated that it was a little frustrating to use.

In comparison to speech recognition, when asked about using word processing, four students indicated that they liked using it, while one indicated a strong dislike of using it. Three students indicated that word processing was not frustrating to use, one student indicated that it was a little frustrating, and one student indicated that it was very frustrating to use. Three students indicated that they were not tired after using word processing, while two indicated that they were a little tired after using it. Four of the participants found word processing easy to use while one found it very hard to use.

When asked which software the students preferred to use when writing a draft, one student reported a preference for Microsoft Word, two students said they preferred Dragon NaturallySpeaking, and three students indicated that they preferred to use both. When asked which program they thought they would use in the future, one student 
Table 4

Social Validity Questionnaire Frequency Count

Frequency

1. It is important for me to produce my work fast.

Strongly

Agree

$\begin{array}{cccc}\text { Agree } & \text { Indiff } & \text { Disagree } & \begin{array}{c}\text { Strongly } \\ \text { Disagree }\end{array} \\ 4 & 0 & 0 & 0\end{array}$

1

4

0

2. It is important for my work to be accurate (without errors).

Strongly

Agree Indiff

Disagree Agree 3

2

0

0

Strongly

Disagree

3. Using Dragon NaturallySpeaking, I produce my work

$\begin{array}{ccccc}\begin{array}{c}\text { A lot } \\ \text { faster }\end{array} & \begin{array}{c}\text { A little } \\ \text { faster }\end{array} & \begin{array}{c}\text { Same } \\ \text { rate }\end{array} & \begin{array}{c}\text { A little } \\ \text { slower }\end{array} & \begin{array}{c}\text { A lot } \\ \text { slower }\end{array} \\ 3 & 2 & 0 & 0 & 0\end{array}$

4. Using Dragon

A lot A few Same A few A lot NaturallySpeaking, my work less err less err amt err more er more err has

3

1

1

0

0

5. Which statement best describes how you feel about using speech recognition software?

$\begin{array}{ccccc}\begin{array}{c}\text { Really } \\ \text { Like }\end{array} & \text { Like } & \text { Indiff } & \text { Dislike } & \begin{array}{c}\text { Really } \\ \text { Dislike } \\ 3\end{array} \\ 2 & 0 & 0 & 0\end{array}$

6. Training Dragon NaturallySpeaking to recognize my voice was

$\begin{array}{cccc}\text { Very easy } & \text { Easy } & \text { Hard } & \begin{array}{c}\text { Very } \\ \text { Hard }\end{array} \\ 1 & 3 & 1 & 0\end{array}$

7. Dragon NaturallySpeaking recognizes

\section{Every-thing I say}

Very easy

Dragon NaturallySpeaking was

9. Making corrections on Dragon NaturallySpeaking took

10. Using speech recognition software is
0

3

\section{Most of what I say}

5
Easy
2
Not much time 1

Very easy 2

Really not
Not much of what I say 0

Hard
0 None of what I say

0 
11. Using speech recognition can be

12. When writing, I will continue using Dragon NaturallySpeaking

13. Using Microsoft Word is

14. Which statement best describes how you feel about using Microsoft Word?

15. Using Microsoft Word can be

16. When using word processing, by the end of the writing session, I am

17. Which do you prefer to use when writing a draft? $\begin{array}{cccc}\text { frustrating } & \text { frustrating } & \text { frustrating } & \text { frustrating } \\ 1 & 3 & 1 & 0\end{array}$

$\begin{array}{cccc}\text { Always } & \text { Some } & \begin{array}{c}\text { Not very } \\ \text { often }\end{array} & \text { Never } \\ 1 & 3 & 1 & 0\end{array}$

$\begin{array}{cccc}\text { Very easy } & \text { Easy } & \text { Hard } & \text { Very hard } \\ 2 & 2 & 0 & 1\end{array}$

$\begin{array}{ccccc}\begin{array}{c}\text { Really } \\ \text { Like }\end{array} & \text { Like } & \text { Indiff } & \text { Dislike } & \begin{array}{c}\text { Really } \\ \text { Dislike }\end{array} \\ 0 & 4 & 0 & 0 & 1\end{array}$

$\begin{array}{cccc}\begin{array}{c}\text { Really not } \\ \text { frustrating } \\ 1\end{array} & \begin{array}{c}\text { Not } \\ \text { frustrating }\end{array} & \begin{array}{c}\text { A little } \\ \text { frustrating }\end{array} & \begin{array}{c}\text { Very } \\ \text { frustrating }\end{array} \\ \begin{array}{c}\text { Really not } \\ \text { tired }\end{array} & \text { Not tired } & 1 & 1 \\ 1 & 2 & \begin{array}{c}\text { A little } \\ \text { tired }\end{array} & \text { Very Tired } \\ & 2 & 2 & 0\end{array}$

Microsoft Word Dragon

Both NaturallySpeaking

1

2

2

$\begin{array}{ccc}\text { Microsoft Word } & \begin{array}{c}\text { Dragon } \\ \text { Naturally- } \\ \text { Speaking }\end{array} & \text { Both } \\ 1 & 3 & 1\end{array}$

Ann- When using speech recognition don't get frustrated. I really liked working with word processing and speech recognition software.

Cady - Fun to make up topics.

Dana- Speech recognition software will make work a lot easier. I would use speech recognition because I would complete my work quicker and I would have more time to hang out.

Emma- It certainly is faster than typing as long as you make an effort to speak clearly and not get frustrated. 
indicated Microsoft Word, three indicated Dragon NaturallySpeaking, and one indicated both.

Responses to the open-ended question asking for comments included that speech recognition made work a lot easier, and is not frustrating. One student indicated that "It certainly is faster than typing as long as you make an effort to speak clearly and not get frustrated.” Another student wrote, “I would use speech recognition because I would complete my work quicker and I would have more time to hang out.”

In terms of the final writing prompt, out of the five participants, only three participants were able to complete the writing task. Beau was not able to complete the final writing prompt due to a conflict in his academic schedule. Emma was not able to complete the writing prompt due to an absence because of a college visit. Ann, Cady, and Dana, however, were able to complete the final writing prompt.

Ann chose to type her final writing prompt using Microsoft Word. She stated that “My experience with speech recognition was really great. It taught me a whole lot. It kept on making a lot of mistakes. I felt really good about the training. I would recommend it to other students in this school. It made me feel really good about myself.”

Cady chose to handwrite her final writing prompt. She stated, “I thought using speech recognition was fun for the most part. I liked watching what I said come up on the screen. One thing I didn't like was sometimes it took a while for it to put the word I am really saying on to the screen. Using speech recognition was easy. The training is fun. Making corrections was one of the best parts. I would recommend using this program to others to make word easier and faster.” 
Dana responded that speech recognition helped her complete work quickly. She stated, "Since the first session of [speech recognition] training [the software has been] able to recognize what I'm saying and my writing is legible.” She indicated that things that were frustrating included that it would say something that it shouldn't and pick up things that other people said and spell things incorrectly. She also stated that assignments did not take as much time as they did with Microsoft Word. Finally, she concluded with the statement, "I would recommend speech recognition to anybody who can't use their hands because of cerebral palsy spinal muscular atrophy, or other physical handicaps. The only drawback to speech recognition is that people who can't talk will not be able to use it.”

\section{Discussion}

Because some physical disabilities can affect writing severely, it is necessary to find ways to increase writing efficiency. The researcher, therefore, set out to determine if the use of speech recognition software could increase the writing fluency of individuals with physical disabilities when writing a draft of a paper. This study asked five research questions. They were:

1. To what extent does the use of speech recognition software affect the fluency rate as compared to word processing for individuals with physical disabilities in writing a first draft of a paper?

2. To what extent does the use of speech recognition software affect the writing accuracy rate compared to word processing for individuals with physical disabilities? 
3. To what extent does the use of speech recognition software affect the production of different types of errors compared to errors produced using word processing?

4. To what extent does the use of speech recognition software affect the students' ability to recall the intended meaning when they begin to identify the errors in their first draft as compared to word processing? and

5. To what extent does the use of speech recognition software affect the length of the draft compared to word processing?

The writing fluency data from this study supported the use of speech recognition software for draft writing of individuals with physical disabilities. The data also demonstrated that when using speech recognition compared to word processing, individuals with physical disabilities wrote longer drafts. Accuracy, in terms of percent correct, however, was lower for all participants when using speech recognition when compared to word processing. Other factors, such as types of word errors and the participants' abilities to recall what they intended to write, despite the errors, were important analyses that were made in order to determine whether or not speech recognition software can help individuals with physical disabilities to write. Fluency

In the area of writing fluency, speech recognition was clearly faster than word processing for all participants. All participants started with higher fluency using speech recognition, and it remained higher than word processing throughout all sessions except for Dana, who started lower with speech recognition but then surpassed her word processing fluency. 
When examining the increase in fluency between word processing and speech recognition, the slower typists were able to increase their speech recognition writing fluency over four times their word processing fluency. Cady and Emma doubled their writing fluency using speech recognition. It is important to note that Emma was the fastest typist and was able to go from 48.0 wcpm to 112.7 wcpm using speech recognition. Although Dana's mean speech recognition writing fluency was 36.6 wcpm, which is aligned with Ann, Beau, and Cady, who ranged from 27.8 wcpm to 37.1 wcpm mean speech recognition fluency, Dana did not have as much of an increase in writing fluency using speech recognition software. Part of this may be due to the fact that she dictated much slower using speech recognition in the first several sessions.

Dictation patterns. Another aspect of fluency relates to dictation patterns of participants. Although the vast majority of the students were dictating in phrases, Dana began the study dictating one word at a time. As she gained more experience with the software through the course of the study, she began dictating in short phrases and sentences. This resulted in her fluency rate consistently being faster than word processing starting at Session 10.

Dictation patterns were also influenced by students who looked at the screen. All participants, with the exception of Emma, looked at the screen as their dictated words appeared, thus monitoring what was written as they dictated. Upon observation, these students spoke in a choppier pattern, pausing to look at the screen, waiting for the words to appear on the screen. Conversely, Emma specifically stated that she did not want to look at the screen in order to avoid becoming distracted by the recognition errors. This may have allowed Emma to speak at a more rapid rate, since she did not wait for the 
words to appear on the screen like the other participants. In speech recognition software, it is not unusual for there to be a delay for the words to appear on the screen. However, the user does not need to wait for the words to appear on the screen before continuing to dictate because the program will eventually catch up. This tendency for four of the students to pause while waiting for the program to catch up may have influenced the fluency rate. It is possible that with more experience using the program and not looking at the screen that their dictation patterns could become more rapid, resulting in an even faster fluency rate than they showed in the study.

It is important to note that during the pre-intervention speech recognition training, all students were taught and were required to practice proper dictation strategies. However, because they did not have any interaction with the software prior to the study, with the exception of the tutorial, watching the words appear on the screen while they were dictating was a new experience and could have been distracting to them, thus impacting their overall fluency. Future training could include practice sessions with the researcher coaching the participants on how to maximize their dictation to achieve higher levels of fluency.

When examining if the fluency rate increased across the study, two of the five participants showed some increase in fluency using speech recognition. For Dana this increase may be attributed to the change in her dictation pattern. This possible conclusion is strengthened by the fact that her error rate stayed fairly constant, hence the increase in fluency was not due to a decrease in errors. It should also be noted that she had twice as many sessions, giving her the opportunity to show an increase in fluency across the sessions. Beau also showed some modest increases in fluency when using speech 
recognition software, which is not attributed to a reduction in errors. The other students did not demonstrate an increase in fluency from the beginning to the end of the study, especially when including the replication phase. It is possible if the other students had ten sessions instead of five using speech recognition software that further gains may have been seen in fluency. However, that cannot be ascertained in this study.

It is clear that speech recognition software provided a faster means of input for draft writing for the participants in this study. In the social validity questionnaire, all participants thought they produced work faster using speech recognition, and they were correct. Therefore, for individuals with physical disabilities who often have much lower typing rates than individuals without disabilities, speech recognition was shown, in this study, to improve fluency rates that greatly improved their rate of input. Accuracy and Word Errors

In contrast to writing fluency, the accuracy of the drafts for all participants was higher when using word processing. Speech recognition accuracy ranged across students from the $62.9 \%$ (Beau) to $98.0 \%$ (Dana). When looking at speech recognition errors, almost one-fourth of the words for three participants were errors $(27.4 \%, 25.8 \%$, and 20.1\%). Dana had the fewest errors at 7.5\%, followed by Emma with 11.7\%. The higher error rates in speech recognition primarily consisted of incorrect words for all participants except Dana, whose error rate was slightly higher for additional unintended words. The second highest error type for three of the participants was additional words, in which the program may have picked an extraneous sound (e.g., sigh, environmental sound) and typed a word. In Cady’s and Dana’s case, the second highest error type was command errors and incorrect words respectively. These speech recognition error rates are in 
contrast to very low error rates using word processing by four of the participants (ranging from $3.7 \%$ to $8.7 \%$ ) in which the errors were almost exclusively spelling/keyboarding errors. The exception was Beau, who in addition to having spelling/keyboarding errors also had keypress errors where he held down a key, getting a repeated key error. His error rate was $12.0 \%$ with word processing.

The high error rate when using speech recognition may be attributed partially to the quality of the students' dictation and voice quality. Some students spoke more clearly than others, and although they practiced dictation prior to intervention, some could have possibly benefited from more practice. When training speech recognition software, all participants created their voice files by reading two passages. For some participants, such as Ann and Beau, training was difficult. Ann's voice had a nasal quality to it, and she had to dictate one word at a time in the first few paragraphs of the first training passage before the software sufficiently recognized her voice. Also, she tended to breathe heavily into the microphone, creating additional unintended words in some instances. During training and intervention, Beau was only able to dictate a few words at a time due to breath issues. As he dictated, his voice tapered off toward the end of the phrase that he was saying. These qualities of his voice are related to his disability, Muscular Dystrophy. In future studies, if accuracy is low, the individual should consider conducting additional training by reading more training passages.

The MDVP (Kay Elemetrics) recording analyses indicated that voice quality for all students was abnormal. It is felt that the abnormality was due to the recording environment (public school with normal background noise) and the recording device (which was thought to be insufficient). Instead of concluding that there was a generalized 
abnormality in all students' voices, it is more likely that the researcher was unable to obtain a true measure of voice quality due to the background noise and the recording device. With this said, however, the analysis did indicate abnormalities for all participants in the area of vAM, which is a measure of amplitude variation. Cady's voice measured abnormal in most areas.

Corrections. With speech recognition software, recognition accuracy can improve as individuals use the program more. Dana’s accuracy, in the first two speech recognition sessions, was $82.5 \%$ and $83.1 \%$. After that time, the rest of her accuracy was $90 \%$ and higher. The other students' accuracy did not show an increase, possibly due to the fewer sessions these students had using speech recognition.

In order for the speech recognition program to improve its accuracy with an individual student, the student needs to correct the errors so the software can learn the student's voice. In order to accomplish this, after dictating their passages using voice commands, students corrected their errors. Between sessions, participants were required, with the help of the researcher, to make corrections to their drafts using voice commands. The reason that this was required was because as long as the user makes corrections with voice commands, the mistakes are updated and the program learns what the user meant to say and therefore correctly updates the voice files. For some, making the corrections was extremely difficult because the program put another error in the document instead of recognizing the student's correction command. When the program did not recognize the student's voice correctly when making corrections, the student was unable to correct with voice commands. If corrections are not made with voice commands, the program may continue making the same errors until the user teaches it otherwise. Participants who 
experienced some difficulty making corrections included Ann, Beau, and Cady. In two of the speech recognition sessions, Ann was not able to use voice commands to edit some of the errors in the draft because the program was not able to recognize her correction commands. Therefore, her voice files were not completely updated in those two sessions. Dana and Emma did not experience any difficulty or frustration making corrections. By the end of the study, Dana needed minimal assistance from the researcher to make corrections. Emma made corrections without the assistance from the researcher.

Types of errors. In addition to accuracy, data also were collected on the different types of word errors that participants made. When using speech recognition software, all participants had fewer additional unintended words (usually due to sounds the student made, which additional training could help with), omissions, and command errors. Four out of five participants made the highest percentage of substituted incorrect words or phrases (word or phrase replacements). These errors could occur for different reasons. The program could have misrecognized the participant’s speech (recognition error) or the participant could have dictated a word or phrase unclearly so the program could not accurately recognize it. One step that could be taken in the future to prevent these issues with substituted incorrect word(s) or phrases would be to train specific words that the speech recognition program consistently misrecognizes (for example, the program substituting the word “theory” for the command "period”, in Cady’s case). Something else that could be done differently in the future is to expand the specific vocabulary within the speech recognition system to improve recognition of specific groups of words. 


\section{Errors and Recall of Intended Meaning}

When writing a draft, errors are often acceptable (Honeycutt, 2003; Kellogg, 1996). However, when writing the final product, the student needs to be able to correct these errors accurately and efficiently. Part of the editing process includes being able to recall the intended meaning of the error. This study examined whether or not the participants could recover from the errors that they made by remembering what they intended to write. Data were taken on whether the students could recall the intended meaning of their errors immediately, recall their errors with a delay, recall the errors differently than they originally wrote them, or could not recall the error at all. Recalling errors immediately is ideal. Recalling errors with a delay could affect efficiency of writing because the writers would have to pause to remember what they meant to say before correcting the error and proceeding with the writing. Recalling errors differently or not at all would affect the accuracy of the writing, in terms of whether or not the final product represented what the writer truly was trying to say.

In word processing, the students were able to recall their errors immediately for the most part. This possibly may be due to the fact that they had fewer errors and the errors they made resembled the words they were trying to type. However, using speech recognition, the students encountered more difficulty. When breaking down recall into the percentage of errors based on all words written in speech recognition (see Table 3) two participants had issues with recalling errors efficiently and a high percentage of recalling errors accurately. For example, out of all of the words written, Ann had efficiency issues in $3.7 \%$ of the words, recalling them with a delay. However, in $12.3 \%$ of the words, Ann had accuracy issues and was not able to recall what she typed correctly or 
at all. In the effective treatment replication, Ann could not recall $23.1 \%$ of the words in the document accurately. Ann had a mild intellectual disability, which may have impacted her ability to recall her writing effectively. In Beau’s case, he had efficiency issues in $2.6 \%$ of the words and accuracy issues in $6.9 \%$ of the words. Beau's difficulty with recall could be attributed, in some cases, to what he was writing and how the speech recognition software interpreted it. For example, in the second speech recognition session, the incorrect word(s) errors that were made were very different than what Beau dictated. For example, in the second speech recognition session, Beau dictated "go outside with friends” and the speech recognition software wrote “OSI with reference.” In this case, Beau could not recall the error at all. Similar errors occurred in other speech recognition sessions as well. In addition, Cady's efficiency was similar to Ann’s and Beau's, given that she had a delay in recall in $2.2 \%$ of the total number of words. Length

Aside from higher rates of fluency, the findings of this study also indicated that all participants increased the length of their drafts when using speech recognition software compared to word processing. There was a considerable difference between the lengths of the drafts using word processing and speech recognition. With speech recognition, on average, Emma wrote 225.9 more words in the three minutes than with word processing, Ann wrote 98.6 more words, Beau wrote 90.6 more words, Cady wrote 79.7 more words, and Dana wrote 57.2 more words. Obviously when individuals are able to input their writing faster, the length of their writing will be longer. 


\section{Student Preference}

The social validity questionnaire that all students took after intervention and effective treatment replication included items about the participants' perceptions of their accuracy when using speech recognition and word processing. Surprisingly, all of the participants except Dana thought their work had fewer errors when using speech recognition. Dana thought her work had the same amount of errors. Dana's perception of accuracy between the two programs was not too far off, because she had 94\% accuracy with word processing and 92.5\% with speech recognition. Everyone else, however, was disillusioned. When asked how much speech recognition recognized what they dictated, all participants responded that speech recognition recognized most of what they said. They all also felt that making corrections was easy and did not take too much time.

Although their accuracy was lower when using speech recognition, the participants indicated that they felt that they made fewer errors when using speech recognition compared to word processing. One reason for this may be that when writing with word processing, the participants may have felt that they were responsible for the errors because they physically made the mistakes when typing. However, with speech recognition, they may have blamed the production of errors on the speech recognition software instead of on themselves. The participants also indicated that they thought that making corrections was easy with speech recognition. By the end of the study, Emma was able to make her corrections without the researcher directing her how (although the researcher observed her correction making process and stood by in case guidance was needed). After the study was over, Dana used speech recognition software to provide the researcher with some feedback and made her own corrections. Interestingly, she made the 
corrections as she dictated instead of waiting until finished with the draft and going back to edit (like in the study). Ann, Beau, and Cady were not able by the end of the study to independently make corrections. They still needed the researcher's guidance on correctly making corrections.

More information from the social validity questionnaire indicated that all participants indicated that they liked or really liked using speech recognition. Four out of the five participants indicated that they liked using word processing. However, Beau indicated that he really disliked using word processing and that it was hard to use. When asked which programs they preferred when writing, Cady indicated that she preferred word processing when writing, Beau and Dana preferred speech recognition, and Emma and Ann indicated that they preferred both. Beau stated that for future writing, he would always use speech recognition for writing, whereas three other participants said they may use it some. Cady indicated that she would not use speech recognition very often. These responses make sense given that Beau's other options for writing are somewhat limited (handwriting is slow, word processing is slow), Dana was very motivated by using speech recognition, and Ann enjoyed using it. Emma is still able to handwrite and type at acceptable speeds, but as her disabilities progress, this may change, and speech recognition may be a good future option for her.

Emma indicated that she would use word processing for writing in the future, Cady said that she would use both word processing and speech recognition, surprisingly, because earlier she said that she did not think she would use speech recognition very often. Ann, Beau, and Dana indicated that they would like to use speech recognition for future writing. 
Interestingly, Dana was the only participant who chose to dictate her response using speech recognition software. In one item of the social validity questionnaire, Ann stated that she preferred both word processing and speech recognition when writing a draft. Cady responded that she preferred word processing when writing a draft, and Dana stated that she preferred speech recognition. When asked which program they would use in the future for writing, however, Ann and Dana both stated speech recognition, while Cady stated that she would use both. However, when given the opportunity, Ann typed her draft, and Cady handwrote hers.

\section{Current and Future Considerations}

The data from this study raise some valid concerns when promoting the use of speech recognition software for individuals with physical disabilities. For example, increased fluency at the expense of making numerous errors can be problematic. If speech recognition users have to spend a large amount of time editing their drafts due to numerous recognition errors and low accuracy rates, other means of inputting their drafts may need to be considered. So the question becomes, in light of the high error rate for some participants, is speech recognition software worth using? Because this study cannot answer that question, it becomes obvious that there is a need for future research to determine efficiency when writing a final draft of a paper using speech recognition.

When analyzing and discussing the results of this study, generalized comments that indicate that speech recognition is effective for students with physical disabilities cannot be made. Although all participants' writing fluency was much higher using speech recognition compared to word processing, accuracy was lower for all participants. It was considerably lower in some cases. Future studies are needed that will consider the impact 
of low accuracy on students' writing and that will help determine whether or not speech recognition is truly more efficient when error correction time is considered.

This study did not take into consideration the time it took participants to correct the mistakes when using speech recognition. Future studies should address correction time, because it is important to determine whether or not speech recognition writing fluency is actually higher when the error rate is high and students have to spend additional time correcting the mistakes. Longitudinal studies could be beneficial in determining whether or not recognition accuracy improves as the speech recognition learns the user's voice and develops more extensive voice files. Future studies should also consider issues of multimodal correcting. If the user corrects errors using voice, keyboard, and/or the mouse, what impact would it have on both error correction time and recognition accuracy?

Training is another consideration. Future studies could incorporate additional training components, such as training select words and specific vocabulary. Future studies should be aimed at trying to determine a decision rule for when additional training is necessary. If future studies expand to include content area writing, training of specific content words would be necessary.

Another consideration that needs to be addressed further is that if the participants had been writing longer, would recalling the intended meaning have been more difficult? Writing longer passages could affect recall because there would be more time between when the students originally wrote the sentence and when they corrected it. Because most people write for more than three minutes at a time, this is an important future consideration. 
Another limitation lies in the fact that Dana corrected her draft as she typed using word processing, and therefore her data may not be comparable with other students. However, this brings good questions for the design of future studies. She wrote her draft as she typically did for her schoolwork, correcting her errors as she composed. Future studies may consider using the participant’s preferred manner of draft writing. Researchers also may want to consider incorporating an editing component to further determine whether or not speech recognition software is worth using for individuals with physical disabilities. Obviously, if the editing process takes too much time, it may not be worth it. However, for individuals who do not have hand functioning, despite the editing process, speech recognition may still be the best option.

Finally, as with most single subject designs, this study included a small number of participants. Further replications of this study need to be conducted to determine the effects of speech recognition across a greater number of students. Additionally, future studies that include individuals with more severe physical disabilities for whom handwriting is difficult or not an option need to be designed and implemented.

Although speech recognition software assisted individuals with physical disabilities to improve their writing fluency, the results should be used with caution because other variables, such as low accuracy rates, exist. Therefore, further research is needed to replicate and extendthis study and to examine some of the limitations of this study.

\section{Conclusions}

The data from this study lead to several conclusions. The use of speech recognition software possibly could be an effective tool for improving writing fluency for 
individuals with physical disabilities because it makes writing hands free, thus removing the physical act of writing. All participants had higher writing fluency when using speech recognition software compared to word processing. Some participants doubled, tripled, or quadrupled their writing rate when using speech recognition software compared to word processing. However, due to recognition accuracy issues, the speech recognition error rates in this study were much higher than when participants used word processing to write. Therefore, the fluency results should be used with caution and on an individualized basis in cases where participants experienced very low accuracy using speech recognition software. For students with high 80s to $90 \%$ accuracy, speech recognition could be a viable solution. However, for those with accuracy rates in the 60 to $70 \%$ range, other factors should weigh in on the decision of whether or not speech recognition could be an effective tool for writing for these individuals. More research is needed to determine whether or not the use of speech recognition is a viable solution for individuals with physical disabilities. 


\section{REFERENCES}

Alberto, P. A., \& Troutman, A. C. (2006). Applied behavior analysis for teachers $\left(7^{\text {th }}\right.$ ed.). Upper Saddle River, NJ: Pearson/Merrill Prentice Hall.

Bangert-Drowns, R. L. (1993). The word processor as an instructional tool: A metaanalysis of word processing in writing instruction. Review of Educational Research, 63(1), 69-93.

Barlow, D. H., \& Hayes, S. C. (1979). Alternating-treatments design: One strategy for comparing the effects of two treatments in a single subject. Journal of Applied Behavior Analysis, 12, 199-210.

Best, S. J., Heller, K. W., \& Bigge, J. L., (2005). Teaching individuals with physical or multiple disabilities (5th ed.). Upper Saddle River, NJ: Pearson/Merrill Prentice Hall.

Bourdin, B., \& Fayol, M. (2000). Is graphic activity cognitively costly? A developmental approach. Reading and Writing: An Interdisciplinary Journal, 13, 183-196.

Bruce, C., Edmundson, A., \& Coleman, M. (2003). Writing with voice: An investigation of the use of a voice recognition system as a writing aid for a man with aphasia. International Journal of Language \& Communication Disorders, 38(2), 131-148.

De La Paz, S. (1999). Composing via dictation and speech recognition systems: Compensatory technology for students with learning disabilities. Learning Disability Quarterly, 22, 173-182. 
De La Paz, S., \& Graham, S. (1997). Effects of dictation and advanced planning instruction on the composing of students with writing and learning problems. Journal of Educational Psychology, 89, 203-222.

Feng, J., Karat, C-M, \& Sears, A. (2005). How productivity improves in hands-free continuous dictation tasks: Lessons learned from a longitudinal study. Interacting with Computers, 17, 265-289.

Heller, K. W., \& Swinehart-Jones, D. (2003). Supporting the educational needs of students with orthopedic impairments. Physical Disabilities: Education and Related Services, 22(1), 3-24.

Hetzroni, O. E., \& Shrieber, B. (2004). Word processing as an assistive technology tool for enhancing academic outcomes of students with writing disabilities in the general classroom. Journal of Learning Disabilities, 37, 143-154.

Higgins, E. L., \& Raskind, M. H. (1995). Compensatory effectiveness of speech recognition on the written composition performance of postsecondary students with learning disabilities. Learning Disability Quarterly, 18, 159-174.

Honeycutt, L. (2003). Researching the use of voice recognition writing software. Computers and Composition, 20, 77-95.

Hux, K., Rankin-Erickson, J., Manasse, N., \& Lauritzen, E. (2000). Accuracy of three speech recognition systems: Case study of dysarthric speech. AAC Augmentative and Alternative Communication, 16, 186-196.

Karat, J., Horn, D. B., Halverson, C. A., \& Karat. C. -M. (2000, April). Overcoming unusabilty: Developing efficient strategies in speech recognition systems. Poster 
session presented at CHI 2000, the AMC Conference on Human Factors in Computer Systems, The Hague, Netherlands.

Kay Elemetrics (1993). Multi-Dimensional Voice Program (MDVP). [Computer program.] Pine Brook, NJ: Author

Kellogg, R. T. (1996). A model of working memory in writing. In C. M. Levy, \& S. Ransdell (Eds.), The Science of writing: Theories, methods, individual differences, and applications (pp. 57-71). Mahwah, NJ: Lawrence Erlbaum Associates.

Koester H. H. (2001). User performance with speech recognition: A literature review. Assistive Technology, 13, 116-130.

Koester, H. H. (2003). Abandonment of speech recognition by new users. Paper presented at the RESNA $26^{\text {th }}$ International Annual Conference, Atlanta, GA.

Koester, H. H. (2004). Usage, performance, and satisfaction outcomes for experienced users of automatic speech recognition. Journal of Rehabilitation Research \& Development, 41, 739-754.

Kotler, A.-L., \& Tam, C. (2002). Effectiveness of using discrete utterance speech recognition software. AAC Augmentative and Alternative Communication, 18, 137-146.

Kotler, A.-L., \& Thomas-Stonell. (1997). Effects of speech training on the accuracy of speech recognition for an individual with a speech impairment. $A A C$ Augmentative and Alternative Communication, 13, 71-80.

Lewis, R. B., Graves, A. W., Ashton, T. M., \& Kieley, C. L. (1998). Word processing tools for students with learning disabilities: A comparison of strategies to increase text entry speed. Learning Disabilities Research \& Practice, 13, 95-108. 
MacArthur, C. A. (1998a). From illegible to understandable: How word recognition and speech synthesis can help. Teaching Exceptional Children, July/Aug, 66-71.

MacArthur, C. A. (1998b). Word processing with speech synthesis and word prediction: Effects of the dialogue journal writing of students with learning disabilities. Learning Disability Quarterly, 21, 151-166.

MacArthur, C. A. (1999a). Overcoming barriers to writing: Computer support for basic writing skills. Reading \& Writing Quarterly, 15, 169-192.

MacArthur, C. A. (1999b). Word prediction for students with severe spelling problems. Learning Disability Quarterly, 22, 158-172.

MacArthur, C. A. (2000). New tools for writing: Assistive technology for students with writing difficulties. Topics in Language Disorders, 20(4), 85-100.

MacArthur, C. A., \& Cavalier, A. R. (2004). Dictation and speech recognition technology as test accommodations. Exceptional Children, 71, 43-58.

MacArthur, C. A., Schwartz, S. S., \& Graham, S. (1991). A model for writing instruction: Integrating word processing and strategy instruction into a process approach to writing. Learning Disabilities Research \& Practice, 6, 230-236.

MacArthur, C. A., \& Shneiderman, B. (1986). Learning disabled students’ difficulties in learning to use a word processor: Implications for instruction and software evaluation. Journal of Learning Disabilities, 19, 248-253.

Poling, A., Methot, L. L., \& LeSage, M. G. (1995). Fundamentals of behavior analytic research. New York: Plenum Press.

Quinlan, T. (2004). Speech recognition technology and students with writing difficulties: Improving fluency. Journal of Educational Psychology, 96, 337-346. 
Reece, J. E., \& Cumming, G. (1996). Evaluating speech-based composition methods: Planning, dictation and the listening word processor. In C. M. Levy, \& S. Ransdell (Eds.), The Science of writing: Theories, methods, individual differences, and applications (pp.361-380). Mahwah, NJ: Lawrence Erlbaum Associates.

Sandberg, A. D. (2001). Reading and spelling, phonological awareness, and working memory in children with severe speech impairments: A longitudinal study. AAC Augmentative and Alternative Communication, 17, 11-26.

Shaer, C. (1997). The infant and young child with Spina Bifida: Major medical concerns. Infants and Young Children, 9(3), 13-25.

Tumlin, J., \& Heller, K. W. (2004). Using word prediction software to increase typing fluency with students with physical disabilities. Journal of Special Education Technology, 19(3), 5-14.

Wetzel, K. (1996). Speech-recognizing computers: A written-communication tool for students with learning disabilities. Journal of Learning Disabilities, 29, 371-380. Wilkinson, G. S. (1993). Wide Range Achievement Test 3. Wilmington, DE: Wide Range. 
APPENDIX A: PROCEDURAL INTEGRITY PROTOCOLS 
Script for determining Research Question \# 5: ABLE TO RECALL INTENDED MEANING

Directions: Let's look at what you wrote.

Word Processing:

Sometimes when people are typing, they make errors, and that's okay. Read back what you wrote the way you meant to write it.

Speech Recognition:

Sometimes, speech recognition software writes something different than what you said. Read back what you wrote and see if you can remember what you told it to say. 


\section{Training Checklist}

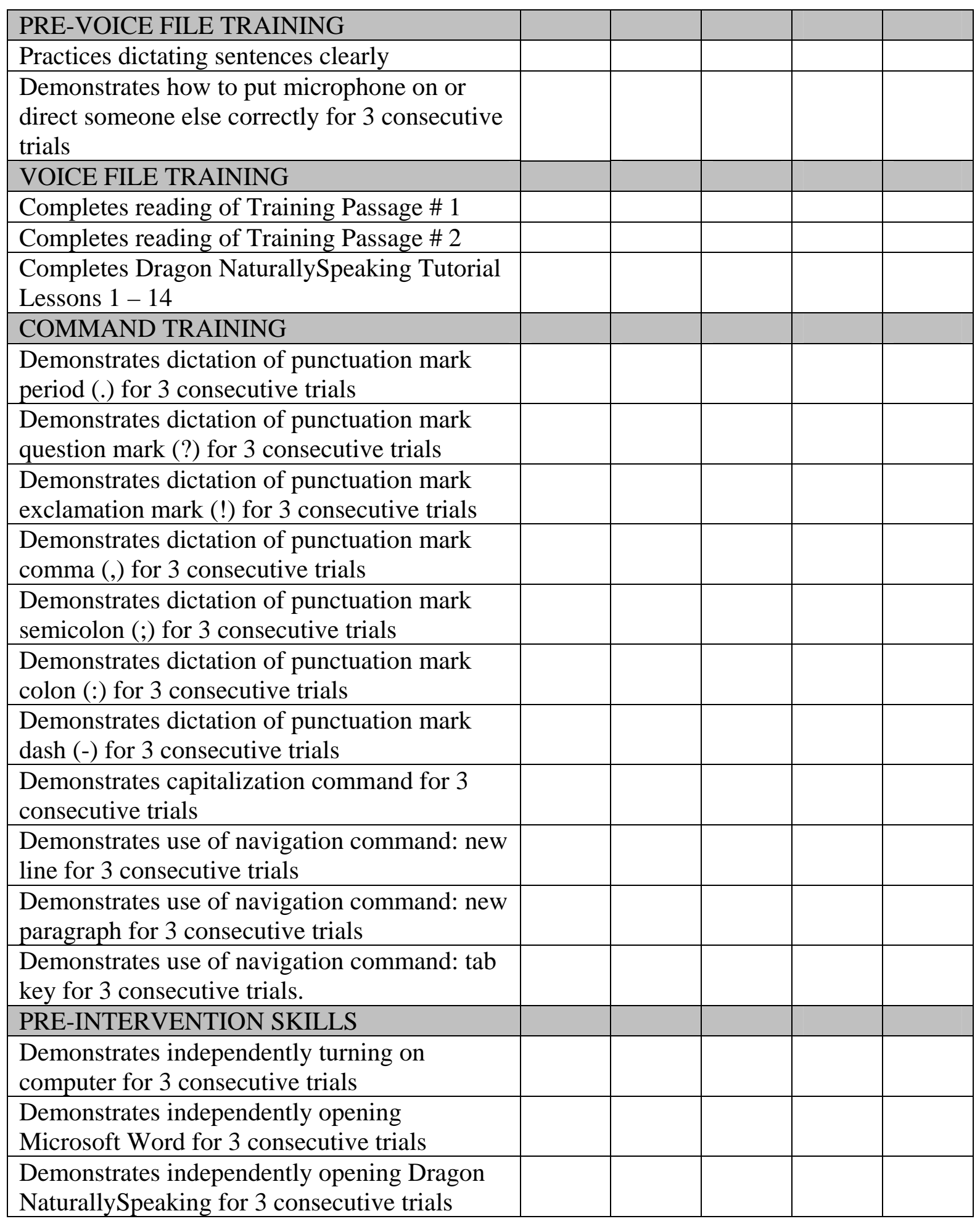




\section{WRITING Procedural Integrity Checklist}

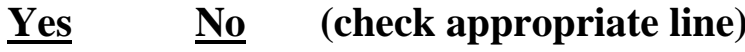

Explain which program the student will be using (word processing or speech recognition).

Have the student prepare the computer (open the program, set up materials, put name, date, session, and topic in header).

Ensure the programs are set to correct settings (e.g., vocabulary, level, spell/grammar check disabled, auto complete and auto correct disabled).

$*$ If using speech recognition, ensure the correct user is open on Dragon NaturallySpeaking.

Once the computer is prepared, provide the student with a choice from the student's list of the general topic. Topic:

$*$

If using speech recognition, record the student saying "ahhh”.

Give the student 5 minutes to think about the prompt, write notes, and rehearse what he or she is going to compose.

Post student's notes and reminder of commands next to the computer.

Before beginning the timing, explain that the student will have as much time as he or she needs to compose, but he or she will draw a line under the writing at the end of three minutes to document what was written for data collection purposes.

Remind the student that this is a draft and not to correct mistakes as he or she composes.

If using speech recognition, the researcher will audio tape the dictation.

Timing will begin when the student types/speaks the first letter/word.

The researcher will note backspaces and pauses when the student is composing.

$1^{\text {st }} 3$ minutes \# of backspaces

$1^{\text {st }} 3$ minutes \# of pauses Addl time \# of backspaces

Addl time \# of pauses 
Timing will end after 3 minutes when the researcher tells the student to draw a line under the last line written.

The student will then be instructed to continue with the writing (and timing will resume) until he or she is finished.

Total Time:

Addl Time Used:

Once the student is finished composing, the researcher will instruct the student to read out loud what he/she just typed, following the script.

The researcher will audio record the read-backs (in both word processing and speech recognition).

The researcher will save the document.

The researcher will print the document.

The researcher will transcribe the audio recordings.

For data analysis, the researcher will conduct a character and word count.

The researcher will score the document and will document the data on the data sheet and graph.

Word Processing: 19 steps

Speech Recognition: 22 steps *

Procedural Integrity Check:

Number of steps correctly completed / total number of steps 
APPENDIX B: DATA SHEETS 
Name:

Date:

Topic: Session:

Circle one: Word Processing or Speech Recognition

wcpm
a) Total number of characters

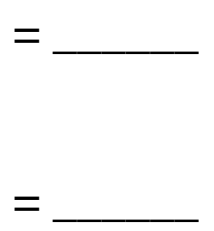
b) Total number of characters w/ errors removed
$=$ __ (number of correct
words via character count)
c) Total correct characters (b) $\div 5$ (a)
d) Correct words (c) $\div$ \# of minutes

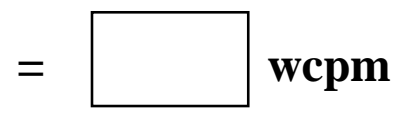

\section{$\underline{\text { ACCURACY }}$}
a) \# of words in passage
$=$
b) \# of errors
$=$
c) \# of correct words $(\mathbf{a}-\mathbf{b})$
$=$ correct words
d) \# correct words $\div$ total number
of words $(c \div a) \times 100$

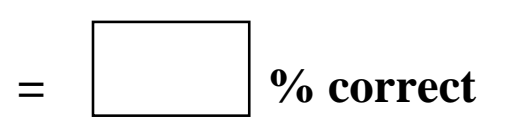

\section{LENGTH}
a) \# of characters
$=$
$=\square$
number of words
b) length $(a \div 5)$ 
WORD ERRORS

\begin{tabular}{|c|c|c|c|}
\hline $\begin{array}{l}\text { What was written } \\
\text { (write exact words) }\end{array}$ & $\begin{array}{l}\text { What they meant } \\
\text { Under SR condition: } \\
\text { (write spoken words from tape } \\
\text { recorder) *note if change } \\
\text { wording as dictating } \\
\text { Under WP condition: } \\
\text { (correct spelling) }\end{array}$ & $\begin{array}{l}\text { Error Code } \\
\text { S, K, I, A, } \\
\text { O, C }\end{array}$ & $\begin{array}{l}\text { Recall : } \\
\text { Immediate recall } \\
\text { Delayed recall ( } 2 \mathrm{sec} \text { ) } \\
\text { Diff = Read differently } \\
\text { without changing meaning } \\
\mathbf{X}=\text { Incorrect (changed } \\
\text { meaning) or no recall } \\
\end{array}$ \\
\hline & & & \\
\hline & & & \\
\hline & & & \\
\hline & & & \\
\hline & & & \\
\hline & & & \\
\hline & & & \\
\hline & & & \\
\hline & & & \\
\hline & & & \\
\hline & & & \\
\hline & & & \\
\hline
\end{tabular}

\section{Key:}

\section{Word Processing:}

S = Spelling/Keyboarding WORD Error;

$\mathbf{K}=$ Keypress Error (extra characters not associated with a word);

$\mathbf{I}=$ Substituted incorrect word(s)
Speech Recognition:

I = Substituted incorrect word(s);

$\mathbf{A}=$ Additional unintended word

(didn't say it but the program wrote it OR environmental sound, stutter, or extraneous sound (ie., thinking sound, um, sneeze, etc.));

$\mathbf{O}=$ Omission of a word (said it but the program didn't write it);

$\mathbf{C}=$ Command Error 